\title{
Exciting excitable brains : a transcranial magnetic stimulation study in migraine
}

Citation for published version (APA):

Mulleners, W. M. (2001). Exciting excitable brains : a transcranial magnetic stimulation study in migraine. [Doctoral Thesis, Maastricht University]. Universiteit Maastricht. https://doi.org/10.26481/dis.20010921wm

Document status and date:

Published: 01/01/2001

DOI:

10.26481/dis.20010921wm

Document Version:

Publisher's PDF, also known as Version of record

\section{Please check the document version of this publication:}

- A submitted manuscript is the version of the article upon submission and before peer-review. There can be important differences between the submitted version and the official published version of record.

People interested in the research are advised to contact the author for the final version of the publication, or visit the DOI to the publisher's website.

- The final author version and the galley proof are versions of the publication after peer review.

- The final published version features the final layout of the paper including the volume, issue and page numbers.

Link to publication

\footnotetext{
General rights rights.

- You may freely distribute the URL identifying the publication in the public portal. please follow below link for the End User Agreement:

www.umlib.nl/taverne-license

Take down policy

If you believe that this document breaches copyright please contact us at:

repository@maastrichtuniversity.nl

providing details and we will investigate your claim.
}

Copyright and moral rights for the publications made accessible in the public portal are retained by the authors and/or other copyright owners and it is a condition of accessing publications that users recognise and abide by the legal requirements associated with these

- Users may download and print one copy of any publication from the public portal for the purpose of private study or research.

- You may not further distribute the material or use it for any profit-making activity or commercial gain

If the publication is distributed under the terms of Article $25 \mathrm{fa}$ of the Dutch Copyright Act, indicated by the "Taverne" license above, 


\section{Exciting excitable brains}

\section{A transcranial magnetic stimulation study in migraine}

\section{Proefschrift}

ter verkrijging van de graad van doctor aan de Universiteit Maastricht, op gezag van de Rector Magnificus

Prof. dr. A.C. Nieuwenhuijzen Kruseman volgens het besluit van het College van Decanen in het openbaar te verdedigen

op vrijdag 21 september 2001 om 12.00 uur

$$
\text { door }
$$

Wilhelmus Marie Mulleners

geboren te Geleen op 30 januari 1962. 


\section{Promotiecommissie}

\section{Promotores}

prof. dr. J. Troost

prof. dr. E.J. Jonkman (Vrije Universiteit Amsterdam)

\section{Co-promotor}

dr. E.P. Chronicle, AFBPsS, C.Psychol. (Lancaster University, U.K.)

\section{Beoordelingscommissie}

prof. dr. F. Spaans (voorzitter)

dr. J. Haan (Universiteit Leiden)

dr. M. van Kleef

dr. R.J. van Oostenbrugge

prof. dr. P.R. Saxena (Erasmus Universeit Rotterdam)

ISBN: 90-74421-10-5

(C)2001 W.M. Mulleners, Heerlen, The Netherlands

Lay out and production: Ingrid Heller \& Hein Berendsen PR.

All rights are reserved. No part of this publication may be reproduced or transmitted in any form or by any means, without permission in writing from the copyright owner.

Financial support by Almirall Prodesfarma, Anglo-Dutch Migraine Association, AstraZeneca, Atrium medisch centrum, GlaxoSmithKline, Janssen-Cilag, Nederlandse Hoofdpijn Vereniging, Pfizer, Sanofi, Schering, Serono. 
Voor Caron, Anne, Sebastiaan en mijn ouders. 


\section{Contents}

Chapter 1

Cortical excitability and migraine pathogenesis

Chapter 2

Visual system dysfunction in migraine. A review of clinical and psychophysical findings

Chapter 3

Self-reported photophobic symptoms in migraineurs and controls are reliable and predict diagnostic category accurately

Chapter 4

Visual cortex excitability in migraine with and without aura

Chapter 5

Visual cortex excitability in migraine before and after valproate prophylaxis. A transcranial magnetic stimulation study

Chapter 6

Suppression of perception in migraine: evidence for reduced inhibition in the visual cortex

Chapter 7

Cortical hyperexcitability is cortical under-inhibition. Evidence from a novel functional test of migraine patients

Chapter 8

General discussion

Summary

Samenvatting

Appendix

Dankwoord

Curriculum vitae

List of abbreviations 
Chapter 1

Cortical excitability and migraine pathogenesis 
Chapter 1 
I dread those mornings in autumn when the trees have shed their leaves and the sun rises just above the horizon. When driving into work along treebordered roads, it is the flickering of the sunlight which time and again evokes a barb-wired visual illusion which may be followed by a terrible pounding headache that sets the tone for the day.

G.B. - Neurosurgeon

\section{Migraine: the syndrome}

Migraine is a common and often debilitating syndrome characterised by attacks of headache and autonomic symptoms. Approximately $30 \%$ of individuals have accompanying transient neurological phenomena with their attacks. Despite numerous case reports in the ancient neurological literature, it was not until Liveing's monograph on migraine ${ }^{1}$ that the various migrainous phenotypes were delineated as separate entities. However, since an objective biological marker for migraine is lacking, accurate diagnosis ultimately relies on taking a careful history. Defining and classifying the disorder proved to be extremely difficult and it was not until 1988, when the Headache Classification Committee of the International Headache Society published their proposed 'Diagnostic Criteria of Headache and Facial Pain', that a comprehensive classification scheme became available ${ }^{2}$. This has provided migraine researchers with a conceptual framework that was uniformly accepted and thus facilitated the comparability of study results.

In cases that come to specialist attention, the condition often runs a protracted course, typically starting in the teens or early twenties and gradually subsiding not before the age of $45-50$ years. Women are afflicted more often than men (2-3:1) and the one-year prevalence ranges from 12 to $14 \%$, peaking at the third to fifth decade for women and the second to fourth decade for men ${ }^{3}$. However, substantially higher prevalence rates have been reported ${ }^{4}$. Because of the high community prevalence afflicting mainly a comparatively young part of the population, its chronic recurrent course and incapacitating character, the condition not only leads to huge medical and pharmacological consumption, but is also held responsible for a considerable financial burden to society due to work loss, lost productivity and idle leisure time. For Dutch society, the total yearly costs attributable to all variants of migraine have been estimated at DFL 675 million (approximately USD 310 million) $)^{5}$. 


\section{Migraine: the pathophysiological concepts}

Despite major achievements in migraine research in recent years, mainly concerning the mechanism of action of the triptans and in the field of (molecular) genetics, the pathophysiology of the clinical migrainous syndrome is by and large not known. Several factors, alone or in combination, are thought to be involved, the most important of which have been reviewed recently by Ferrari ${ }^{6}$ and are summarised in Table 1 . Of these, cortical hyperexcitability and cortical spreading depression are thought to be important phenomena in the initiation and/or early stages of the migraine attack, and will be discussed below.

\section{Table I}

\section{Current pathophysiological concepts in migraine}

\begin{tabular}{lll} 
Attack stage & Pathophysiology & Proposed mechanism(s) \\
\hline Trigger & Attack threshold modulation & $\begin{array}{l}\text { Hormones, fatique, stress, } \\
\text { meteorological change }\end{array}$ \\
\hline $\begin{array}{l}\text { Corticaly } \\
\text { hyperexcitability }\end{array}$ & Reduced threshold & $\begin{array}{l}\text { Mitochondrial oxidative } \\
\text { phophorylation, low } \mathrm{Mg}^{2+}, \text { high } \\
\text { glutamate, } \mathrm{Ca}^{2+} \text { chanellopathy }\end{array}$ \\
\hline
\end{tabular}

Aura

Cortical spreading depression

Mitochondrial oxidative phophorylation, low $\mathrm{Mg}^{2+}$, high glutamate, $\mathrm{Ca}^{2+}$ chanellopathy, reduced $\mathrm{K}^{+}$clearance (low glia/ neuron ratio)

Attack initiation Brainstem generator

Headache initiation Vasodilation and maintenance Dural plasma extravasation

Nitric oxide, trigeminovascular activation

\subsection{Spreading depression}

Leão was the first to observe the spreading phenomenon of shortlasting neuronal discharge followed by prolonged suppression of cortical activity after noxious stimulation of the rat cerebral cortex, for which he coined the term cortical spreading depression $(\mathrm{SD})^{7}$. This spreading depolarisation propagates with a speed of $2-3 \mathrm{~mm} / \mathrm{min}$ over the cerebral cortex. At about the same time, Lashley reported his observations on his own visual aura and calculated that, if an occipital cortical phenomenon were to be held responsible for his visual symptoms, it would need to travel at a speed of $3 \mathrm{~mm} / \mathrm{min}$ to keep pace with the observed rate of expansion in the visual field $^{8}$. The remarkable similarity between the rates of propagation of SD and 
Lashley's calculations led Leão to believe that it is in fact SD that is at the origin of the migrainous aura ${ }^{9}$.

The renewed interest in Leão's spreading depression theory was fuelled by the observation of spreading oligaemia/hypoperfusion in ictal cerebral blood flow studies ${ }^{10-12}$. Evidence is accumulating that this phenomenon is probably not a primary vascular event, but rather induced by an expanding and prolonged depression of neuronal activity. To which extent it may be accompanied by relative ischaemia is not yet known, although blood flow never falls below tissue damage thresholds ${ }^{12}$. Spreading oligaemia, and hence $\mathrm{SD}$, are thought to be primarily responsible for the development of the migrainous aura. Moreover, some authors have reported that SD is capable of trigeminal activation ${ }^{13}$ and some believe that migraine attacks (both migraine with and without aura) are initiated by SD originating in the posterior part of the brain ${ }^{14}$.

Evidence of spreading depression in vivo in humans has been difficult to obtain, largely due to technical shortcomings. Recently, Welch's group published their findings in migraineurs with and without aura, tension-type headache and headache-free controls, using magneto-encephalography ${ }^{15,16}$. Exclusively in ictal migraineurs they observed neuronal suppression and longduration DC shifts, observations that are consistent with SD findings in experimental animal models. Recently, Cao et al reported a spreading suppression of neuronal activation in visually triggered migraine attacks, using fMRI-BOLD ${ }^{17}$. This spreading wave of suppression travelled at a rate of 5 $\mathrm{mm} / \mathrm{sec}$ to adjacent cortical areas, which is strikingly similar to Leão's and Lashley's observations.

\subsection{Cortical hyperexcitability}

Although spreading depression is an intuitively attractive model for migraine with aura, it leaves unexplained why this physiological event does occur repeatedly in migraineurs and not in non-migraineurs. One way to account for this phenomenon would be to assume that the threshold for (triggered?) SD is lower in migraine and that normals are protected from SD by a more stable and less excitable cortex. In this respect, the findings reported by Welch's group ${ }^{18}$ are encouraging. Using magneto-encephalography in migraine with aura, they found that in the interictal phase large amplitude waves occurred which could reflect focal spontaneous depolarisation with limited spread, suggestive of central neuronal hyperexcitability. It was hypothesised that the latter phenomenon could form the basis of a susceptibility to (spontaneous) spreading depression ${ }^{19}$, which in turn would then be the trigger for trigeminal or trigemino-vascular activation.

As such, the observation of neuronal hyperexcitability is not new and it may be a feature that distinguishes migraineurs from non-headache subjects. Apart from the MEG-studies there are other lines of circumstantial evidence 
pointing at a fundamental derangement in the neurophysiology and neuronal stability of the (interictal) migrainous brain. Frequently observed elements like prominent photic driving and sharp transients on standard interictal EEG traces may well reflect excessive excitability of the occipital cortex. Although the results of visual evoked potential (VEP) work have been variable, there are several papers reporting increased P100 amplitudes, which suggests hyperexcitability of occipital cortex ${ }^{20,21}$. Studies on cortical auditory evoked potentials, contingent negative variation and the $\mathrm{P} 300$ have shown a deficient cortical habituation ${ }^{21}$. Very recently Schoenen's group has demonstrated that steady-state amplitudes of pattern-reversal VEP do not decrease in time in migraineurs compared to headache-free controls ${ }^{22}$. As a whole, these studies seem to point at a generalised dysfunction of information processing in migraineurs.

Levels of visual illusions and discomfort induced by looking at squarewave gratings have consistently been shown to be increased, the effect being most prominent in migraine with aura ${ }^{23-26}$. Moreover, target detection against a background grating is impaired in migraine with aura ${ }^{27}$ and response times for low-level visual tasks are shorter in migraineurs ${ }^{28}$. Taken together, these psychophysical findings are in agreement with and further substantiate the concept of central neuronal hyperexcitability.

Recently, transcranial magnetic stimulation (TMS) of the cerebral cortex has been applied to study cortical excitability in migraine. Although there has been some disagreement between the results from different research groups, the majority of the studies have generated evidence in support of cortical hyperexcitability. In paragraph 4 below, an overview of all the research employing TMS in migraine until 1999 is provided.

Central neuronal hyperexcitability and the spontaneous occurrence of spreading depression may be caused by several independent mechanisms and is likely to be multifactorial. For one, it may be related to glial inability to maintain potassium- and glutamate-homeostasis ${ }^{14}$. Brain $\mathrm{Mg}^{2+}$ content may be another factor providing a link between the physiological threshold for a migraine attack and the mechanisms of the attack itself ${ }^{29}$. An abnormal presynaptic $\mathrm{P} / \mathrm{Q}$ type calcium channel has been demonstrated in familial hemiplegic migraine ${ }^{30}$ and also in the more common migraine varieties ${ }^{31}$, possibly enhancing postsynaptic neuronal excitability through excitatory monoaminergic or inhibitory serotonergic neurotransmission. Additional to the aforementioned factors, a disorder of brain energy conserving mechanisms may be implicated in the pathogenesis of hyperexcitability ${ }^{32}$.

Another mechanism possibly of relevance to cortical hyperexcitability is a lack of inhibitory control in the primary visual cortex (V1). In V1, GABA-ergic inhibitory neurons form diffuse horizontal networks that make crucial 
contributions to visual processing, and also maintain the physiological stability of the cortex. It is known that GABA-antagonists render the cortex considerably more susceptible to $\mathrm{SD}^{33}$ and seizure activity ${ }^{34}$. Furthermore, lamina IV contains sparsely spinous stellate cells ${ }^{35}$; because of their anatomical equivalence to the large stellate cells in the Rhesus monkey motor cortex ${ }^{36}$, it is very likely that these neurons are selectively vulnerable to ischemic conditions. Chronicle and Mulleners have therefore advanced the view that ischemic or near-ischemic events during the migraine aura may give rise to selective damage to the GABA-ergic inhibitory network of sparsely spinous stellate cells in $V 1^{37}$, which would (at least in part) explain the observed hyperexcitability of V1 in migraine with aura. Although with current knowledge it seems less likely that the events leading to a migraine attack are primarily of a vascular nature, the hypothesis of selective damage to inhibitory networks in V1 as a result of attacks is still plausible. Kruger et $\mathrm{al}^{38}$ have demonstrated that repeated episodes of SD selectively impair GABA-ergic inhibitory function (but not excitatory functioning) in a rat neocortical slice model. Given the release of glutamate during SD, it is possible that cumulative damage to GABA-ergic cells may occur through excitotoxic mechanisms. Some circumstantial evidence exists that favours the Chronicle \& Mulleners hypothesis ${ }^{37}$ : for example, the observation done by Khalil and Legg that contrast sensitivity is normal in subjects with a relatively short history of migraine with aura (MA) but significantly reduced in patients with a migraine history $>30$ years ${ }^{39}$. Others were unable to obtain evidence in support of this theory ${ }^{40}$, but this may have been because they assessed excitability in the motor cortex, which is less likely to be involved. Wilkinson et $\mathrm{al}^{41}$ report that, although visual orientation discrimination thresholds in migraine (a measure of cortical inhibitory function) are not different from control, there was a trend towards worse foveal performance on this task for those subjects with migraine with aura with the highest lifetime migraine incidence.

\section{Transcranial magnetic stimulation}

\subsection{Physiology}

Transcranial magnetic brain stimulation (TMS) as it is currently used was introduced by Barker in 1985 ${ }^{42}$, and is a non-invasive and safe method for studying the functional integrity of neuronal populations within the central nervous system. Building on the idea that powerful electromagnetic pulses, generated by passing current from decharging capacitors through the windings of a coil (figure 1) would be able to induce electric currents in (sub)cortical areas, it has been mainly employed to evoke motor potentials (MEP) by local stimulation of pyramidal cells in the primary motor cortex 
(Brodmann's area 4). Stimulation of these cells is achieved by placing the coil tangentially on the skull over the motor cortex, while a brief electric current (< $200 \mathrm{msec}$ ) is passed through the copper windings of the coil. According to the physical principles of electromagnetic induction, a brief magnetic field develops around the stimulator coil, with magnetic flux lines emanating in arcs around the coil. The flux density is highest under the windings of the coil, progressively declining as the distance to the coil increases. Thus, the field strength is attenuated by two-thirds at a distance of one coil radius. The electric field in the volume conductor is oriented parallel to the magnetic coil by which it is induced, but the polarity of this electric field is opposite to that of the coil current ${ }^{43}$.

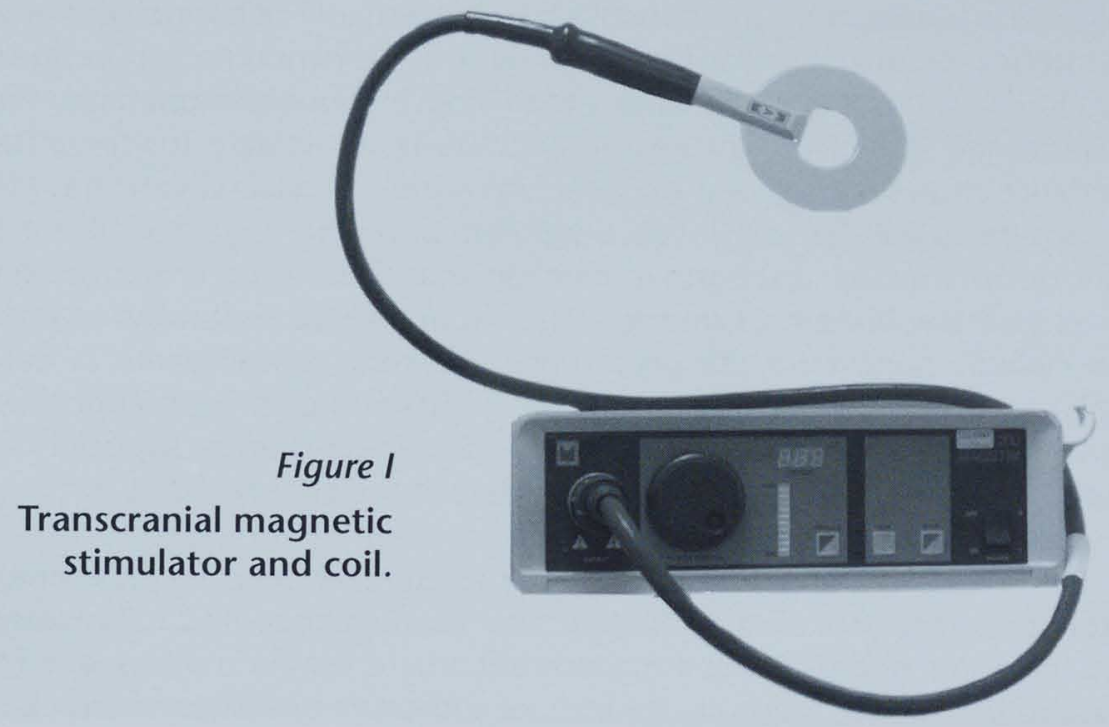

Single pulse magnetic stimulation does not result in depolarisation of the nerve cell body, but rather generates a spreading action potential in the axon. Thus, the effectiveness of a magnetic stimulator in generating an action potential in a nerve in a volume conductor depends not only on the local flux density, but also on the orientation of this nerve relative to the coil. When the neuraxis is running parallel to the electric current flow the stimulation threshold will be lowest, while axons oriented perpendicular to the electric field will not depolarise. Moreover, large diameter neurones are more amenable to magnetic stimulation than their small diameter counterparts ${ }^{43}$.

Apart from the factors mentioned above, other variables may contribute to the effectiveness by which activation of nerve axons occurs. Activation thresholds are lowest at nerve bends and in areas of local conductivity change in a homogenous volume conductor, as occurs near to the brain ventricles and the grey/white matter interface ${ }^{44}$. 


\subsection{Procedure}

When interest is focussed on the motor systems of the brain, the (circular) coil is placed just behind and lateral to the vertex. The region of interest is located by moving the coil relative to the motor cortex, while observing and recording the contractions in the muscle under scrutiny, contralateral to the stimulation area. The stimulation is then repeated several times, both at rest and with the target muscle slightly precontracted. Stimulus intensity is set at a level moderately above threshold, usually some $20-50 \%$. MEP's are recorded with surface EMG electrodes attached to the skin overlying peripheral muscles, usually the first dorsal interosseus, biceps or tibialis anterior. Although, strictly speaking, it would be more appropriate to use Fwaves, it has become common practice to evoke MEP's through spinal root magnetic stimulation to obtain data on peripheral conduction. MEP amplitudes and latencies are available on the display and amplitude ratios and central conduction time can be calculated. Data sets are readily obtainable and have been shown to exhibit a low intra-individual variability. It is assumed on experimental grounds that magnetic stimulation of the motor cortex results in activation of the proximal axon of pyramidal neurones, reflected by $\mathrm{D}$ (irect) waves. Moreover, axonal activation of cortical excitatory interneurones are held responsible for the occurrence of I(ndirect) waves after stimulation, which can only be recorded when the cortex is intact. Both $D$ and I volleys descend down the corticospinal tracts and connect monosynaptically with $\alpha-$ motor neurones, causing excitatory post-synaptic potentials ${ }^{45}$.

In view of its unique functional, neuro-anatomical and cyto-architectural properties, it is not surprising that the electrophysiological processes and responses induced by magnetic stimulation over the primary visual cortex are quite distinct from those at the level of the primary motor cortex. Occipital pole stimulation results in rather unstructured visual illusions called phosphenes or may cause transient visual scotomata and suppress the perception of standard visual stimuli (e.g. letter trigrams); the exact site in the occipital area at which activation occurs may not necessarily be the same for the two phenomena, as has been argued by Marg and Rudiak ${ }^{44}$. Occipital cortex phosphenes are usually reported as dim, white flashes of light in the lower half of the visual field and it requires stimulus intensities approximately equal to the threshold for eliciting a hand muscle response to be just visualised. It is best evoked when the superior coil windings are $6-8 \mathrm{~cm}$ above the inion in the midline, roughly where the middle coil windings pass over the polar part of the cuneus (supracalcarine part of the occipital pole) ${ }^{46 .}$ Marg and Rudiak $^{44}$ found that the optic radiation fibres at some 4 centimetres distance from the surface of the skull are preferentially activated at a given stimulus intensity. This depth corresponds to the middle part of the calcarine fissure, where the optic radiation fibres projecting from the peripheral visual field 
terminate in the striate cortex (figure 2). Because these fibres bend around the occipital pole of the lateral ventricle, the axons are roughly parallel to the electric current and thus optimally oriented for activation. Fibres from the central visual field, however, run a more perpendicular course relative to the coil windings and are therefore least likely to be excited. Moreover, it is conceivable that the different anatomical relation between the occipital horn on the one hand and both the central and peripheral fibres on the other contributes to the differential probability of these tracts being triggered, relating to local differences in conductivity change ${ }^{44}$. Experimental observations are consistent with this hypothesis, as phosphenes are primarily observed in the periphery of the visual field. The visual hemifield in which the phosphenes occur depends on the direction in which the electric current passes through the upper windings of the coil. Coil current passing from left to right results in right primary visual cortex activation and the perception of phosphenes in the left visual hemifield ${ }^{46 .}$

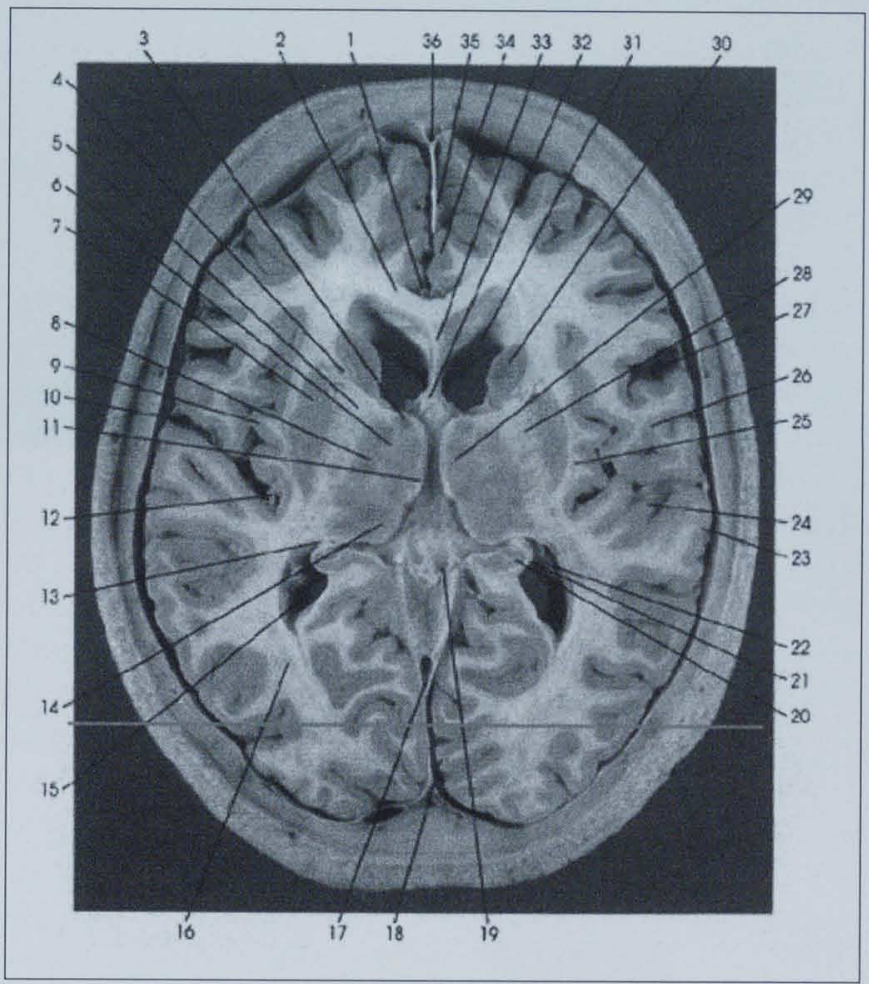

\section{Figure 2}

The primary visual cortex

Geniculocalcarine fibers pass through the optic radiation (16), bend at the posterior border of the occipital pole of the lateral ventricle (15) and continue in a coronal plane (-) towards the striate cortex (18) in the calcarine fissure From: Virtual Hospital. Atlas of Human Anatomy in Cross Sections (www.vh.org/Providers/T extbooks/HumanAnatom y/1Section/09.html). 
When occipital pole stimulation is applied shortly after the brief presentation of a standardised visual stimulus (i.e. a letter trigram on a computer screen), the stimulus may no longer be perceived, depending on the delay between stimulus presentation and magnetic pulse ${ }^{47}$. The suppression of visual perception is almost complete when the delay between visual stimulus and magnetic pulse is $80-100 \mathrm{msec}$. As a stimulus of this type is projected onto and processed in the fovea, the magnetic activation in this paradigm probably occurs in the cortical representation area of the central visual field, i.e. the superficial striate cortex of the occipital pole ${ }^{44}$. The neurophysiological correlate of this phenomenon is likely to be the inhibition of ongoing visual processing by TMS elicited inhibitory postsynaptic potentials (IPSP) within the calcarine cortex ${ }^{47-49}$. Alternatively, it may be explained by collision of antidromically excited genico-calcarine axons with incoming impulses in the optic radiations or inhibition of impulse relay in the lateral geniculate nucleus through axon collaterals of antidromically activated optic radiation fibres. However, according to the literature it is the generation of IPSP's which is the most plausible electrophysiological candidate in the aetiology of the phenomenon ${ }^{47-49}$. It seems thus likely that this method may be useful in the assessment of the functional integrity of inhibitory neuronal populations in the primary visual cortex.

\section{Transcranial magnetic stimulation in migraine}

Recently, transcranial magnetic brain stimulation (TMS) has been used to investigate cortical (dys)function in migraine. Until now, the results of magnetic stimulation of various regions of the brain have been conflicting. Maertens de Noordhout et al $^{50}$ found an increased threshold and reduced amplitudes of motor evoked potentials (MEP) in interictal migraine with aura, which could not be reproduced in migraine without aura. Bettucci's group reported an increased MEP threshold in menstrual migraine ${ }^{51}$. However, standardisation of levels of muscular precontraction, known to be a prominent confounding variable, was not mentioned in the latter paper and may thus not have been performed. In contrast, van der Kamp and colleagues were the first to demonstrate cortical hyperexcitability to magnetically evoked MEP's: although they did not find reduced MEP thresholds, a robust increase in MEP amplitudes and MEP/CMAP (compound muscle action potential) amplitude ratios suggested that the cortical motor neurones, at a given stimulus level, were more likely to be recruited in migraineurs than in controls. This increase was most prominent in migraineurs with frequent attacks. Again, a difference in favour of migraine with aura was apparent ${ }^{52}$. A year later, the same group reported a decreased excitability of the symptomatic hemisphere in familial 
hemiplegic migraine ${ }^{53}$, suggesting subclinical damage in this rare condition. Recently, Aurora et al published that the cortical stimulation silent period (CSSP) after TMS is reduced in migraineurs, suggestive of deficient cortical inhibition ${ }^{54}$. This, or indeed any other indication of motor cortical excitability change, was not reproduced in a very recent paper by Werhahn et al, who studied resting motor threshold, CSSP and paired-pulse inhibition and facilitation in a small group of migraine with aura and familial hemiplegic migraine $^{55}$.

As the posterior brain areas are thought to be predominantly involved in migraine, Aurora et al used an occipital TMS design to assess cortical excitability in interictal migraine with aura and controls ${ }^{56,57}$. Because stimulation of an afferent network does not yield a neurophysiological target organ response, a paradigm that differed substantially from the motor studies had to be employed. As it is to be expected that stimulation of primary visual cortex will cause visual illusions or phosphenes, they assessed thresholds at which phosphenes could just be induced. Whereas all migraine subjects reported phosphene perception, they could only be generated in $27.3 \%$ of control subjects. Moreover, there was a significant group difference for mean phosphene threshold level $(44.3 \% \pm 8.6$ versus $68.7 \% \pm 3.1)$. The results on cortical motor and visual excitability published by Afra et al did not corroborate most of the earlier findings. Motor thresholds were found to be higher and phosphene prevalence lower in migraine with aura compared to controls, whereas data for (among others) MEP-amplitude and CSSP did not differ between groups ${ }^{40}$. The authors argued that their findings are indicative of cortical hypo- rather than hyperexcitability. More recent data by Aurora et $\mathrm{al}^{58}$ and Aggugia et al ${ }^{59}$, however, argue strongly in favour of an enhanced excitability of the primary visual cortex in migraine.

In summary, although the majority of TMS studies in migraine seem to point at a state of enhanced cortical excitability, there is still some unexplained variability across different studies. However, several issues can be raised concerning the various methodologies used, which have been summarised in a recent publication by Mulleners et a ${ }^{60}$.

\section{Hyperexcitability in migraine: state or trait?}

The finding of a correlation between increased MEP/CMAP ratio (=cortical hyperexcitability) and attack frequency ${ }^{52}$ is interesting in that it suggests that the degree to which the migrainous brain is hyperexcitable determines the migraine load. However, interpretation of this finding is not straightforward as there are at least two predictions possible as to how 
enhanced excitability and high attack frequency might be linked.

On the one hand, the increased MEP/CMAP ratio may relate to a stable trait of increased excitability of the migrainous brain, signifying an increased resting membrane potential of certain neuronal populations. Thus, it would be reasonable to assume that this could lead to a reduced clearance from SD threshold, leading to a higher probability of spontaneously occurring spreading depolarisation and depression: a 'hyperexcitable trait'.

On the other hand however, it is conceivable that, in the build up to a migraine attack, various stimuli may cause a sudden increase in brain excitability, thereby triggering a cascade of events starting with spreading depolarisation to, finally, activation of the trigemino-vascular pathways. In this scenario parameters of brain excitability would only be increased just before and after the migraine attack. If the premonitory symptoms prior to the aura and headache stages of the attack were the clinical correlate of the gradual increase in excitability, it would imply that this change in brain responsiveness would start 12-24 hours before the headache. As the likelihood of a TMS assessment being performed close to a migraine attack is highest in subjects with a high migraine attack frequency, the finding of higher MEP/CMAP ratio in subjects with the highest attack frequencies ${ }^{52}$ complies with what would be predicted with this model, thus supporting a 'hyperexcitable state' concept.

This controversy between 'trait' and 'state' is interesting, more than just from a philosophical point of view. For instance, in the 'trait' scenario it would be reasonable to advocate the use of prophylactic remedies, which attenuate the enhanced excitability, whereas with respect to the 'state' hypothesis it would intuitively be more sensible to prefer acute treatments. To resolve this problem, it would be necessary to obtain excitability data longitudinally, i.e. in the days prior to and just after the migraine attack.

\section{Conclusion}

The theory of central neuronal hyperexcitability in migraine predicts that the development of cortical spreading depression, and hence a migraine attack, is determined by the propensity of certain neuronal populations to depolarise synchronously in response to specific (external) triggers, due to a decreased neuronal stability of that population. This propensity is reflected by lowered excitability thresholds and, together with an increased synchronisation of neuro-electrical activity, may lead to spreading depolarisation followed by long-lasting cortical depression. This, in turn, is thought to be responsible for the migraine aura, but may also be involved in the pathogenesis of migraine without aura. The factors involved in this increased brain excitability may be manifold, probably partly inherited but possibly also acquired. To what extent 
hyperexcitability is a stable characteristic of the migrainous brain or rather is subject to variations remains to be established. This study seeks to make a contribution in exploring and clarifying some of the many unresolved issues that remain with regard to central neuronal hyperexcitability in migraine.

\section{Project objectives}

The aim of the current study was to further investigate various aspects of the presumed central neuronal hyperexcitability in migraineurs.

Chapter 2 reviews the available research data concerning the various neurological and ophthalmological systems involved in the adaptation to and processing of visual stimuli, with respect to migraine. All structures of the visual system are systematically discussed, starting at the globe and continuing through the optic tract, lateral geniculate body and optic radiation back to the occipital pole. Possible areas for future research are highlighted.

In chapter 3 the findings of three studies examining self-reported interictal photophobic symptoms of patients with migraine and, in a subset of the same patients, responses to a laboratory visual stress test are described. Interest was focussed on these migraine symptoms as they may represent possible clinical counterparts of neuronal hyperexcitability. Thus, it would be predicted that migraineurs will report increased levels of discomfort and disapprovement to environmentally shared visual stimuli. Data on self-reported photophobic symptoms were obtained in a cohort of self-selected patients and a series of consecutive referrals to a specialised Headache Clinic. In the latter population a specially designed laboratory test to examine the threshold for visual stress was also used. Similar data were obtained in a headache-free control population.

Chapter 4 reports the prevalence of magnetophosphenes and the median thresholds at which they were obtained, using transcranial magnetic stimulation (TMS) of the occipital cortex. Data were obtained in migraine with and without aura, and findings were compared to the data collected in an age and sex matched control group.

On the assumption that enhanced GABA-ergic neurotransmission may interact with cortical excitability parameters, the findings on magnetophosphene thresholds before and after valproate treatment in the migraine population described in the previous chapter are presented in chapter 5. Additionally, changes in phosphene threshold were analysed in relation to change in migraine frequency, postulating that the neuronal hyperexcitability concept would dictate that an increase in phosphene threshold should be paralleled by a decrease in migraine load.

In chapter 6, the suppression of visual perception with TMS was compared in migraineurs with aura and headache-free subjects. As was 
mentioned before, this phenomenon most likely represents activation of cortical inhibitory networks. As this parameter may be a more objective measure than phosphene threshold, and since deficient intracortical inhibition may be responsible for enhanced excitability, we applied this technique in search for a more robust indication of cortical hyperexcitability in migraine for the first time. As far as we know, this is the first study applying this comparatively novel technique in migraine research.

In chapter 7 the findings of a study employing a psychophysical paradigm known as metacontrast masking are reported. There is very good evidence that the performance on this task is dependent on cortical inhibitory function. Migraineurs with visual aura were tested and compared to headache free controls to test the hypothesis that visual cortical inhibition is deficient in migraine with aura.

Finally, in chapter 8 , the findings from the various studies are discussed and put into perspective. 


\section{References}

1. Liveing $\mathrm{E}$. On the origin of megrim, sick headache and some allied disorders: a contribution to the pathology of nerve storms (1873). IHC Congress Edition Nijmegen, 1997, Arts \& Boeve

2. Headache Classification Committee of the International Headache Society. Classification and diagnostic criteria for headache disorders, cranial neualgias and facial pain. Cephalalgia 1988;8(suppl 7):1-96

3. Sheffield RE. Migraine prevalence: a literature review. Headache 1998;38:595-601

4. Launer LJ, Terwindt GM, Ferrari MD. The prevalence and characteristics of migraine in a population-based cohort: the GEM Study. Neurology 1999;53:537-542

5. Van Roijen L, Essink-Bot L. Maatschappelijke gevolgen van migraine in Nederland: een onderzoek naar de directe en indirecte kosten van migraine patiënten - deel 2. Rotterdam: Instite for Medical Technology Assessment, 1995:1-57 (iMTA Report 95.37).

6. Ferrari MD. Migraine. Lancet 1998;351:1043-1051

7. Leão AAP. Spreading depression of activity in the cerebrall cortex. I Neurophysiol $1944 ; 7: 359-390$

8. Lashley KS. Patterns of cerebral integration indicated by the scotomas of migraine. Arch Neurol Psychiatry 1941;46:331-339

9. Leão AAP, Morrison RS. Propagation of cortical spreading depression. J Neurophysiol 1945;8:33-45

10. Olesen J, Larsen B, Lauritzen M. Focal hyperemia followed by spreading oligemia and impaired activation of rCBF in classic migraine. Ann Neurol 1981;9:344-352

11. Woods RP, lacoboni M, Mazziota JC. Bilateral spreading cerebral hypoperfusion during spontaneous migraine headache. N Eng / Med 1994;331:1689

12. Cutrer FM, Sorensen AG, Weisskoff RM, Ostergaard L, Sanchez del Rio M, Lee J, Rosen BR, Moskowitz MA. Perfusion-weighted imaging defects during spontaneous migrainous aura. Ann Neurol 1998;43:25-31

13. Moskowitz MA, Nozaki K, Kraig RP. Neocortical spreading depression provokes the expression of c-fos protein-like immunoreactivity within trigeminal nucleus caudalis via trigeminovascular mechanisms. I Neurosci 1993;13:1167-1177

14. Lauritzen M. Pathophysiology of the migraine aura: the spreading depression theory. Brain 1994;117:199

15. Welch KMA, D'Andrea G, Tepley N, Barkley GL, Ramadan NM. The concept of migraine as a state of central neuronal hyperexcitability. Neurol Clinics 1990;8:817-828

16. Bowyer SM, Burdette D, Aurora SK, Moran J, Tepley N, Welch KMA. Neuromagnetic measurements of evoked and spontaneous migraine with aura. Cephalalgia 1999;19:352

17. Cao Y, Welch KMA, Aurora S, Vikingstad EM. Functional MRI-BOLD of visually triggered headache in patients with migraine. Arch Neurol 1999;56:548-554

18. Barkley GL, Tepley N, Nagel-Leiby S, Moran JE, Simkins RT, Welch KMA. Magnetoencephalographic studies of migraine. Headache 1990;30:428-434

19. Welch KMA, Barkley GL, Tepley N, Ramadan NM. Central neurogenic mechanisms of migraine. Neurology 1993;43 (suppl 3):\$21-\$25

20. Schoenen 1. Clinical neurophysiology studies in headache: a review of data and pathophysiological hints. Funct Neurol 1992;7:191-204 
21. Khalil NM, Legg NJ, Anderson DJ. Long term decline of P100 amplitude in migraine with aura. I Neurol Neurosurg Psychiatry 2000;69:507-511

22. Afra J, Cecchini AP, De Pasqua V, Albert A, Schoenen J. Visual evoked potentials during long periods of pattern-reversal stimulation in migraine. Brain 1998;121:233-241

23. Marcus DA, Soso MJ. Migraine and stripe-induced visual discomfort. Arch Neurol 1989;46:1129-1132

24. Khalil NM. Investigations of visual function in migraine using visual evoked potentials and visual psychophysical tests. PhD Thesis: University of London, 1991

25. Legg N, Khalil N. Visual dysfunction in migraine with aura. Cephalalgia 1995;15:536

26. Coleston DM, Kennard C. Visual changes in migraine: indications of cortical dysfunction. Cephalalgia 1993;13 (suppl 13):11

27. Chronicle EP, Wilkins A], Coleston DM. Thresholds for detection of a target against a background grating suggest visual dysfunction in migraine with aura but not migraine without aura. Cephalalgia 1995;15:117-122

28. Wray SH, Mijovic-Prelec D, Kosslyn SM. Visual processing in migraineurs. Brain 1995; $118: 25-35$

29. Ramadan NM, Halvorson H, Vande-Linde A, Levine SR, Helpern JA, Welch KMA. Low brain magnesium in migraine. Headache 1989;29:590-593

30. Ophoff RA, Terwindt GM, Vergouwe MN, Eijk R van, Oefner PJ, Hoffman SM et al. Familial hemiplegic migraine and episodic ataxia type- 2 are caused by mutations in the Ca2+ channel gene CACNL1A4. Cell 1996;87:543-552

31. Terwindt GM, Ophoff RA, van Eijk R, Vergouwe MN, Haan I, Frants RR, Sandkuijl LA, Ferrari MD. Involvement of the FHM locus on 19p13 in migraine. In: Terwindt GM. Clinical genetics of migraine. Leiden University 1998, PhD Thesis, pp 105-116

32. Welch KMA, Levine SR, D'Andrea G, Schultz LR, Helpern JA. Preliminary observations on brain energy metabolism in migraine studied by in vivo 31 NMR spectroscopy. Neurology 1989;39:538-541

33. Harreveld Van A, Stamm JS. Cortical responses to metrazol and sensory stimulation in the rabbit. Electroencephalogr Clin Neurophysiol 1955;7:363-370

34. Chagnac-Amitai $Y$, Connors BW. Synchronized excitation and inhibition driven by intrinsically bursting neurons in the neocortex. J Neurophysiol 1989;62:1149-1162

35. Valverde $F$. The organizing principles of the primary visual cortex in the monkey. In: Peters A, Jones EG (eds). Cerebral cortex. Vol 3: Visual cortex. New York: Plenum Press, 1985

36. Sloper IJ, Johnson P, Powell TPS. Selective degeneration of interneurons in the motor cortex of infant monkeys following controlled hypoxia: a possible cause of epilepsy. Brain Res 1980;198:204-209

37. Chronicle EP, Mulleners WM. Might migraine damage the brain? Cephalagia $1994 ; 14: 415-418$

38. Krüger $H$, Luhmann $H J$, Heinemann $U$. Repetitive spreading depression causes selective suppression of GABA-ergic function. Neuroreport 1996;7:2733-2736

39. Khalil NM, Legg NJ. Pathophysiology of migraine: a study using VEP and contrast sensitivity. In: Clifford Rose F, editor. New advances in headache research. London: Smith-Gordon, 1989

40. Afra J, Mascia A, Gérard P, Maertens de Noordhout A, Schoenen J. Interictal cortical excitability in migraine: a study using transcranial magnetic stimulation of motor and visual cortices. Ann Neurol 1998;44:209-215

41. Wilkinson $F$, Crotogino ). Orientation discrimination thresholds in migraine: a measure of visual cortical inhibition. Cephalalgia 2000;20:57-66 
42. Barker AT, Jalinous R, Freeston IL. Non invasive magnetic stimulation of the human motor cortex. Lancet 1985;1:1106-1107

43. Marg E. Magnetostimulation of vision: direct noninvasive stimulation of the retina and the visual brain. Optom Vis Sci 1991;68:427-440

44. Marg E, Rudiak D. Phosphenes induced by magnetic stimulation over the occipital brain: description and probable site of stimulation. Optom Vis Sci 1994;71:301-311

45. Chiappa. Transcranial motor evoked potentials. Electromyogr Clin Neurophysiol 1994;34:15-21

46. Meyer B-U, Diehl R, Steinmetz H, Britton TC, Benecke R. Magnetic stimuli applied over motor and visual cortex: influence of coil position and field polarity on motor responses, phosphenes, and eye movements. Electroencephalogr Clin Neurophysiol 1991;43 (suppl):121-134

47. Amassian VE, Cracco RQ, Maccabee PJ, Cracco JB, Erberle L, Rudell A. Suppression of visual perception by magnetic cortical stimulation of human occipital cortex. Electroencephalogr Clin Neurophysiol 1989;74:458-462

48. Amassian VE, Cracco RQ, Maccabee PJ, Cracco JB, Rudell AP, Erberle L. Transcranial magnetic stimulation in study of the visual pathway. I Clin Neurophysiol 1998;15:288-304

49. Cracco RQ, Amassian VE, Maccabee PJ, Cracco JB. Flow of symbolic visual information from retian to vocalization. In: Kimura J and Shibasaki $\mathrm{H}$ (eds). Recent Advances in Clinical Neurophysiology. Elsevier Sciences, 1996, 963-969

50. Maertens de Noordhout A, Pepin JL, Schoenen J, Delwaide PJ. Percutaneous magnetic stimulation of the motor cortex in migraine. Electroencepalogr Clin Neurophysiol 1992;85:110-115

51. Bettuci D, Cantello R, Gianelli M, Naldi P, Mutani R. Menstrual migraine without aura: cortical exciatbility to magnetic stimulation. Headache 1992;32:345-347

52. Kamp Van der W, MaassenVanDenBrink A, Ferrari MD, Dijk van JG. Interictal cortical hyperexcitability in migraine patients demonstrated with transcranial magnetic stimulation. I Neurol Sci 1996;139:106-110

53. Kamp Van der W, MaassenVanDenBrink A, Ferrari MD, Dijk van JG. Interictal cortical excitability to magnetic stimulation in familial hemiplegic migraine. Neurology 1997;48:1462-1464

54. Aurora SK, Ahmad BK, Al-Sayed F, Welch KMA. Cortical stimulation silent period is shortened in migraine with aura. Neurology 1998;50 (suppl 4):A351-A352

55. Werhahn KJ, Wiseman K, Herzog J, Förderreuther S, Dichgans M, Straube A. Motor cortex excitability in patients with migraine with aura and hemiplegic migraine. Cephalalgia 2000;20:45-50

56. Aurora SK, Ahmad BK, Bhardhwaj P, Ramadan NM, Welch KMA. Transcranial magnetic stimulation confirms hyperexcitability of occipital cortex in migraine. Cephalagia 1997;17 (suppl):254-255

57. Aurora SK. Ahmad BK, Welch KMA, Bhardhwaj P, Ramadan NM. Transcranial magnetic stimulation confirms hyperexcitability of occipital cortex in migraine. Neurology 1998;50:1111-1114

58. Aurora SK, Al-Sayed F, Welch KMA. The treshold for magnetophosphenes is lower in migraine. Neurology 1999;52 (suppl 2):A472.

59. Aguggia M, Zibetti M, Febbraro A, Mutani R. Transcranial magnetic stimulation in migraine with aura: further evidence of occipital cortex hyperexcitability. Cephalalgia 1999;19:465.

60. Mulleners WM, Chronicle EP, Vredeveld JW, Koehler PJ. Cortical excitability in migraine. Ann Neurol 1999;45:415-416. 


\section{Chapter 2}

Visual system dysfunction in migraine. A review of clinical and psychophysical findings

Chronicle EP, Mulleners WM

Cephalalgia 1996;16:525-535 


\section{Abstract}

This paper reviews both clinical and experimental literature relating to visual dysfunction in migraine, starting with the eye and progressing via the retina and visual pathways to the visual cortex. Migraine has consistently been shown to be associated with (i) a pupillary sympathetic hypofunction, and (ii) a cortical hypersensitivity to visual stimuli (perhaps only in migraine with aura). The exact pathophysiologies of these dysfunctions are not known: various hypotheses are discussed, and it is proposed that the methods of visual psychophysics may represent a useful approach in the future study of cortical hyperexcitability in migraine. Paradoxically, rather little research attention has been directed towards explanations of the common clinical observations that (i) migraineurs are photophobic during attacks, and (ii) that migraine may be triggered by visual stimuli. It is argued that research aimed at elucidating the mechanisms of these phenomena may enhance our understanding of the general pathophysiology of migraine. 


\section{Introduction}

As Liveing ${ }^{1}$ and many other writers since have noted, visual symptoms are prominent in attacks of migraine. In addition to the characteristic hallucinations of the visual aura, photophobia is a feature of most attacks, either with or without aura (to the extent that it is a diagnostic criterion in the 1988 classification of the International Headache Society ${ }^{2}$ ). Blurred vision is often complained of during the headache phase ${ }^{3}$. Furthermore, there are reportedly patients whose attacks may be triggered by visual stimuli ranging from falling snow ${ }^{1}$ to fairground lighting ${ }^{4,5}$. Finally, less conspicuous signs of visual system dysfunction, including disorders of pupillary dynamics, have become apparent with neurophysiological and psychophysical techniques.

In spite of the clinical evidence of visual involvement, the literature dealing specifically with the visual system in migraine is not, on the whole, extensive. One notable exception is in the field of electrophysiology: photic driving in the electroencephalogram, visual evoked potentials and electroretinographic records have been the foci of many studies. Electrophysiological findings have already been amply reviewed; the interested reader is referred to Gronseth and Greenberg ${ }^{6}$, van Dijk et $\mathrm{al}^{7}$, Sand $^{8}$, Hockaday and Debney ${ }^{9}$ and Winter ${ }^{10}$ for a variety of perspectives.

This review will, therefore, restrict itself to clinical and psychophysical studies of visual function in migraine, starting with the eye and progressing from retina to visual cortex. It will attempt (a) to present an overview of the currently available evidence for visual system dysfunction in migraine; (b) to summarise explanations, where they exist, of the clinically-observable visual symptoms in migraine; (c) to draw attention to those research areas where our understanding is limited, and (d) tentatively to suggest that an increased understanding of visual dysfunction in migraine may provide certain clues to the general pathophysiology of the disorder.

\section{The eye}

\subsection{Errors of refraction}

During the early part of the twentieth century, a number of authors insisted that migraine was caused by small errors of refraction, particularly astigmatic errors, and that migraine could be cured completely by correcting these errors with appropriate lenses. Gould $11, p .244$, for example, proposed a radical unifying hypothesis: 'Eyestrain produces almost an infinity of morbid results, and migraine, typical or not, is, if not absolutely, almost always, one of the products of the malfunction of astigmatic eyes'.

Snell ${ }^{12}$ supported Gould's views, suggesting that eyestrain caused the 
great majority of headaches, 'often of a very aggravated character' (p.55), and that a cylindrical correction (for astigmatism) of even 0.25 dioptres would give great benefit. No experimental evidence was cited by either Snell or Gould; by 1922 , Collier was driven to complain that 'Very undue prominence has been given to the importance of errors of refraction as causes of migraine ${ }^{13, p .91}$.

The lack of conclusive evidence concerning the involvement of refractive error in the ætiology of migraine persists today, as the number of reports on this topic is very limited. Turville ${ }^{14}$ reported that the correction of small refractive errors resulted in 'complete relief' of migraine for 69 out of 123 patients; no control group was included in the study, however. Three more recent papers have examined the relationship between minor refractive errors and the symptoms of headache and asthenopia that may occur during the use of video display units (VDUs). Knave et al ${ }^{15}$ and Nyman et a $\left.\right|^{16}$ reported that a group of VDU users were more likely to report asthenopic symptoms, but had a prevalence of refractive error no higher than a control group of non-users of VDUs. Daum et al ${ }^{17}$ showed, in a group of 32 VDU users, that refractive status was significantly related to various asthenopic symptoms, but not to the incidence, severity or duration of headache. In none of these studies were headache symptoms classified according to accepted diagnostic criteria, nor was there a specific focus on migraine.

Despite the lack of research on this topic, the generally held ophthalmological opinion seems to be that minor refractive error in and of itself rarely causes any significant headache problem ${ }^{18-20}$. Tomsak ${ }^{20, p .694}$ asserts that eyestrain is '...never associated with other symptoms like nausea, vomiting or prodromal aura'.

\subsection{Glaucoma and migraine}

The main reason for headache researchers to show an interest in glaucoma appears to have been because of the possible diagnostic dilemmas in differentiating the two disorders. After Corbett et $\mathrm{al}^{21}$ found an unexpectedly high prevalence of migraine in a sample of 27 low-tension glaucoma (LTG) patients who were under investigation for signs of cerebral atrophy, the possibility of a pathophysiological link suggested itself. Optic nerve ischæmia has been implicated $22-24$ in the pathophysiology of LTG. Phelps and Corbett ${ }^{25}$ therefore examined the prevalence of migraine in 54 patients with LTG, with the rationale that optic nerve damage may be a result of migrainous ischæmia. Although LTG patients were significantly more likely than controls to report a history of headache (particularly when elderly patients and matched controls were compared), the prevalence of strictlydefined migraine was not significantly higher in LTG patients. Usui et al ${ }^{26}$ also found no significant difference in the prevalence of strictly-defined migraine, comparing a group of 77 LTG patients with 75 normal subjects.

The studies of Phelps and Corbett ${ }^{25}$ and Usui et $\mathrm{al}^{26}$ also included 
patients with primary open-angle glaucoma. Neither found an elevation of migraine prevalence in this group of patients. Furthermore, a recent largescale population-based survey reported no association between open-angle glaucoma and migraine (Klein et $\mathrm{al}^{27}$ ). Although the size of Klein et al's sample was impressive, it is not clear that their diagnoses of migraine conformed to the criteria of the Headache Classification Committee of the IHS ${ }^{2}$. This difficulty notwithstanding, it is perhaps not surprising to find no association between these two disorders, given (i) the widely differing pattern of prevalence by $\operatorname{age}^{28}$ and (ii) the dissimilarity of their presumed pathophysiologies 29 .

A number of authors have nonetheless drawn attention to subtler relationships between glaucoma and migraine. $\operatorname{Tan}^{30}$ argues that there is still the potential for diagnostic confusion between classical migraine (in neurology) and intermittent primary angle-closure glaucoma (in ophthalmology), and provides some discussion on differentiating features. Sujatha et $a^{31}$ also comment on this diagnostic dilemma. Gupta ${ }^{32,33}$ has sought to explain visual field defects in migraine by a mechanism of retinal barotrauma caused by transient and undetected interictal increases in intraocular pressure. It is not clear whether this hypothesis has been tested empirically; this would appear to be a formidable task, given the need for continuous monitoring of intraocular pressure over a lengthy period of time.

\subsection{The pupil}

Pupillary abnormalities are not a conspicuous feature of migraine headaches in everyday clinical practice, neither during nor in between attacks ${ }^{34}$. Systematic attempts to examine ictal pupillary function may often be precluded by photophobia. It was after Wolff ${ }^{35}$ and later Lance ${ }^{36}$ had postulated that migraine may be viewed as a paroxysmal derangement of autonomic monoaminergic function that interest in experimental pupillodynamics increased. Pupillary function in migraine has been assessed, both in light- and dark-adaptation and with a broad spectrum of topical pharmacological interventions, and been found both clinically and subclinically defective. Most of the available data point to a cervical sympathetic hypofunction with subsequent receptor hypersensitivity both ictally 37,38 and inter-ictally ${ }^{37-43}$. Two studies, however, either find no significant differences in pupillary function between migraine and control ${ }^{44}$ or conclude that parasympathetic deficiency and/or sympathetic hyperfunction occur in migraine ${ }^{45}$. Furthermore, evidence for the existence of a strictly ipsilateral relationship between side of headache and side of pupillary dysfunction is equivocal (compare refs. $38 \& 39$ ); bilateral pupillary deficits have also been observed in patients with unilateral headache ${ }^{40}$.

It is notable that many investigations of pupil function in migraine have 
been prone to methodological difficulties: (i) illumination levels are rarely adequately specified; (ii) it is not always clear that controls and migraineurs have been age-matched; (iii) one study did not differentiate between pupillometric data carried out in ictal and inter-ictal periods ${ }^{46}$; (iv) none of the studies encountered have specified whether, in manual measurement of pupil diameter, investigators have been blind as to the diagnosis of the subject. Minor anisocoriæe in migraineurs of $0.2 \mathrm{~mm}$ or less may be statistically significantly greater than those in control subjects ${ }^{39}$; we would contend that such small effects are highly likely to be subject to experimenter biases. These objections aside, the majority of investigations reach the consensus that sympathetic hypofunction is likely, via one of two possible mechanisms. First, the observations are consistent with a central monoaminergic deficit, as postulated by Lance's neurogenic model of migraine ${ }^{36}$. Second, they could reflect a postganglionic sympathetic dysfunction due to vasodilation-induced compression of the pericarotid sympathetic fibres; in Drummond's view ${ }^{38}$, the carotid vasodilation may be secondary to reflex activity in the greater superficial petrosal nerve.

That trigeminal activation may induce miosis is not in doubt ${ }^{47-49}$. Little is known, however, about this trigemino-pupillary interaction in migraine patients. It has been demonstrated that infratrochlear transcutaneous electrical stimulation gives rise to a non-cholinergic miotic response, both in interictal migraineurs and in volunteers ${ }^{50,57}$. It is not known, however, if this trigemino-pupillary response is defective in migraine attacks, as it has been shown to be in attacks of cluster headache ${ }^{50}$. It is therefore possible to speculate that activation of the trigemino-pupillary reflex by the ongoing attack causes ictal miosis, whereas interictal miosis is a result of sympathetic hypofunction.

\section{The oculomotor system}

\subsection{Ocular motor nerve dysfunction}

Ophthalmoplegic migraine is characterised by prolonged ocular motor nerve palsy (internal and/or external), usually lasting several days, and temporally related headache, in the absence of related intracranial pathology. The exact pathogenetic mechanism underlying the ophthalmoplegia is not known, but is supposedly due to ocular motor nerve ischæmia, predominantly of the peripherally situated nerve fibres; alternatively, intracavernous nerve compression by the carotid artery may be presumed ${ }^{52}$. Indeed, Stommel's case report of a contrast enhancing lesion in the perimesencephalic part of the right oculomotor nerve on $\mathrm{MRI}$ in supposedly ophthalmoplegic migraine suggests an ischæmic mechanism ${ }^{53}$. A similar contrast enhancing lesion was 
documented by Straube et $\mathrm{al}^{54}$, who contend that the prepontine lesion of the oculomotor nerve would argue in favour of Tolosa-Hunt syndrome. The significance of Stommel's observation remains somewhat doubtful since the atypical features reported are, in our view, not supportive of a diagnosis of ophthalmoplegic migraine.

The ensuing debate ${ }^{55}$ may be regarded as indicative of the continuing controversy as to whether ophthalmoplegic migraine is a separate diagnostic entity. The literature on this matter does not allow firm conclusions, as it predominantly deals with case reports or small cohorts and does not involve prospectively studied patient material. As a result reliable epidemiological data are not available. In a recent hospital-based retrospective study epidemiological and headache characteristics of ophthalmoplegic migraine were found to be distinctively different from the more common migraine variants ${ }^{56}$. Because it cannot be readily differentiated from other rare afflictions, most notably the Tolosa-Hunt syndrome ${ }^{56,57}$, this debate has led the Headache Classification Committee of the $\mathrm{IHS}^{2}$ to include ophthalmoplegic migraine as a separate diagnostic category (1.3), though stressing that 'whether ophthalmoplegic migraine in fact has anything to do with migraine is uncertain ${ }^{2, p .23 \prime}$.

\subsection{Central ocular motor dysfunction}

Discongruent eye position may be caused by a functional derangement at the nuclear or internuclear level. Apart from the abnormal relative position of the globes, limitation of eye movement, nystagmus and paralysis of horizontal gaze may occur, resulting in blurred vision, diplopia and oscillopsia. With respect to headache syndromes, ictal diplopia (along with other brain stem symptoms) may be a diagnostic feature of basilar migraine, caused by a dysfunction in the flow distribution of the basilar artery ${ }^{2}$. However, diplopia without accompanying signs of oculomotor dysfunction needs to be regarded with caution, as it may also be reported by patients afflicted with tension-type headache or hyperventilation syndrome.

Disorders of voluntary eye movements (intentional and reflexive saccades, smooth pursuit) in migraine have been studied only scantily. Both saccadic and pursuit movements are initiated by cortical neurons, which project onto the brainstem through multi-synaptic pathways; both systems are under cerebellar control (for an overview of the optokinetic system see ref. 58). We are not aware of any study on voluntary eye movements in migraine with or without aura, ictally or interictally. Zifkin and colleagues report on a mother and son with childhood-onset hemiplegic migraine and nystagmus, who also showed loss of smooth pursuit, biplanar failure of fixation suppression of the vestibulo-ocular reflex and low optokinetic nystagmus gain on neuroophthalmological examination ${ }^{59}$. These findings pointed at a dysfunction at brainstem and cerebellar levels, and autosomal dominant inheritance was proposed. The only existing studies on supranuclear eye movement disorders 
in primary headache report a reduced velocity of both saccadic and smooth pursuit movements in tension-type headache, possibly reflecting pathological proprioceptive signals from cervical structures interfering with normal eye motor functioning ${ }^{60,61}$. Although the vestibular and oculomotor systems are intimately related, a thorough review of vestibular and vestibulo-ocular dysfunction in migraine is beyond the scope of this paper. The interested reader is referred to an excellent review and study by Olsson ${ }^{62}$.

\section{The retina}

\subsection{Retinal migraine}

Retinal migraine is defined as 'repeated attacks of monocular scotoma or blindness lasting less than an hour and associated with headache. Ocular or structural vascular disorder must be ruled out ${ }^{2, p .25}$. Patients with retinal migraine experience monocular blackouts, whiteouts, and occasionally flashes or sparkles ${ }^{63}$. The prevalence of strictly-defined retinal migraine has not been established, as far as we are aware; it is generally thought to be rare ${ }^{64,65}$.

The pathophysiology of this condition is scantily understood, although, given the monocular symptoms, a prechiasmatic origin may be supposed. It may involve vasoconstriction either in the retina or in the optic nerve ${ }^{66,67}$. On the other hand, it is known that spreading depression may be induced in the chicken retina in vitro ${ }^{68}$; hence a primarily neuronal mechanism may be responsible for the loss of vision. Given (a) that fleeting monocular blindness is observed in other situations, such as temporary retinal artery occlusion by emboli from internal carotid artery atheroma ${ }^{69}$, (b) that fleeting monocular blindness unassociated with headache has also been described in patients who also have typical migraines ${ }^{70}$, and (c) that patients commonly have difficulty in distinguishing between monocular and homonymous symptoms, it is possible that retinal migraine is not a single entity. Indeed, Hupp et al ${ }^{64}$, after a comprehensive review of case material, assert 'On the basis of history alone, there are no distinguishing symptoms to separate ocular migraine from amaurosis fugax due to retinal microembolization' (pp.226-9). It should be stressed, however, that since migraine can be regarded as a paroxysmal derangement of the brain and its vasculature, and that the eye and its arterial supply are essentially an extension of the brain, retinal migraine may conceivably be physiologically analogous to migraine with aura.

The possibility of retinal microembolisation and consequent ischæmia during monocular visual loss associated with migraine suggests that permanent retinal lesions may occasionally result. Permanent occlusions of retinal and ciliary vessels associated with migraine have repeatedly been demonstrated ${ }^{71,72}$. 


\subsection{Colour vision in migraine}

Disorders of colour vision may be a result of abnormality at the retinal level; colour deficiency may arise through the lack of one of the cone types. Alternatively, patients may appear to have all three cone types but still give abnormal colour-matches. It is thought that the spectral sensitivity curve of one of the cone types is displaced in such patients, who are termed anomalous trichromats ${ }^{73}$. Such colour vision abnormalities may be discovered easily by use of a printed test (for examples, those of Ishihara ${ }^{74}$ or Fletcher ${ }^{75}$ ).

We have been unable to discover any published study dealing with the incidence of retinal colour deficiency in the migraine population. An isolated case report of complete central achromatopsia during the aura of migraine has appeared in the recent literature ${ }^{76}$. The authors suggest that, in this case, the cortical disturbance giving rise to aura symptoms may have originated bilaterally in visual area $\mathrm{V} 4$, which is thought to be responsible for the central processing of colour 77 . Bilateral onset of aura symptoms is not, however, typical of migraine with aura, and an explanation for this highly unusual observation is not provided.

\section{The visual pathways}

Monocular visual symptoms, including fleeting blindness, may be brought about by a temporary disruption of blood supply to the optic nerve in association with other migrainous symptoms ${ }^{63}$. As in the case of retinal migraine, a variety of possible causes has been identified ${ }^{64}$; it is not always clear that the optic nerve dysfunction in such cases is strictly migrainous in nature. An interesting, if isolated, case report ${ }^{78}$ has reported monocular visual symptoms appearing in close association with the administration of oral sumatriptan, and persisting at 12-month follow-up. Examination revealed mild impairment of acuity, dyschromatopsia, impaired contrast sensitivity and an arcuate nerve fibre bundle scotoma on the affected side. The authors contend that the vasoconstrictive effect of sumatriptan may have acted to reduce perfusion pressure in the posterior ciliary artery circulation.

A number of studies have used psychophysical methods to examine the functional status of the visual pathways. In particular, Coleston and coworkers $^{79}$ have utilised tests which separately assess magnocellular and parvocellular pathways. The ST-1 spatial response is obtained by measuring the threshold target illumination at which a subject can just detect that target moving back and forth across a square-wave background grating. Using a range of background frequencies, a characteristic curve reflecting the functioning of X-type (i.e. parvocellular) neurons may be obtained. The ST-2 temporal response curve is obtained in a similar manner, but this time the 
background is modulated in the temporal rather than the spatial domain. ST-2 temporal responses are thought to reflect Y-type (i.e. magnocellular) function 80,81 . Patients suffering from conditions thought to involve abnormalities in their pre-cortical visual pathways demonstrate certain abnormalities in their ST-1 and ST- 2 responses. For example, amblyopic patients show a peak in their ST-1 spatial functions at a lower spatial frequency than do control subjects ${ }^{82}$.

Coleston et al $^{79}$ have examined the ST-1 and ST-2 curves in migraine with aura, migraine without aura, and matched controls. In the ST-1 experiment, the background spatial frequency at which the threshold target illumination peaked was slightly lower for both groups of migraineurs than for controls. In the ST-2 data, the background temporal frequency at which the threshold target illumination peaked was also slightly lower for migraineurs than for controls. These findings suggest that both magnocellular and parvocellular pathways are functionally altered to a small but measurable degree in patients both with and without aura. Coleston and Kennard ${ }^{83}$ have also examined the critical flicker fusion frequencies (CFF) of migraineurs with and without aura, and controls. CFF is thought to be dependent on the integrity of the magnocellular system. Migraineurs without aura had the lowest CFF, and controls the highest: the mean CFF of the migraine with aura group was intermediate. Only the difference between patients without aura and controls reached statistical significance. Coleston and Kennard ${ }^{83}$ felt that it was '...difficult to explain...' the difference between their two patient groups, given the previous findings using the ST- 1 and ST- 2 methods.

The studies of Coleston and co-workers thus provide some evidence to suggest that the functioning of the visual pathways is impaired in inter-ictal migraineurs, although it is not entirely clear whether with and without aura patients are equally afflicted. Coleston et al $^{79}$ suggest three pathophysiological possibilities: first, there may be some intrinsic abnormality of the magnocellular and parvocellular pathways in migraine; second, the functional integrity of the pathways may in some way be directly compromised by repeated migraine attacks; third, it is possible, given the existence of rich back projections from the striate cortex to the lateral geniculate nuclei, that the cortical disruptions of the migraine attack may cause retrograde geniculate disturbances. Insufficient evidence exists at present to give priority to any one of these hypothetical pathophysiologies.

\section{The primary visual cortex}

The migraine aura has been described in medical and other literatures for hundreds, if not thousands, of years ${ }^{84}$. It was perhaps Lashley's ${ }^{85}$ seminal 
observation of the rate of progression of his own aura across the visual field, however, which turned the primary visual cortex into a site of special scientific interest for those researching the pathophysiology of migraine. The typical aura has, in addition, provided visual science with data on the functional organisation of the visual cortex ${ }^{86}$.

The homonymous visual hallucinations of the typical aura are thought to be pathognomonic for migraine ${ }^{87}$. In a few patients, aura is not followed by headache ${ }^{88}$; this condition is now termed migraine aura without headache ${ }^{2}$. The typical aura has usually been thought of as a benign and transient neurological disturbance ${ }^{89}$; useful central vision is typically restored as soon as the scintillating scotoma has expanded towards the periphery ${ }^{90}$. In more recent years, a number of case-reports of patients with very prolonged aura-like symptoms have appeared, however. Haas ${ }^{91}$ reported two patients (18 and 70 years of age) in whom aura-like symptoms were continuously present for a period of several weeks. Luda et al ${ }^{92}$ reported a 'totally new variation of migraine': the case of a patient with scintillating scotomata continuing unchanged (although unassociated with headache) for a period of over 12 months. A SPECT scan demonstrated relative hypoperfusion in the left parieto-occipital and frontal areas; no structural abnormality was evident from CT or MRI images. Liu et al ${ }^{93}$ give details of ten patients (age range 9-67), all of whom had a history of migraine, and who developed persistent positive visual phenomena lasting from 2 months to 5 years. None had any significant findings on MRI examination; EEGs, performed in 8 of the 10, were normal. Four of the series showed relative parieto-occipital hypoperfusion on the SPECT image, one a temporal lobe defect. The authors cautioned, however, that any conclusions drawn from the SPECT data should be tempered by the lack of control data for these patients. It is also of note that 4 of the 10 patients developed the persistent visual phenomena at times when they were not having a migraine attack, which perhaps casts some doubt on whether the phenomena were a result of migraine. With respect to persistent negative visual phenomena, Wakakura and Ichibe ${ }^{94}$ reported two patients with initially transient, then persistent homonymous hemianopia. A SPECT scan on one of these patients showed decreased tracer uptake in the left basal ganglion area. Again, no SPECT data was available before the onset of hemianopia, which renders interpretation more difficult. Lewis et al $^{95}$ reported a wide variety of visual field defects, including homonymous hemianopia, in $35 \%$ of a sample of 60 migraineurs, tested interictally using automated static perimetry. Lewis et al were not able to demonstrate a replication of the visual field defects in a subset of their sample, however, which suggests that, in some patients, transient visual loss may be a consequence of temporally proximate attacks. This suggestion is supported by the study of Drummond and Anderson ${ }^{96}$, who found a depression of peripheral sensitivity and central blurring in 10 patients with aura tested the day after an attack. These visual disturbances had resolved at retest, 7-10 days later. 
The association of migraine with stroke is a much-debated topic, discussion of which is outside the scope of this review. Recent commentary is to be found in Olesen et $\mathrm{al}^{97}$ and Welch ${ }^{98}$. Regardless of the pathophysiological basis of migraine-related stroke, however, unilateral occipital lobe infarctions in migraine affecting normal vision have been reported on occasion 99,100 . Bilateral occipital infarction has, to our knowledge, been reported in only one paper ${ }^{101}$.

The primary visual cortex in migraine has recently been the focus of a number of psychophysical investigations. Several of these have involved the use of high-contrast square-wave grating stimuli of intermediate fundamental spatial frequency (medium-spaced patterns of black and white stripes; see ref. 102 for an example stimulus). Wilkins and co-workers ${ }^{103,104}$ have adduced considerable data suggesting that the visual illusions and subjective visual discomfort experienced when viewing such patterns arise in the visual cortex. In their original paper, Wilkins et al ${ }^{103}$ found that subjects who suffered from unilateral headache were more likely to report asymmetric illusions in a 4 cycles/degree grating pattern, although there was no relationship between the side of illusions and the side of head pain. No formal diagnoses of these subjects were provided, however, although from the symptom checklist provided it seems likely that many of them had migraine. Marcus and Soso ${ }^{105}$, in an ingenious experiment, measured visual discomfort by recording the number of aversive movements (wincing, head-turning, etc.) subjects made when shown an appropriate grating pattern and a control pattern. It was found that migraineurs were significantly more averse to the gratings than were the control subjects. Khalil ${ }^{106,107}$ used patients with diagnosed migraine and reported that: (i) overall, migraineurs saw more illusions than control subjects, regardless of the size of the stimulus; (ii) migraineurs experienced more discomfort on viewing the patterns than did controls; (iii) illusions and discomfort were more frequent in those suffering migraine with aura than those without aura; (iv) patients with unilateral aura saw more illusions on the aura side than on the contralateral side and $(v)$ those with frequent migraine attacks ( $\geq 1$ per week) tended to see $(t=1.94 ; p=0.06)$ more illusions than those with infrequent attacks ( $5-10$ per year). Coleston and Kennard ${ }^{108}$ used a slightly different methodology, in that they asked patients to rate the intensity of the illusions they saw, rather than simply listing them. Patients with aura reported significantly more intense illusions over a range of spatial frequencies than did patients without aura.

These studies ${ }^{103-108}$ examining the effects of square-wave gratings are in good general agreement; it is conceivable, however, that their findings have been due in part to differences between migraine and control groups in respect to their propensity to report on the adverse effects of gratings. Migraineurs have been reported to be more hypochondriacal than control subjects $^{109}$; it is therefore possible that they have a tendency to overemphasise grating-induced illusions and visual discomfort. This is particularly 
likely in the study of Marcus and Soso ${ }^{105}$, where patients were aware they were being videotaped. The study of Chronicle et al ${ }^{102}$ aimed to overcome this difficulty by employing a method wherein the degree to which the perception of a target stimulus was disrupted by a background grating was measured; hence the emphasis was less on subjective reports of discomfort, but rather on the presence or absence of the target. Patients with aura had significantly higher thresholds for target perception than either patients without aura or controls.

Other psychophysical methods have also been employed to assess visual function in migraine. Spatial and temporal contrast sensitivity were determined by Khalil ${ }^{106}$ : both were significantly reduced in migraine with aura, but not migraine without aura, as compared to a control group. In addition, in the migraine with aura group only, Khalil reported a significant relationship between migraine chronicity and spatial contrast sensitivity (sensitivity declined with increasing chronicity). Drummond and Anderson ${ }^{96}$ used a masking procedure to determine the presentation time required for correct identification of visually-presented words. One day after an attack, migraine with aura patients required longer to identify words than did patients without aura. This difference was clearly not as marked 7-10 days after an attack, although the statistical interaction between diagnosis and time of testing was not, strictly speaking, significant. Wray et al ${ }^{110}$ employed four computerised visual tasks, two 'low-level' and two 'high-level' to assess visual functioning in ten migraine with aura patients and matched controls, in whom other neurological or ophthalmological disorder had rigorously been excluded. Testing was carried out in the inter-ictal period. Patients demonstrated faster response times than controls for the low-level tasks (orientation search and temporal order judgement) but not for the high-level tasks (picture naming and repetition priming). Wray et al suggested that the shorter response times in patients were likely to have been due to hypersensitivity in the primary visual cortex, either intrinsic, acquired, or an interaction of both. Boles $^{111}$, in a longitudinal study of his own visual processing during attacks of migraine with aura (in both right and left visual fields), demonstrated a somewhat different pattern of findings. On a 'low-level' (typing) task, functioning was impaired only in the visual field in which the aura symptoms had appeared, but on a 'high-level' (location matching) task, performance was impaired in both visual fields after an aura localised in the right visual field. Boles ${ }^{111}$ argues that this latter finding '...seems consistent with interference on a higher level spatial positional function lateralized to the right hemisphere'.

In general, psychophysical research examining visual cortical functioning in migraine has consistently suggested an hypersensitivity in migraine with aura, but not migraine without aura. We consider the cause of this hypersensitivity in the next section. 


\section{Unresolved issues}

The foregoing has aimed to provide an overview of recent research on the functioning of the visual system in migraine. We now consider a number of issues that in our opinion are unresolved, and deserving of further investigation.

First, despite clinical evidence that migraine may be triggered by visual stimuli ${ }^{4}$, little is known about visually triggered attacks. Estimates of the importance of visual triggers vary widely: Van den Bergh et al ${ }^{12}$, from a survey of 217 patients, found that the most common trigger factors were menstruation ( $48 \%$ of female patients), alcoholic beverages $(52 \%$ of all patients) and stress (49\%). Visual triggers were implicated in only $2.7 \%$ of patients. On the other hand, in a review of 494 patients, Robbins ${ }^{113}$ discovered that sunlight or bright light was a 'leading trigger factor' (38\% of all patients), whereas alcoholic beverages were not mentioned at all. Other studies of migraine triggers have also differed with respect to the prevalence of visual triggering 5,114 . Interpretation of the findings from these studies is unfortunately hampered by a number of methodological difficulties. First, diagnostic criteria are not always specified. Second, such studies are almost entirely retrospective in nature: it is therefore likely that patients' own imperfect memories of attacks and/or personal opinions about triggers influence their responses to questionnaires. Third, it is noticeable that trigger questionnaires are only infrequently designed according to established psychological principles for questionnaire construction; there is thus the possibility that patients' responses may be influenced by the phrasing of questions.

We are not aware, furthermore, of any published work which examines the mechanism of visually triggered migraine. It is not known, for example whether visual stimuli in isolation are sufficient to trigger an attack (as in photosensitive epilepsy) or whether an interaction between visual stimuli and other situational factors (stress, dietary components, etc.) is required. Neither is it known whether those patients whose attacks are frequently visually triggered have any visual system dysfunction which could conceivably contribute towards the onset of an attack. Hay et al ${ }^{5}$ have, however, examined the types of visual stimuli to which migraine patients are subjectively sensitive: the three most common are glare, flicker, and alternate light and shade.

The paucity of research in this area is perhaps somewhat surprising, given that many general models of migraine either implicitly or explicitly assume the operation of some kind of environmental trigger, activator, or generator $36,98,115,116$. We would argue that clear links between visual stimuli and the aura phase are evident: (a) aura symptoms are most commonly visual ${ }^{28,88}$; (b) neuronal spreading depression has been strongly implicated in the pathophysiology of the aura phase ${ }^{116}$; and (c) it is known that, in an animal model, appropriate visual stimulation (flickering light) can elicit cortical 
spreading depression ${ }^{117}$. In human migraine, flickering light is often cited by patients as an effective trigger ${ }^{4,5}$. Despite these theoretical connections, little or no experimental attention has been paid to the mechanism of operation of visual triggers.

Second, relatively little attention has been paid to the photophobia that accompanies migraine. Although it is a near-universal feature of attacks and usually very uncomfortable and disabling, we have only limited knowledge about its exact nature and causative mechanisms in migraine. It is not clear, for example, whether migrainous photophobia is phenomenologically similar to the photophobia evident in disorders such as meningitis and subarachnoid hæmorrhage: if it is similar, might there be a common pathophysiology of photophobia across these various conditions? Moreover, the distinction between true photophobia (i.e. pain induced or exacerbated by exposure to bright light) and an unpainful though uncomfortable sense of glare or dazzle is rarely assessed in clinical practice and infrequently addressed in clinical research. In fact, only one paper reports on the nature of photophobia in migraine, indicating that both phenomena are distinguishable in migraineurs ${ }^{118}$.

Painful photophobia depends on the functional integrity of both the optic and trigeminal nerve ${ }^{119}$ and may result from the interaction of an appropriate light stimulus and ophthalmic nerve irritation ${ }^{19}$. Apart from pain, blepharospasm and lacrimation may be recorded. Photophobia is most frequently encountered in diseases of the anterior segment of the eyeball, but is also very prominent in several neurological disorders like subarachnoid hæmorrhage, meningitis, trigeminal neuralgia and migraine. The question as to whether photophobia with iridal inflammation and 'neurological' photophobia share a similar pathophysiological mechanism remains to be answered ${ }^{19,119}$. Dazzle, as distinct from true photophobia, is thought to be based either on diffusion of light in the ocular media or on a lack of adaptation ${ }^{119}$; it has also been reported after right occipital and right thalamic infarction as well as in trigeminal sensory neuropathy ${ }^{120,121}$. That photophobia and dazzle are separate entities has been elegantly demonstrated by Fuchs: application of homatropine eyedrops prevented photophobic pain while dazzle sensation was increased on light adaptation ${ }^{122}$.

Controversy about the mechanism behind migrainous photophobia remains. While Pearce ${ }^{123}$ states that 'photophobia and phonophobia are almost certainly primary cerebral mechanisms of excitation or of a heightened arousal of the special senses...', Blau's opinion appears more equivocal when expressing that '...we have no idea about its mechanism'124. It may well be that more vigorous attempts to assess the individual's experience will lead the way to disclosing the probable pathogenesis of photophobia: hyperexcitability of the visual pathways in dazzle and glare or trigeminal/trigeminovascular activation in truly painful photophobia.

Third, although psychophysical research has tended to converge on the finding of visual cortical dysfunction in migraine with aura, the pathogenesis 
of this dysfunction is not known. Chronicle and Mulleners ${ }^{125}$ have pointed out that there is a population of GABA-ergic inhibitory interneurons in the primary visual cortex which are (i) known to be of great importance for visual processing ${ }^{126,127}$, and (ii) are likely to be selectively vulnerable to borderline ischæmic states ${ }^{128-130}$. The functioning of these neurons might therefore be selectively and permanently impaired if regional cerebral blood flow falls sufficiently during the aura phase ${ }^{131}$. Chronicle and Mulleners ${ }^{125}$ contend that such a mechanism would explain the observed psychophysical changes. It is alternatively conceivable that neuronal spreading depression, rather than ischæmia, might cause neuronal damage via the release of neuroexcitatory amino acids and subsequent cell death after persistent depolarisation ${ }^{117,130,132,133}$.

The possibility of intrinsic visual dysfunction in migraine with aura cannot, however, be ruled out by the available evidence. Indeed, the concept of migraine as a state of central neuronal hyperexcitability has been strongly suggested by studies using magnetoencephalography (MEG) and magnetic resonance spectroscopy (MRS) ${ }^{134-136}$. It is interesting to note that the results of the studies examining cortical function in migraine, reviewed above, are susceptible to interpretation in terms of an hyperexcitability of primary visual cortex, which might plausibly be expected both (a) to speed processing of lowlevel visual stimuli ${ }^{10}$ and (b) increase the aggregate neuronal response to grating stimuli, giving rise to subjective and psychophysically-observable effects $^{102,105}$. The possibility that visual psychophysical parameters may reflect central neuronal hyperexcitability is potentially a promising avenue of research, as straightforward (relative to MEG and MRS) and easily-repeatable assessment of cortical function in large groups of patients would thereby be facilitated.

\section{Summary and conclusions}

The clinical and psychophysical findings reviewed above reveal a broad agreement that migraine is associated with (i) a pupillary sympathetic hypofunction, and (ii) a cortical hypersensitivity to visual stimuli (perhaps only in migraine with aura). Evidence for other dysfunctionality in the eye, retina or visual pathways is, in our view, equivocal.

In spite of the research effort thus far, visual phenomena which are integral to migraine symptomatology are very poorly understood. We would contend that research aimed at understanding the neurological basis of the visual triggering of migraine, and of photophobia would assist a more complete understanding of the disorder, and perhaps shed light on processes occurring at the very initiation of an attack. We suggest also that further investigations into the nature and cause of the dysfunction of the visual cortex in migraine with aura may assist the development of general pathophysiological theories. 


\section{References}

1. Liveing E. On megrim, sick-headache and some allied disorders: a contribution to the pathology of nerve-storms. London: I \& A Churchill, 1873

2. Headache Classification Committee of the International Headache Society. Classification and diagnostic criteria for headache disorders, cranial neuralgias and facial pain. Cephalalgia 1988;8: supplement 7

3. Vincent AJP, Spierings EH, Messinger HB. A controlled study of visual symptoms and eye strain factors in chronic headache. Headache 1989;29:523-527

4. Debney LM. Visual stimuli as migraine trigger factors. In: Rose FC, editor. Progress in migraine research II. London: Pitman, 1984:30-54

5. Hay KM, Mortimer M], Barker DC, Debney LM, Good PA. 1044 women with migraine: the effect of environmental stimuli. Headache 1994;34:166-168

6. Gronseth GS, Greenberg MK. The utility of the electroencephalogram in the evaluation of patients presenting with headache: a review of the literature. Neurology 1995;45: 1263-1267

7. Dijk van JG, Haan J, Ferrari MD. Photic stimulation and the diagnosis of migraine. Headache Quarterly 1992;3:387-397

8. Sand T. EEG in migraine: a review of the literature. Funct Neurol 1991;6:7-22

9. Hockaday JM, Debney LM. The EEG in migraine. In: Olesen J, Edvinsson L, editors. Basic mechanisms of headache. North Holland: Elsevier, 1988

10. Winter AL. Neurophysiology and migraine. In: Blau JN, editor. Migraine: clinical and research aspects. Baltimore: Johns Hopkins University Press, 1987: 485-510

11. Gould GM. The history and etiology of migraine. JAMA 1904;42:168-172 \& 239-244

12. Snell S. Eye-strain as a cause of headache and other neuroses. London: Simpkin Marshall, Hamilton, Kent \& Co., 1904

13. Collier J. Migraine (paroxysmal headache). In: Price FW, editor. A textbook of the practice of medicine. London: Frowde and Hodder \& Stoughton, 1922

14. Turville AE. Refraction and migraine. Br J Physiol Optics 1934;10:62-80

15. Knave BG, Wibom RI, Voss $M$, Hedström LD, Bergqvist UOV. Work with video display terminals among office employees, I: Subjective symptoms and discomfort. Scand ] Work Environ Health 1985; 11:457-466

16. Nyman KG, Knave BG, Voss M. Work with video display terminals among office employees, IV: Refraction, accommodation, convergence and binocular vision. Scand I Work Environ Health 1985; 11:483-487

17. Daum KM, Good G, Tijerina L. Symptoms in video display terminal operators and the presence of small refractive errors. I Am Optom Assoc 1988;59:691-697

18. Hedges TR. An ophthalmologist's view of headache. Headache 1979;19:151-155

19. Worthen DM. The eyes as a source of headache. In: Dalessio DS, editor. Wolff's headache and other head pain. 4th edition. New York: Oxford University Press, 1980: 388-402

20. Tomsak RL. Ophthalmologic aspects of headache. Med Clin N Amer 1991;75:693-706

21. Corbett JI, Phelps CD, Eslinger P, Montague PR. The neurologic evaluation of patients with low-tension glaucoma. Invest Ophthalmol Vis Sci 1985;26:1101-1104

22. Levene, RZ. Low tension glaucoma: a critical review and new material. Surv Ophthalmol $1980 ; 24: 621-664$

23. Gasser P, Flammer J, Guthauser U, Mahler F. Do vasospasms provoke ocular diseases? Angiology 1990;41:213-220 
24. Flammer J. Psychophysical mechanisms and treatment of vasospastic disorders in normal-tension glaucoma. Bull Soc Belge Ophtalmol 1992;244:129-134

25. Phelps CD, Corbett J). Migraine and low-tension glaucoma: a case control study. Invest Ophthalmol Vis Sci 1985;26:1105-1108

26. Usui T, Iwata K, Shirakashi M, Abe H. Prevalence of migraine in low-tension glaucoma and primary open-angle glaucoma in Japanese. $\mathrm{Br} J$ Ophthalmol $1991 ; 75: 224-226$

27. Klein BEK, Klein R, Meuer SM, Goetz LA. Migraine headache and its association with open-angle glaucoma: the Beaver Dam eye study. Invest Ophthalmol Vis Sci 1993;34:3024-3027

28. Rasmussen BK. Epidemiology of headache. Cephalalgia 1995;15:45-68

29. Shields MB, Ritch R, Krupin T. Classifications and mechanisms of the glaucomas. In: Ritch R, Shields MB, Krupin T, editors. The Glaucomas. St. Louis: CV Mosby, 1989: 751-5

30. Tan BB. Migraine versus glaucoma - a diagnostic dilemma. Ann Acad Med Singapore 1990;19:856-858

31. Sujatha S, Fison PN, Sampath R, Leatherbarrow B. Migraine vs glaucoma - a diagnostic confusion. Br J Hosp Med 1995;53:410-411

32. Gupta VK. Pupillary disturbances in migraine: what is the relation to autonomic dysfunction? I Neurol Neurosurg Psychiatry 1991;54:847-848

33. Gupta VK. Visual function impairment in migraine: cerebral versus retinal deficit. Cephalalgia 1993;13:431-432

34. Fanciullacci $M$, Boccuni $M$, Pietrini $U$. The pupil and migraine. In: Blau JN, editor. Migraine: clinical, therapeutic, conceptual and research aspects. London: Chapman and Hall, 1987: 635-650

35. Wolff HG. Headache and other head pain. New York: Oxford University Press, 1963: 333-336

36. Lance JW. Current concepts of migraine pathogenesis. Neurology 1993;43(suppl 3): S11-\$15

37. Drummond PD. Pupil diameter in migraine and tension headache. I Neurol Neurosurg Psychiatry 1987;50:228-230

38. Drummond PD. Disturbances in ocular sympathetic function and facial blood flow in unilateral migraine headache. J Neurol Neurosurg Psychiatry 1991;54:121-125

39. Drummond PD. Cervical sympathetic deficit in unilateral migraine headache. Headache 1991;31:669-672

40. Fanciullacci $M$. Iris adrenergic impairment in idiopathic headache. Headache 1979;19:8-13

41. Gotoh F, Komatsumoto S, Araki N, Gomi S. Noradrenergic nervous activity in migraine. Arch Neurol 1984;41:951-955

42. Batistella PA, Ruffilli R, Zacchello F. Pupillary adrenergic sensitivity and idiopathic headache in pediatric patients. Headache 1989;29:163-166

43. Takeshima T, Takao $Y$, Takahashi K. Pupillary sympathetic hypofunction and asymmetry in muscle contraction headache and migraine. Cephalalgia 1987;7:257-262

44. Balottin U, Arisi D, Frigo GM, Lanzi $G$. Iris adrenergic sensitivity and migraine in pediatric patients. Headache 1983;23:32-33

45. Micieli G, Tassorelli C, Magri M, Sandrini G, Cavallini A, Nappi G. Vegetative imbalance in migraine. A dynamic TV pupillometric evaluation. Funct Neurol 1989;4:105-111

46. Herman P. The pupil and headaches. Headache 1983;23:102-105

47. Anders B. The 1990 Andre Balzs Lecture. Effects of some neuropeptides on the uvea. Exp Eye Res 1991;53:3-11 
48. Micieli G, Tassorelli C, Viotti E, Ruiz L, Sandrini G, Nappi G. The trigeminal-pupillary reflex as a model of vegetative-nociceptive interaction: physiological and clinica! aspects. Funct Neurol 1990;5:239-244

49. Micieli G, Tassorelli C, Sandrini G, Antonaci F, Nappi G. The trigemino-pupillary reflex: a model of sensory-vegetative integration. I Autonom Nerv Syst 1992;41: 179-186

50. Fanciullacci $M$, Fusco BM, Allessandri $M$, Campagnolo $V$, Sicuteri F. Unilateral impaiment of pupillary response to trigeminal nerve stimulation in cluster headache. Pain 1989;36:185-191

51. Fusco BM, Alessandri M, Campagnolo V, Fanciullacci M. Transcutaneous electrical stimulation applied to the infratrochlear nerve induces a homatropine-resistant miosis in humans. Clin Sci 1990;78:457-462

52. Vijayan N. Ophthalmoplegic migraine: ischemic or compressive neuropathy? Headache 1980;20:300-304

53. Stommel EW, Ward TN, Harris RD. MRI findings in a case of ophthalmoplegic migraine. Headache 1993;33:234-237

54. Straube A, Bandmann O, Büttner U, Schmidt, H. A contrast enhanced lesion of the III nerve on MR of a patient with ophthalmoplegic migraine as evidence for a TolosaHunt syndrome. Headache 1993;33:446-448

55. Stommel EW, Ward TN, Harris RD. Ophthalmoplegic migraine or Tolosa-Hunt syndrome? Headache 1994;34:177

56. Hansen SL, Borelli-Møller L, Strange P, Nielsen BM, Olesen J. Ophthalmoplegic migraine: diagnostic criteria, incidence of hospitalization and possible etiology. Acta Neurol Scand 1990;81:54-60

57. Kandt RS, Goldstein GW. Steroid-responsive ophthalmoplegia in a child. Diagnostic considerations. Arch Neurol 1985;42:589-591

58. Goldberg ME, Eggers HM, Gouras P. The ocular motor system. In: Kandel ER, Schwartz JH, Jessell TM, editors. Principles of neural science, 3rd edition. London: Prentice Hall International, 1991: 660-678

59. Zifkin B, Andermann E, Andermann F, Kirkham T. An autosomal dominant syndrome of hemiplegic migraine, nystagmus and tremor. Ann Neurol 1980;8:329-332

60. Carlsson J, Rosenhall U. Oculomotor disturbances in patients with tension headache. Acta Otolaryngol (Stockh) 1988;106:354-360

61. Carlsson J, Rosenhall U. Oculomotor disturbances in patients with tension headache treated with acupuncture or physiotherapy. Cephalalgia 1990;10:123-129

62. Olsson JE. Neuro-otologic findings in basilar migraine. Laryngoscope 1991;101 (suppl. 52):1-41

63. Corbett IJ. Ocular aspects of migraine. In: Blau JN, editor. Migraine: clinical and research aspects. Baltimore: Johns Hopkins University Press, 1987: 625-633

64. Hupp SL, Kline LB, Corbett JJ. Visual disturbances of migraine. Surv Ophthalmol 1989;33:221-236

65. Hupp SL, Kline LB, Corbett J]. Complicated migraine and vision. Headache Quarterly 1990;1:146-151

66. Wolter JR, Burchfield WJ. Ocular migraine in a young man resulting in unilateral transient blindness and retinal edema. J Pediatr Ophthalmol 1971;8:173-176

67. Klein LB, Kelly CL. Ocular migraine in a patient with cluster headaches. Headache $1980 ; 20: 253-257$

68. Harreveld van A. Two mechanisms for spreading depression in the chicken retina. J Neurobiol 1978;9:419-431 
69. Sandercock PAG, Smart SE. Migraine or amaurosis fugax? The value of ultrasound. Scot Med J 1990;35:147

70. Carroll D. Retinal migraine. Headache 1970;10:9-13

71. Glenn AM, Shaw PJ, Howe JW, Bates D. Complicated migraine resulting in blindness due to bilateral retinal infarction. $\mathrm{Br}$ / Ophthalmol 1992;76:189-90

72. Inan LE, Uysal H, Ergün U, Yurdakul M, Karagöz H. Complicated retinal migraine. Headache 1994;34:50-52

73. Mollon JD. Color vision. Ann Rev Psychol 1982;33:41-85

74. Ishihara S. Tests for colour-blindness. 38 plates edition. Tokyo: Kanehara Shuppan, 1970

75. Fletcher R. The City University colour vision test. Second edition. London: Keeler, 1980

76. Lawden MC, Cleland PG. Achromatopsia in the aura of migraine. I Neurol Neurosurg Psychiatry 1993;56:708-709

77. Zeki, S. A vision of the brain. Oxford: Blackwell, 1993: 125-126

78. Chiari M, Manzoni GC, van de Geijn EJ. Ischemic optic neuropathy after sumatriptan in a migraine with aura patient. Headache 1994;34:237-238

79. Coleston DM, Chronicle E, Ruddock KH, Kennard C. Precortical dysfunction of spatial and temporal visual processing in migraine. I Neurol Neurosurg Psychiatry 1994;57:1208-1211

80. Barbur JL, Ruddock $\mathrm{KH}$. Spatial characteristics of movement detection mechanisms in human vision: I - achromatic vision. Biological Cybernetics 1980;37:77-92

81. Holliday IE, Ruddock KH. Two spatio-temporal filters in human vision: 1 - temporal and spatial frequency response characteristics. Biological Cybernetics 1983;47:173-190

82. Grounds AR, Holliday IE, Ruddock KH. Two spatio-temporal filters in human vision: II - selective modification in amblyopia, albinism and hemianopia. Biological Cybernetics 1983;47:191-201

83. Coleston DM, Kennard C. Responses to temporal visual stimuli in migraine: the critical flicker fusion test. Cephalalgia 1995;15:396-398

84. Sacks O. Migraine, revised edition. London: Picador, 1993

85. Lashley KS. Patterns of cerebral integration indicated by the scotomas of migraine. Arch Neurol Psychiatry 1941;46:331-339

86. Richards W. The fortification illusions of migraines. Scientific American 1971; 224:89-96

87. Raskin NH. Headache. Second Edition. New York: Churchill Livingstone, 1988

88. Blau JN. Adult migraine: the patient observed. In: Blau JN, editor. Migraine: clinical and research aspects. Baltimore: Johns Hopkins University Press, 1987: 3-30

89. Bannister R. Brain's clinical neurology, 6th edition. London: Oxford University Press, 1985: 218

90. Oestreich AE. Intactness of useful central vision during migraine scotoma. Headache $1980 ; 20: 217$

91. Haas DC. Prolonged migraine aura status. Ann Neurol 1982;11:197-199

92. Luda $E$, Bo E, Sicuro R, Comitangelo R, Campana M. Sustained visual aura: a totally new variation of migraine. Headache 1991;31:582-583

93. Liu GT, Schatz NJ, Galetta SL, Volpe NJ, Skobieranda F, Kosmorsky GS. Persistent positive visual phenomena in migraine. Neurology 1995;45:664-668

94. Wakakura $M$, Ichibe $Y$. Permanent homonymous hemianopias following migraine. I Clin Neuro-opthalmol 1992;12:198-202

95. Lewis RA, Vijayan N, Watson C, Keltner J, Johnson CA. Visual field loss in migraine. Ophthalmology 1989;96:321-326

96. Drummond PD, Anderson M. Visual field loss after attacks of migraine with aura. Cephalalgia 1992;12:349-352 
97. Olesen J, Friberg L, Skyhøj Olsen T, Renard Andersen A, Lassen NA, Evald Hansen $P$, Karle A. Ischaemia-induced (symptomatic) migraine attacks may be more frequent than migraine-induced ischaemic insults. Brain 1993;116:187-202

98. Welch KMA. Migraine: A Biobehavioural Disorder. Arch Neurol 1987;44:323-327

99. Rich WM. Permanent homonymous quadrantanopia after migraine. Br Med J 1948; 11:592-594

100. Connor RCR. Complicated migraine: a study of permanent neurological and visual defects caused by migraine. Lancet 1962;2:1072-1075

101. Ganji S, Williams W, Furlow J. Bilateral occipital lobe infarction in acute migraine: clinical, neurophysiological, and neuroradiological study. Headache 1992;32:360365

102. Chronicle EP, Wilkins Al, Coleston DM. Thresholds for detection of a target against a background grating suggest visual dysfunction in migraine with aura but not migraine without aura. Cephalalgia 1995;15:117-122

103. Wilkins A, Nimmo-Smith I, Tait A, McManus C, della Sala S, Tilley A, Arnold K, Barrie M, Scott S. A neurological basis for visual discomfort. Brain 1984;107:989-1017

104. Wilkins A. Visual stress. Oxford: Oxford University Press, 1995

105. Marcus DA, Soso MJ. Migraine and stripe-induced visual discomfort. Arch Neurol 1989;46:1129-1132

106. Khalil NM. Investigations of visual function in migraine using visual evoked potentials and visual psychophysical tests. Ph.D. thesis: University of London, 1991

107. Legg N, Khalil N. Visual dysfunction in migraine with aura. Cephalalgia 1995; 15:536

108. Coleston DM, Kennard C. Visual changes in migraine: indications of cortical dysfunction. Cephalalgia 1993;13 (suppl. 13):11

109. Burker $\mathrm{E}, \mathrm{Hannay} \mathrm{H}$ ], Halsey $\mathrm{JH}$. Neuropsychological functioning and personality characteristics of migrainous and non-migrainous female college students. Neuropsychology 1989;3:61-73

110. Wray SH, Mijovic-Prelec D, Kosslyn SM. Visual processing in migraineurs. Brain 1995; 118:25-35

111. Boles DB. Visual field effects of classical migraine. Brain and Cognition 1993; 21:181-191

112. Bergh van den $V$, Amery WK, Waelkens J. Trigger factors in migraine: a study conducted by the Belgian Migraine Society. Headache 1987;27:191-196

113. Robbins L. Precipitating factors in migraine: a retrospective review of 494 patients. Headache 1994;34:214-216

114. Turner LC, Molgaard CA, Gardner CH, Rothrock JF, Stang PE. Migraine trigger factors in a non-clinical Mexican-American population in San Diego county: implications for etiology. Cephalalgia 1995;15:523-30

115. Saxena PR. The pathogenesis and pharmacology of migraine. Rev Contemp Pharmacother 1994;5:259-269

116. Lauritzen M. Pathophysiology of the migraine aura: the spreading depression theory. Brain 1994;117:199-210

117. Harreveld van A, Stamm JS. Cortical responses to metrazol and sensory stimulation in the rabbit. Electroencephalogr Clin Neurophysiol 1955;7:363-370

118. Drummond PD. A quantitative assessment of photophobia in migraine and tension headache. Headache 1986;26:465-469

119. Lebensohn JE. The nature of photophobia. Arch Ophthalmol 1934

120. Cummings JL, Gittinger JW. Central dazzle, a thalamic syndrome? Arch Neurol $1981 ; 38: 372-374$ 
121. Gutrecht JA, Lessell IM, Zamani AA. Central dazzle in trigeminal sensory neuropathy. Neurology 1990;40:722-723

122. Fuchs E. Ueber Lichtscheu. Wien Klin Wochenschr 1912;-25:33

123. Pearce JMS. Neural aspects of migraine. In: Blau JN, editor. Migraine: clinical, therapeutic, conceptual and research aspects. London: Chapman and Hall, 1987: 251

124. Blau JN. Prospect. In: Blau JN, editor. Migraine: clinical, therapeutic, conceptual and research aspects. London: Chapman and Hall, 1987: 676-677

125. Chronicle EP, Mulleners WM. Might migraine damage the brain? Cephalalgia 1994; $14: 415-418$

126. Orban GA. Neuronal operations in the visual cortex. Berlin: Springer-Verlag, 1984: 272-299

127. Berman NJ, Douglas RJ, Martin KAC. GABA-mediated inhibition in the neural networks of visual cortex. Prog Brain Res 1992;90:443-476

128. Sloper II, Johnson P, Powell TPS. Selective degeneration of interneurons in the motor cortex of infant monkeys following controlled hypoxia: a possible cause of epilepsy. Brain Res 1980;198:204-209

129. Romijn HJ, Ruijter JM, Wolters PS. Hypoxia preferentially destroys GABA-ergic neurons in developing rat neocortex explants in culture. Exp Neurol 1988;100: 332-340

130. Cervós-Navarro I, Diemer NH. Selective vulnerability in brain hypoxia. Crit Rev Neurobiol 1991;6:149-182

131. Skyhøj Olsen T. Spreading oligaemia in the migraine aura - most likely an artifact due to scattered radiation. Cephalalgia 1993;13:86-88

132. Gelder van NM. The hyperexcited brain: glutamic acid release and failure of inhibition. Adv Exp Med Biol 1986;203:331-347

133. Cananzi AR, D'Andrea G, Perini F, Zamberlan F, Welch KMA. Platelet and plasma levels of glutamate and glutamine in migraine with and without aura. Cephalalgia 1995; 15:132-135

134. Welch KMA, D'Andrea G, Tepley N, Barkley G, Ramadan NM. The concept of migraine as a state of central neuronal hyperexcitability. Neurol Clin 1990;8:817828

135. Welch KMA, Barkley GL, Ramadan NM, D'Andrea G. NMR spectroscopic and magnetoencephalographic studies in migraine with aura: support for the spreading depression hypothesis. Path Biol 1992;40:349-354

136. Welch KMA, Barkley GL, Tepley N, Ramadan NM. Central neurogenic mechanisms of migraine. Neurology 1993;43 (suppl. 3):S21-S25 


\section{Chapter 3}

Self-reported photophobic symptoms in migraineurs and controls are reliable and predict diagnostic category accurately

Mulleners WM, Aurora SK, Chronicle EP, Stewart R, Gopal S, Koehler PJ

Headache 2001;41:31-39 


\section{Abstract}

\section{Objectives}

To assess the reliability of self-reported photophobia across different patient populations. To examine how visual stress thresholds and photophobic symptoms may be predictive of diagnosis.

\section{Background}

Relatively little is known about inter-ictal photophobia in migraine. In particular, (a) the variability of photophobia across different patient samples has not previously been studied, and (b) a pathophysiological hypothesis to account for the symptoms is not agreed upon.

\section{Methods and Results}

Study 1 compared 99 self-selected Dutch patients and 101 headache-free controls using survey methods. Patients both with and without aura were significantly more likely to report symptoms - such as the wearing of sunglasses in normal daylight - consistent with inter-ictal photophobia. Study 2 replicated these findings in a series of consecutive referrals to a Headache Clinic in the United States. Study 3 used a specially designed laboratory test to examine the threshold for visual stress in those patients who had participated in Study 2. Visual stress thresholds were significantly lower in patients than in controls. A discriminant function analysis of data from both Studies 2 and 3 showed that diagnostic category (migraine; control) could be predicted from photophobic symptoms and visual stress thresholds at a level significantly better than chance.

\section{Conclusions}

We suggest that inter-ictal photophobia is common in migraine, and similar across different patient populations. One compelling pathophysiological hypothesis is that it is likely to be associated with cortical hypersensitivity to stimulation. The predictive validity of inter-ictal photophobic symptoms suggests that clinical diagnosis may be aided by questioning the patient about light sensitivity in the period between attacks. 


\section{Introduction}

Intolerance to light (photophobia) is a well-recognised symptom of the migraine attack, which is often ameliorated by the patient's behaviour of retreating to a dark room. Clearly, the need to do so can be inconvenient at best. Photophobia has been accepted by the International Headache Society's Classification Committee as a criterion in the diagnosis of migraine ${ }^{1}$, and in several surveys the phenomenon has been reported by 66 to $88 \%$ of subjects to occur during the migraine attack ${ }^{2}$. A number of authors have found increased levels of discomfort and pain to light in the interictum $3,4,5,6,7$ which appears to be wavelength-dependent in some respects ${ }^{7}$. In addition, the tendency of a variety of visual stimuli to trigger attacks has been widely demonstrated $5,8,9,10$.

The pathophysiology of ictal photophobia has received some attention in the literature. It has been speculated that photophobia results from a heightened sensitivity of the special senses ${ }^{11}$. Drummond and Woodhouse contend that ictal photophobia may be due to an enhanced interaction of trigeminal and visual input in the brainstem, either through a release of an inhibitory gating mechanism or facilitation of excitatory control ${ }^{12,}{ }^{13}$. The pathophysiological basis of interictal photophobia, however, has thus far been elusive. Hyperexcitability of the primary visual cortex is one candidate mechanism that has been proposed ${ }^{14}$. Enhanced responsiveness of cortical neuronal networks may have a contributory role in the pathophysiological sequence of events leading to a migraine attack and may be responsible for an increased sensitivity of occipital neurons to visual stimuli in the interictum. Although disputed by some ${ }^{15}$, evidence for interictal visual cortical hyperexcitability is now accumulating at a rapid pace, with several studies using the method of transcranial magnetic stimulation having found an increased susceptibility to phosphene generation following occipital singlepulse stimulation in migraineurs as compared to matched controls ${ }^{16}, 17,18$. Furthermore, a number of investigators have studied the functional integrity of the visual cortex using a variety of tests drawn from visual science, with a broad consensus emerging that the primary visual cortex is over-reactive to stimuli19,20,21; see also 14 . One notable finding from this literature is that certain patterns of closely-spaced black and white stripes, known as square-wave grating patterns, exert a substantial physiological load on the primary visual cortex ${ }^{22}$. The viewing of such patterns is accompanied by a variety of sensations of visual stress; these sensations are correlated closely to signal intensity in the normal visual cortex, as assessed by the fMRI - BOLD technique $^{23}$. It is therefore satisfactorily established that square-wave grating patterns act as stressors of normal physiological processing in the visual cortex.

Few studies have hitherto attempted to relate self-reported inter-ictal photophobic symptoms with findings from theoretically-motivated laboratory 
findings. In the current study we therefore addressed four questions: first, do patients report characteristic inter-ictal photophobic symptoms; second, are these symptoms consistent over different patient populations; third, do patients have lowered thresholds for visual stress when viewing square-wave grating patterns; fourth, is it possible to predict diagnostic category (migraine without aura; migraine with aura; control) from both subjective and objective measures of (inter-ictal) photophobia?

\section{Study 1}

\subsection{Method}

\subsubsection{Patients and control subjects}

\subsubsection{Migraine}

In order to minimise ascertainment bias, the migraine group consisted of patients recruited from two different sources. First, 42 patients were enrolled from the migraine database of the Headache Clinic at the Department of Neurology, Atrium Medical Center Heerlen, The Netherlands. This group is referred to as diagnosed voters (DV). Second, a group of undiagnosed voters (UV) was made up of respondents to an advertisement in several local papers, in which subjects with troublesome migraines were called to visit a migraine information session. 57 respondents participated in the study. The DVs were classified by two of the authors (PJK or WMM) according to IHS criteria (1). All DV's were diagnosed as having migraine with and/or without aura (IHS categories 1.1 and 1.2); an additional diagnosis of episodic tension-type headache was not considered an exclusion criterion. The diagnostic status of the UVs was assessed by direct enquiry upon registration at the venue. Only self-reported migraineurs were included in the voting sessions. The majority of UVs reported that their condition had been previously diagnosed either by a general practitioner or a neurologist (not necessarily one of the authors). Overall, 58 patients could be unambiguously classified as migraine with aura (MA) and 34 as migraine without aura (MO).

\subsubsection{Control subjects}

Control subjects were volunteers who were recruited during a University summer school. 132 subjects participated, but of these, 31 were excluded because of a self-report of migraine.

\subsubsection{Apparatus}

For the migraine group only, questions were asked via an Interactive Voting System (IVS) provided by Mediselect BV, The Netherlands. As the IVS 
could not be made available except for use with patients, data from control subjects was gathered by means of a standard paper-and-pencil questionnaire, incorporating identical questions and response scales as used in the IVS questions.

\subsubsection{Questions}

Migraine subjects were presented 48 questions on a variety of topics: only the questions on diagnosis and photophobic symptoms are the concern of this paper. The photophobic symptom questions are shown in the Table. Each question had a maximum of 9 alternatives that contained one or more 'escape' options ('don't know', 'not applicable') if appropriate, in order to avoid loss of responders to each question as much as possible. The response rate to each question was automatically recorded by the computer, of which the study participants were not aware. Because of the diagnostic uncertainty of the UVs several questions on headache features and severity were also included. In order to assess consistency of responding, self-reported headache features were assessed on two occasions, once at the start of the session and once nearing the end, with an interval of approximately one-and-a-half hours. In order to minimise the risk of recognition, the questions were phrased differently, as was the order of the alternatives. For the control subjects, photophobic symptom questions were slightly modified in wording so as to avoid references to migraine attacks.

\subsubsection{Procedure}

Migraine patients participated in the study during a single group session. After a brief registration session in which demographic information was obtained and the general purposes of the study explained, each subject was provided with a hand-held electronic keypad containing 10 numbered buttons. The questions and numbered choices were displayed on a central screen. In order to increase the response validity, all questions and choices were verbally explained by one of the investigators. Subjects were requested to make their choice by pressing the corresponding key within 10 seconds of the appearance of a time bar. This bar indicated the time that remained for pressing a button; entries made after disappearance of the time bar were not included in the analysis. Data were immediately analysed by the computer and displayed on the central screen in histogram format. The raw data for each keypad were stored on the computer and used for subsequent analysis. Control subjects participated singly through completion of the paper questionnaire, although, as with the IVS format, the investigator was on hand to deal with any queries or misunderstandings. At the end of all testing sessions, participants were debriefed as to the purpose of the study. 


\subsection{Results}

\subsubsection{Comparability of DV and UV groups}

In order to assess the equivalence of the two patient groups, clinical data were compared statistically. The distribution of DV and UV patients across the five diagnostic categories (migraine, migraine with chronic tension-type headache, migraine with episodic tension-type headache, chronic tensiontype headache alone, episodic tension-type headache alone) was not significantly different $\left(\chi^{2}=4.32, d f=4 ; p=0.36\right)$. Frequency of migraine attacks was assessed by asking patients to place themselves in one of six frequency categories, from $<4$ per annum to $>4$ per month. The distribution of patients across these categories was not significantly different across groups $\left(\chi^{2}=1.45\right.$, $\mathrm{df}=5 ; \mathrm{p}=0.92$ ). Furthermore, UV and DV patients were not statistically different in their distribution over 6 categories of work days lost through headache $\left(\chi^{2}=0.78, \mathrm{df}=5 ; \mathrm{p}=0.98\right)$.

\section{Figure I}

Photophobic symptoms in patients and controls, Study 1 . The vertical axis gives the means of all measures expressed as binary values, hence $0=$ no photophobia; 1 =maximum photophobia.
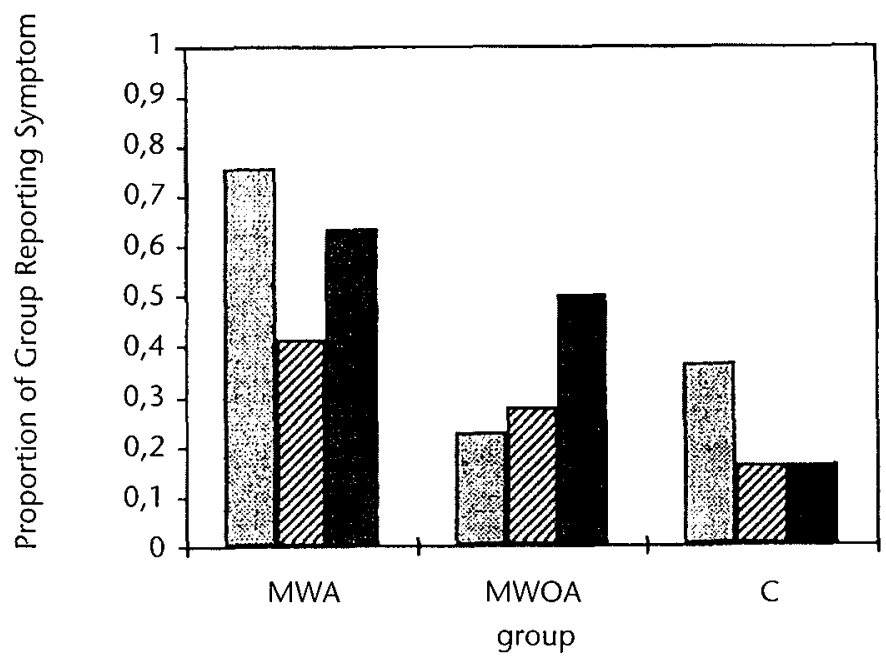

网 TRIG

ש SUNG

ERIGHT 


\subsubsection{Response consistency}

Consistency of response was analysed in the migraine group for two questions designed a priori to assess the reliability of headache classification. $96.9 \%$ of patients provided consistent responses. In addition, post hoc analyses of responses to questions concerning photophobia indicated a consistency of $84.8 \%$, although inter-individual variability in the interpretation of the wording of these questions may mean that this is an underestimate.

\subsubsection{Photophobic symptoms}

Responses to photophobia questions were re-coded as binary variables and submitted to a Multivariate Analysis of Variance (MANOVA), with diagnosis (MA, MO, C) as the between-subjects independent variable and responses to the questions concerning photophobia on a bright day (BRIGHT), the wearing of sunglasses (SUNG) and the triggering of attacks by visual stimuli (TRIG) as the three dependent variables. Cases were excluded from the analysis if data were missing, or if an unambiguous distinction between MA and $\mathrm{MO}$ could not be made. The resultant means for the three variables are shown in Figure 1. There was a significant difference overall between diagnostic groups $(F[6,304]=9.45 ; p<0.001)$. Planned comparisons indicated that $\mathrm{MA}$ and $\mathrm{MO}$ patients together were more photophobic than control subjects $(F[3,152]=10.87 ; p<0.001)$, and that MA patients were in turn more photophobic than $M O$ patients $(F[3,152]=6.16 ; p<0.001)$. Subsequent univariate analyses revealed that all three variables contributed significantly $(p<0.01)$ to the differences between groups. Although it was notable from examination of means that $C$ subjects had a greater likelihood of being affected by visual triggers than MO patients, this difference did not reach statistical significance.

\subsection{Discussion}

Study 1 found a clear difference between migraine patients and control subjects with regard to self-reported photophobic symptoms outside the attack period. MA and MO patients considered together were significantly more likely to be bothered by light, and to wear sunglasses during normal daylight. MA patients, but not MO patients, were significantly more likely than controls to have attacks triggered by visual stimuli. 


\section{Table}

\section{Questions assessing photophobia in Study 1, and responses available to participants}

\begin{tabular}{lcccccccc} 
Question & A & B & C & D & E & F & G & H \\
\hline $\begin{array}{l}\text { 1. Are you, outside } \\
\text { a migraine attack, } \\
\text { troubled by light } \\
\text { on a clear day }\end{array}$ & Yes & No & DK & & & & & \\
\hline
\end{tabular}

2. Do you often Yes No DK

wear sunglasses

in normal daylight?

\begin{tabular}{|c|c|c|c|c|c|c|c|}
\hline $\begin{array}{l}\text { 3. When you're } \\
\text { troubled by } \\
\text { normal daylight, } \\
\text { how would you } \\
\text { best describe it? }\end{array}$ & Blinding & $\begin{array}{l}\text { Eye } \\
\text { pain }\end{array}$ & $\begin{array}{c}\text { Head } \\
\text { pain }\end{array}$ & $\begin{array}{c}a, b \\
\text { and/or } c\end{array}$ & $\begin{array}{c}\text { Other than } \\
a, b \\
\text { and/or } c\end{array}$ & DK & NA \\
\hline $\begin{array}{l}\text { 4. Are some or all } \\
\text { migraines } \\
\text { triggered by: }\end{array}$ & Flicker & $\begin{array}{c}\text { Bright } \\
\text { light }\end{array}$ & $\begin{array}{l}\text { Bright } \\
\text { colour }\end{array}$ & $\begin{array}{l}\text { High } \\
\text { contrast }\end{array}$ & $\begin{array}{c}\text { More than } \\
1 \text { of a-d }\end{array}$ & $\begin{array}{l}\text { Other than } \\
\text { a-d }\end{array}$ & DK \\
\hline
\end{tabular}

$D K=$ don't know: NA = not applicable

These findings are highly consistent with previous experimental work 3, 5, 6,7, and demonstrate that photophobic symptoms elicited in controlled laboratory conditions are also found in the everyday situations of patients drawn from a heterogeneous clinic population. Statistical similarities between the DV and UV groups notwithstanding, there was a residual concern in Study 1 that the diagnoses of the UV patients could not be validated against the gold standard of neurological consultation. Moreover, the MA/MO ratio (1.71) in this study was well in excess of what would have been expected from population data, which was probably due to selection bias inherent to the sampling procedure. Study 2 therefore aimed to replicate the core findings of Study 1 in a sample consisting of consecutive referrals to a neurologist specialising in headache. Study 2 also took place in a different country (the USA), to check that findings were not simply an artefact of local habit or study demand characteristics. 


\section{Study 2}

\subsection{Method}

\subsubsection{Patients and control subjects}

\subsubsection{Migraine}

Seventy consecutive patients with IHS-defined migraine were seen during routine clinic appointments by one of the authors (SKA). Twelve were diagnosed as having migraine with aura (MA) and 57 as having migraine without aura (MO: IHS categories 1.2 and 1.1 respectively). As with Study 1, an additional diagnosis of episodic tension-type headache was not considered an exclusion criterion. In one patient, the description of symptoms preceding the headache phase did not able a precise categorisation into either the MA or MO group.

\subsubsection{Control subjects}

Twenty-eight control subjects participated in the study: all were staff at the Henry Ford Hospital. A headache history was taken prior to testing by one of the authors (SKA) and a diagnosis of migraine, tension-type headache or cluster headache was excluded.

\subsubsection{Questions and procedure}

IVS equipment was not available for this sample and questions were therefore put to all participants via a standard paper-and-pencil questionnaire. As diagnosis was always made by the neurologist, three questions focussed exclusively on photophobic symptoms:

1. Do you think that your headaches are triggered by light? (yes/no/don't know).

2. Are you bothered by bright light, outside of a migraine attack? (yes/no/don't know)

3. What proportion of the time (apart from in bright sunlight) do you wear sunglasses? $(0,20,40,60,80,100 \%)$

As with Study 1, questions were slightly modified for control subjects to avoid reference to headaches. No consistency check was made in this study. All questions were presented to patients to complete in their own time at the end of a routine clinic appointment, or for controls, during a speciallyscheduled appointment. The consulting neurologist was on hand to answer any queries. Participants were debriefed as to the purpose of the study after providing their responses. 


\subsection{Results}

Data were analysed using MANOVA, with diagnosis (MA, MO, C) as the between-subjects independent variable and responses to the questions concerning photophobia in a bright environment (BRIGHT), the wearing of sunglasses (SUNG) and the triggering of headaches by visual stimuli (TRIG) as the three dependent variables. Cases were again excluded from the analysis on the grounds of missing data, or if an unambiguous distinction between MA and $\mathrm{MO}$ could not be made. Figure 2 shows the resultant means across groups. There was a highly significant difference between groups in the responses to the three questions, considered jointly $(F[6,174]=6.01$; $\mathrm{p}<0.001)$. Planned comparisons demonstrated that $M A$ and $M O$ patients together were significantly more photophobic than $C$ subjects ( $F[3$, 87]=10.94; $\mathrm{p}<0.001)$; however, $M A$ patients were not found to be significantly more photophobic than $M O$ patients $(F[3,87]=1.22 ; p=0.31)$. Follow-up univariate analyses revealed that both BRIGHT and TRIG variables contributed significantly $(p<0.01)$ to the overall difference between diagnostic groups, but that SUNG did not.

\section{Figure 2}

Photophobic symptoms in patients and controls, Study 2. The left vertical axis gives means of binary variables as in Figure 1; the right gives percentage use of sunglasses.
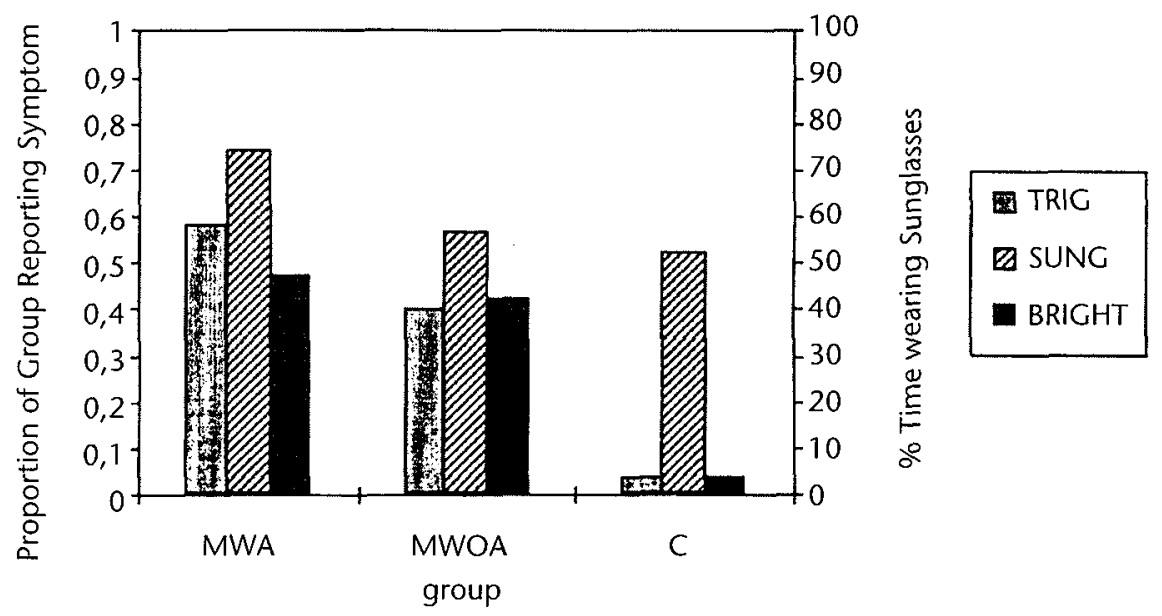


\subsection{Discussion}

The results of Study 2, in a well-diagnosed population drawn from a specialist clinic, served to confirm the core findings of Study 1. Patients, both $\mathrm{MA}$ and $\mathrm{MO}$, were significantly more likely to report aversion to light outside of attacks, and that their attacks could be triggered by visual stimuli. It was notable that MA patients were not significantly more photophobic than MO patients, in contrast to the findings from Study 1 . It is possible that this is an artefact of the relatively small number of MA patients in Study 2, as compared to Study 1. It is also noticeable that the SUNG variable did not contribute significantly to the overall difference between groups in Study 2, and it is plausible to argue that this may result from cultural differences in the everyday use of sunglasses in a predominantly suburban European sample (Study 1) and an inner-city American sample (Study 2).

Taken together, the results of Studies 1 and 2 are consistent with earlier findings, and extend them in three ways: first, by focussing on self-reported photophobic symptoms in everyday life; second, by the use of matched control populations in which headache is rigorously excluded; third, by replication across different patient populations in different countries. Neither study, however, was able to investigate the pathophysiological basis of the photophobic symptoms revealed. Study 3 therefore aimed to use a simple and specially-designed laboratory test to examine visual stress in patients and controls.

\section{Study 3}

\subsection{Methods}

\subsubsection{Patients and control subjects}

Both migraine patients and control subjects were those who had previously participated in Study 2.

\subsubsection{Apparatus and procedure}

The visual stress test consisted of 50 square cards measuring $7 \times 7 \mathrm{~cm}$. On each was printed a circular patch, $5 \mathrm{~cm}$ in diameter, of a grating with square-wave luminance profile and spatial frequency in the range 3-4 cycles per degree of visual angle when viewed at a normal reading distance. The contrasts of the 50 grating patches varied in nominal $2 \%$ increments from $2 \%$ to $100 \%$ : in other words, the stripes of the grating ranged linearly from very faint grey-scale variations to pure black-and-white. All gratings had approximately equal space-averaged luminance, and the grey background of each card was also set to the equivalent space-averaged luminance value. An 
example card is shown in Figure 3. Calibration with a photometer confirmed a very close linear relationship of nominal to measured contrast; for convenience, data are presented as nominal contrast values. Participants in the study, both patients and controls, were tested individually under identical lighting conditions (normal incandescent light in the consulting room).

\section{Figure 3}

\section{Example visual stress test card}

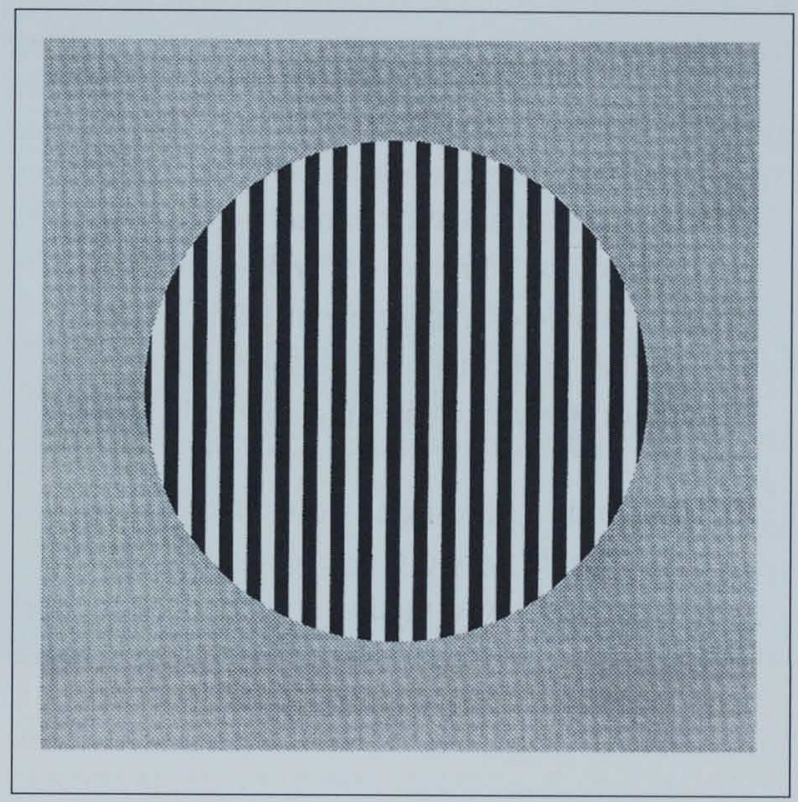

Each participant was instructed to tell the neurologist as soon as a grating pattern was shown that was visually stressful (bothersome, painful to look at, or irritating to the eyes). The neurologist first showed the $10 \%$ card for 5 seconds, then the $20 \%$ card for 5 seconds, then increased in $10 \%$ increments until the participant reported visual stress. Visual stress threshold was then fine-tuned by showing all the cards in the previous $10 \%$ contrast range, and the card selected which just noticeably gave rise to visual stress. If no visual stress was reported to any card, a value of $100 \%$ was recorded. At the end of testing, participants were debriefed as to the purpose of the study. 


\subsection{Results}

\subsubsection{Visual stress thresholds}

Mean visual stress thresholds are shown for patients and controls in Figure 4. There was a significant overall effect of diagnostic category on threshold $(F[2,94]=6.88 ; p<0.01)$. Planned comparisons revealed that $M A$ and MO patients together had significantly lower thresholds than $C$ subjects $(F[1$, 94] $=12.88 ; \mathrm{p}<0.001$ ); however, MA patients did not differ from MO patients $(F[1,94]=0.42 ; p=0.52)$.

\subsubsection{Predictive validity of measures of photophobia}

As both clinical and laboratory assessments of interictal photophobia had been made in the same groups of patients and controls (in Studies 2 and 3 , respectively), it was of interest to determine whether these measures had any predictive validity in the determination of diagnostic category. Data from both studies were therefore entered into a standard discriminant function analysis with the three photophobia measures from Study 2, and the threshold measure from Study 3 as the predictor variables, and diagnosis (migraine vs. control) as the predicted category. The analysis did not attempt to discriminate MA from $\mathrm{MO}$ in view of the relatively small number of MA patients that were tested. The discriminant function correctly identified $86 \%$ of the controls and $75 \%$ of the migraine patients. This was substantially and significantly more accurate than would be expected on the basis of chance alone $\left(\chi^{2}=28.65, \mathrm{df}=4 ; \mathrm{p}<0.001\right)$.

\subsection{Discussion}

The results of Study 3 indicate that migraine patients, both with and without aura, have lower thresholds for visual stress than control subjects. This finding is highly consistent with the notion that migraine patients experience visual cortical hyperexcitability between attacks: the stimuli used in the visual stress test provide considerable processing load for the primary visual cortex, thus giving rise to perceptual distortions and feelings of visual discomfort or stress $^{21,22}$. One possible criticism of the study method is that the visual stress test as administered may lead to exaggerated responding in patients who wish to impress upon the physician the seriousness of their migraine. Set against this potential disadvantage, however, is the ability to administer it rapidly to a large number of patients during a routine clinic visit; furthermore, differences between patients and controls remain when using similar stimuli in controlled laboratory settings ${ }^{21,} 24$. 
Figure 4

Visual stress thresholds (nominal percentage contrast) in patients and controls, Study 3

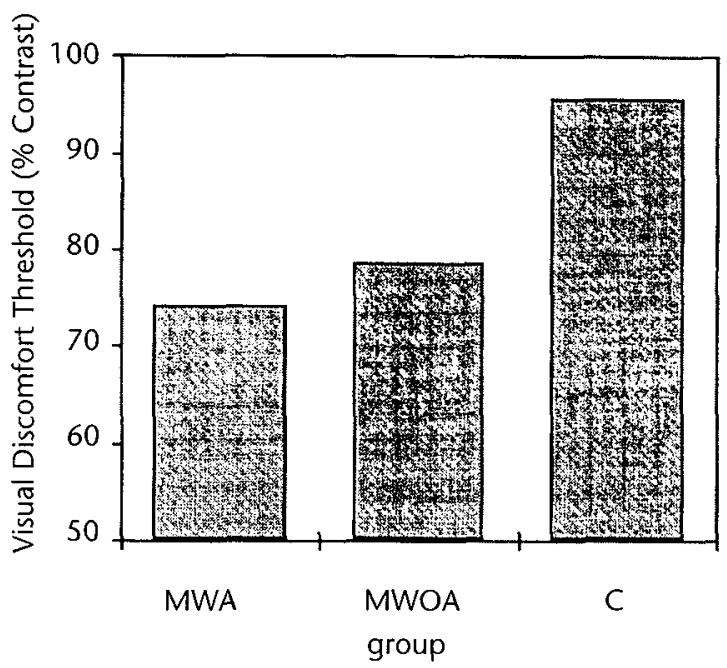

\section{General discussion}

Three studies examined reports of everyday photophobia and results of a visual stress test in two samples of migraine patients, with and without aura, recruited from both tertiary and primary care sources. In both Dutch and American samples (Studies 1 and 2, respectively), patients reported significantly more everyday symptoms of photophobia than did controls. Furthermore, thresholds for visual stress in Study 3 were significantly lower in patients than in controls.

These findings are of importance for three reasons. First, they emphasise the high prevalence of photophobia in patients in the interictum. Although it is universally accepted that photophobia is likely to occur during a migraine attack, relatively little attention has been paid to the similar, though perhaps less intense, symptoms that patients experience during their everyday lives. In our laboratory it is a not infrequent occurrence to hear a patient express relief and gratitude that their complaints of interictal photophobia are finally being heard and understood. Perhaps because the symptoms of everyday photophobia are nebulous and difficult to treat, it seems that they have been underemphasised in the migraine literature as a legitimate part of the 
symptom complex. Furthermore, there is an impression amongst ophthalmologists that the frequent wearing of sunglasses indoors is pathological25: it would be unfortunate if this impression extended to photophobic but otherwise normal migraineurs in between attacks.

Second, it is notable that photophobic symptoms are not simply observable on the basis of a statistical comparison between the means of large groups. Such comparisons, while undeniably important, can sometimes overlook the need to examine group membership on the basis of behaviours or symptoms. The reanalysis presented in Study 3, using discriminant function analysis, suggests that photophobic symptoms can be used to predict diagnosis on a case by case basis, and on average $79 \%$ of cases are classified correctly. Photophobic symptoms in everyday life may therefore provide another diagnostic pointer for migraine in cases of clinical uncertainty, although further confirmation of the findings presented in this paper is necessary.

Third, these findings add weight to the growing consensus that migraine patients may be characterised by visual cortical hyperexcitability, which is likely to predispose their cortices to develop pathophysiological events (perhaps spreading depression) and thus precipitate a full-blown attack. Indeed, this phenomenon has been proposed as an explanatory mechanism for photophobia ${ }^{26}$. An interesting question remains as to the relationship between interictal photophobia and the visual triggering of attacks: if photophobia is indeed consequent on a hyperexcited cortex, one might expect those patients who are highly photophobic to notice frequent visual triggering of attacks by particular light sources (flicker, striped stimuli, glare). Unfortunately, our data did not permit a fine-grained analysis of this kind.

Given that interictal photophobia appears common and troublesome for patients, it is important to examine the mechanisms involved. Certainly, cortical hyperexcitability appears a likely candidate mechanism: photophobia is noticeable in both meningitis and subarachnoid haemorrhage, and the cortex is presumably irritated in both these conditions. It is not possible at this stage to exclude other contributory mechanisms, however. Central sensitization of specialized sensory pathways and derangement of serotonergic systems have been named in this respect ${ }^{26}$. Although disorder of the visual pathways is not common in migraine ${ }^{14}$, it may be a contributory factor in some cases, and the parallel with optic neuritis suggests that photophobia could certainly be caused by pathway disorders (cf. 'release' phenomena, as with paraesthesia in disorders involving the sensory system). Because of the positive interaction between pain and photophobia in migraine, it has been suggested that convergence of visual and pain pathways, probably at the mesencephalic-diencephalic junction, must be involved ${ }^{5}, 12,13$. Very few investigators have considered the anterior segment of the eye as a potential structure for the generation of photophobic symptoms, but some notable findings in the experimental ophthalmological literature 
suggest that chronic stimulation of sensory trigeminal afferents may cause antidromic release of substance $P$ and/or calcitonin gene-related peptide in the uvea ${ }^{27}$. It has been shown in animal experiments that electrical stimulation of the trigeminal ganglion induces an ocular inflammatory response, characterised by hyperaemia in the anterior eye segment, increased intraocular pressure, breakdown of the blood-aqueous barrier and miosis through release of these neurotransmitters ${ }^{28}, 29$. Building on the trigemino-vascular hypothesis of migraine, which assumes neurogenic inflammation and vasodilation through antidromic neuropeptide release in the distribution of the first branch of the trigeminal nerve, it would thus be conceivable that exposure to light and subsequent pupillary constriction may be painful if the uvea is sensitised in this manner during the migraine ictum. In this respect, it is notable that levels of photophobia are increased upon noxious stimulation of the ophthalmic division of the trigeminal nerve ${ }^{12}$, thus supporting the notion of an interaction between optic and trigeminal input in the (patho)physiology of photophobia. Whether this interaction occurs at a central (i.e. mesencephalic-diencephalic ${ }^{12}$ ) or peripheral (i.e. uvea) site needs to be established. It therefore remains possible that (inter)ictal photophobia in migraine involves a number of contributory mechanisms, of which cortical hyperexcitability is just one. 


\section{References}

1. International Headache Society. Members' Handbook 1998/99. Oxford: Scandinavian University Press, 1999

2. Aurora SK, Cao Y, Bowyer SM, Welch KMA. The occipital cortex is hyperexcitable in migraine; evidence from TMS, fMRI and MEG studies. Headache 1999;39:469-476

3. Drummond PD. A quantitative assessment of photophobia in migraine and tension headache. Headache 1986;26:465-469

4. Vincent AJP, Spierings EH, Messinger HB. A controlled study of visual symptoms and eye strain factors in chronic headache. Headache 1989;29:523-527

5. Vanagaite J, Pareja JA, Storen O, White LR, Sand T, Stovner LJ. Light-induced discomfort and pain in migraine. Cephalalgia 1997;17:733-741

6. Main A, Dowson A, Gross M. Photophobia and phonophobia in migraineurs between attacks. Headache 1997;37:492-495

7. Main A, Vlachonikolis I, Dowson A. The wavelenght of light causing photophobia in migraine and tension-type headache between attacks. Headache 2000;40:194-199

8. Debney LM. Visual stimuli as migraine trigger factors. In: Rose FC, editor. Progress in migraine research II. London: Pitman, 1984:30-54

9. Bergh van den V, Amery WK, Waelkens J. Trigger factors in migraine: a study conducted by the Belgian Migraine Society. Headache 1987;27:191-6

10. Hay KM, Mortimer MJ, Barker DC, Debney LM, Good PA. 1044 women with migraine: the effect of environmental stimuli. Headache 1994;34:166-168

11. Pearce JMS. Neural aspects of migraine. In: Blau JN, editor. Migraine: clinical, therapeutic, conceptual and research aspects. London: Chapman and Hall, 1987: 251

12. Drummond PD, Woodhouse A. Painful stimulation of the forehead increases photophobia in migraine sufferers. Cephalalgia 1993;13:321-324

13. Woodhouse A, Drummond PD. Mechanisms of increased sensitivity to noise and light in migraine headaches. Cephalalgia 1993;13:417-421.

14. Chronicle EP, Mulleners WM. Visual system dysfunction in migraine: a review of clinical and psychophysical findings. Cephalalgia 1996;16:525-535.

15. Áfra J, Mascia A, Gérard P, Maertens de Noordhout A, Schoenen J. Interictal cortical excitability in migraine: a study using transcranial magnetic stimulation of motor and visual cortices. Ann Neurol 1998;44:209-215

16. Aurora SK, Ahmad BK, Welch KMA, Bhardwaj P, Ramadan NM. Transcranial magnetic stimulation confirms hyperexcitability of visual cortex in migraine. Neurology 1998;50:1111-1114.

17. Aggugia M, Zibetti M, Febbraro A, Mutani R. Transcranial magnetic stimulation in migraine with aura: further evidence of occipital cortex hyperexcitability. Cephalalgia 1999;19:465.

18. Chronicle EP, Mulleners WM, Palmer JE, Vredeveld JW, Koehler PJ. Transcranial magnetic stimulation confirms visual cortical hyperexcitablity in migraine, but response to valproate is variable. Neurology 2000;54 (suppl 3):A128

19. Wilkins A, Nimmo-Smith I, Tait A, McManus C, della Sala S, Tilley A, Arnold K, Barrie M, Scott S. A neurological basis for visual discomfort. Brain 1984;107:989-1017.

20. Coleston DM, Kennard C. Responses to temporal visual stimuli in migraine: the critical flicker fusion test. Cephalalgia 1995;15:396-398. 
21. Chronicle EP, Wilkins AJ, Coleston DM. Thresholds for detection of a target against a background grating suggest visual dysfunction in migraine with aura but not migraine without aura. Cephalalgia 1995;15:117-122.

22. Wilkins A. Visual stress. Oxford: Oxford University Press, 1995.

23. Cao Y, Welch KMA, Aurora SK, Vikingstad EM. Functional MRI-BOLD of visually triggered headache and visual change in migraine sufferers. Arch Neurol 1999;56:548-554

24. Marcus DA, Soso MJ. Migraine and stripe-induced visual discomfort. Arch Neurol 1989;46:1129-1132.

25. Howard RJWM, Valori RM. Hospital patients who wear tinted spectacles- physical sign of psychoneurosis: a controlled study. J Royal Soc Med 1989;82:606-608.

26. Vanagaite Vingen J. Photophobia and phonophobia in primary headaches. PhD Thesis. Norwegian University of Science and Technology, Trondheim, 1999

27. Bill A. Effects of some neuropeptides on the uvea. Exp Eye Res 1991;53:3-11

28. Wahlestedt C, Beding B, Ekman R, Oksala O, Stjernschantz J, Håkanson R. Calcitonin gene-related peptide in the eye: release by sensory nerve stimulation and effects associated with neurogenic inflammation. Regul Pept 1986;16:107-115

29. Bill A, Stjernschantz J, Mandahl A, Brodin E, Nilsson G. Substance P: release on trigeminal nerve stimulation, effects in the eye. Acta Physiol Scand 1979;106:371-733 


\section{Chapter 4}

Visual cortex excitability in migraine with and without aura

Mulleners WM, Chronicle EP, Palmer JE, Koehler PJ, Vredeveld JW

Headache 2001;41:565-572 


\section{Abstract}

\section{Objectives}

Previous research using transcranial magnetic stimulation (TMS) has produced equivocal findings concerning thresholds for the generation of visual phosphenes in migraine with aura (MA). These studies were methodologically varied and did not systematically address cortical excitability in migraine without aura (MO). We therefore studied magnetophosphene thresholds in both MA and MO as compared to headache free controls.

\section{Methods}

Sixteen MA and $12 \mathrm{MO}$ subjects were studied and compared to 16 sex and age matched controls. Using a standardized TMS protocol of the occipital cortex, we assessed the threshold stimulation intensity at which subjects just perceived phosphenes via a method of alternating coarse and fine tuning of stimulator output.

\section{Results}

There were no significant differences across groups in the proportion of subjects seeing phosphenes. However, the mean threshold at which phosphenes were reported was significantly lower in both migraine groups (MA $=47 \%, M O=46 \%)$ than in controls (66\%). Moreover, there was no significant correlation between individual phosphene threshold and the time interval to the closest migraine attack.

\section{Conclusion}

Our findings confirm that the occipital cortex is hyperexcitable in the migraine interictum, both in migraine with and without aura. 


\section{Introduction}

Debate about the origin of migraine seems to have settled in recent years as there is now broad agreement that it is probably a primary neuronal event that is responsible for this neurovascular disorder. This contention builds mainly on two lines of evidence:

1. Of several neurotransmitter systems implicated, the serotonergic system is believed to play a major role in the migrainous cascade of events; in particular the neurotransmission in the trigemino-vascular system depends to a great extent on serotonergic transmission.

2. The observation that cortical spreading depression (CSD) may be at the basis of the migrainous aura is interpreted by many that CSD is of major importance in the pathophysiology of migraine, at least migraine with aura. Spreading depression has never been convincingly demonstrated in migraineurs. However, blood flow ${ }^{1}$ and oxygen metabolism ${ }^{2}$ studies have provided converging evidence that, during migraine aura, parameters of cerebral perfusion and metabolism show temporal and spatial alterations consistent with what would be expected in CSD (reviewed by Lauritzen ${ }^{3}$ ).

It has been speculated that an increased cortical excitability may put the migrainous brain at risk for the spontaneous occurrence of CSD, and thus that the brain's enhanced responsiveness to external stimuli is at the etiological basis of the disorder ${ }^{4}$. This hypothesis has its origin in four independent lines of research: psychophysics, evoked potentials, transcranial magnetic stimulation and magneto-encephalography. There are numerous reports of enhanced cortical excitabilty in the psychophysical literature, applying various experimental paradigms ${ }^{5-10}$. Some findings, however, could not be replicated by others ${ }^{11}$ (compare Wray with Palmer \& Chronicle). Evoked potential studies in migraine have shown increased P100 amplitudes on VEP traces (reviewed by Schoenen ${ }^{12}$ ) and deficient cortical habituation with intensity dependent cortical auditory evoked potentials ${ }^{13}$, contingent negative variation ${ }^{14}$, and steady-state pattern-reversal VEP ${ }^{15}$. Again, some findings have been difficult to replicate by independent research groups ${ }^{12}$. Applying transcranial magnetic stimulation over the occipital cortex, most authors found higher proportions of migraineurs reporting phosphenes at lower stimulus intensities compared to controls ${ }^{16-18}$, but others were not able to obtain similar results ${ }^{19}$. Data from motor cortex stimulation are conflicting too ${ }^{19-23}$. Finally, in the few reports of magneto-encephalography in migraine there is mention of large amplitude waves in the interictum, possibly representing spontaneous depolarisations with limited spread 24,25 .

The objective of our study was therefore to investigate the interictal excitability of the visual cortex both in migraine with and without aura and controls using a rigorously standardised transcranial magnetic stimulation protocol. 


\section{Methods}

\subsection{Subjects}

Thirty nine patients with migraine with aura (MA) or migraine without aura (MO), diagnosed according to IHS criteria ${ }^{26}$, were recruited from the Headache Outpatient Clinic of the Neurology Department at Atrium Medical Center Heerlen, The Netherlands. Patients were eligible for entry if suffering from two or more attacks per month in the three months prior to entry. Diary data were collected in the month before and the month after the TMS assessment.

Seventeen age matched controls with a lifetime history of no more than 2 attacks of migraine and no migraines in the past year were recruited.

Subjects with a contra-indication for magnetic stimulation, any neurological or ophthalmological condition other than refractive error, or use of prohibited concommitant medication (antidepressants, minor and major tranquillizers, lithium, anti-convulsants, anti-parkinsonians, muscle relaxants, systemic anticholinergics, migraine prophylactics, Ca-channel blockers, anti-emetics, betahistine, cinnarizine, piracetam, hormone replacement therapy) in the month prior to study entry were excluded. The study protocol was approved by the local Ethics Committee and all subjects consented to participation in the study.

\subsection{TMS procedure}

Occipital TMS was not performed within 24 hours of a migraine attack or use of migraine abortive medication. The investigators were not blinded regarding headache status. During magnetic stimulation, subjects were seated in a dark room with their eyes shut during the assessment, any source of ambient light being placed behind them. They were instructed to pay attention to any bright forms or objects that might appear in their visual field, and when observed report to the staff immediately. A tightly fitting EEG cap, marked with an orientation grid at the back and stripped of its metal containing electrodes and wiring, was fitted onto the head, such that the grid was symmetrically projected over the occipital area of the scalp. Inion, nasion and preauricular points were used as reference points for the appropriate fitting of the cap. The orientation grid covered a rectangular area ranging from 4 to $10 \mathrm{~cm}$ superior to the inion and $4 \mathrm{~cm}$ from the midline on either side; stimulation coordinates were at $2 \mathrm{~cm}$ intervals along $X$ - and $Y$-axis.

Transcranial magnetic stimulation was performed with a MagStim 200, The MagStim Company, with a maximal output of $\sim 2.0 \mathrm{~T}$. A circular coil (core diameter $90 \mathrm{~mm}$ ) was used in all patients and controls. The center of the coil was held tangentially against the occipital scalp in the midline $6 \mathrm{~cm}$ above the inion. The interval between consecutive stimuli was kept at a minimum of 5 seconds. If the subject hesitated at reporting phosphenes, additional pulses at the same intensity level were allowed, observing the 5 seconds interstimulus interval. 
Stimulation started at $30 \%$ stimulus intensity and was increased by $10 \%$ increments until either phosphenes were reported or the $100 \%$ maximum was reached. As soon as phosphenes were reported by the subjects, the stimulus intensity was fine tuned to determine the threshold for phosphenes to be just visualised. The area surrounding the stimulation point thus obtained was 'scanned' in 2-cm steps by moving the coil in each direction along the axes of the grid in search for a coordinate with an even lower phosphene threshold. To improve results further, the coil was then slightly tilted and turned, such that the magnetic field axis would follow the linings of an imaginary cone with its base pointing towards the brain. A similar procedure was followed in case no phosphenes could be induced at the $100 \%$ level at the initial stimulation point. The stimulation intensity threshold and the grid coordinate for optimal phosphene generation were recorded.

\subsection{Analysis}

In line with previous work on phosphenes upon magnetic stimulation of the occipital cortex we choose the following study end points:

1. The proportion of subjects in which phosphenes could be induced compared between the 3 groups

2. The group mean threshold for the subjects reporting phosphenes Moreover, as we, compared to Áfra et $\mathrm{al}^{19}$, had chosen a narrower time window around the migraine attack in which no TMS was performed, we addressed the issue of a possible confounding effect of migraine frequency on phosphene thresholds in a posthoc correlation analysis of threshold to time lapsed to nearest attack (including only those subjects for whom complete diary and threshold data were available).

\section{Results}

Of 39 patients recruited, 11 were withdrawn for the following reasons: withdrawal of consent prior to the TMS assessment (4), inadvertent use of migraine prophylaxis before TMS assesssment (2), incomplete threshold data (5). Thus 28 patients, 16 with migraine with aura and 12 without aura completed the study and their findings were included in the final analyses.

of 17 control subjects recruited, one (age 18 years) was excluded because she had a positive and extensive family history of migraine; her phosphene threshold was $39 \%$. The remaining 16 control subjects had no history of migraine attacks and were evaluable for this analysis.

In the MA group there were 14 women (mean age 45, range 19-59) and 2 men (mean age 34, range 18-49), whereas the MO group consisted of 6 women (mean age 43, range 26-57) and 6 men (mean age 50, range 40-62). For the control group, data were obtained in 2 men (mean age 34, range 1849 ) and 14 women (mean age 44 , range 18-61). There were no statistical 
differences between groups in sex or age (ANOVA).

The proportion of subjects who had reported phosphenes was similar across groups (MA=12 [75\%], $M O=10[83 \%], C=15[94 \%]$ ), and no significant differences were apparent on statistical comparison (MA vs C: $p=.17 ; M O$ vs $C: p=.39 ;(M A+M O)$ vs $C: p=.19 ; M A$ vs $M O: p=.48$; Fisher's exact) (fig.2).

For individuals confirming the perception of phosphenes, the group mean threshold was significantly lower in both $M A[47 \%(S E=4.7)]$ and $M O$ [46\%(SE=3.6)] as compared to controls [66\%(SE=2.6)] (ANOVA $F(2,34)$ $=10.1 ; p<.0005$ ) (fig. 3).

Subsequent planned comparisons confirmed an overall difference between the migraine groups together (MA and $\mathrm{MO}$ ) and the control group $[(M A+M O)$ vs $C: F(1,34)=20.2 ; p<.0001]$, whereas the $M A$ and $M O$ groups were not statistically different [MA vs MO: $F(1,34)=.007 ; p=.93]$.

\section{Figure 1}

Proportion of subjects reporting phosphenes

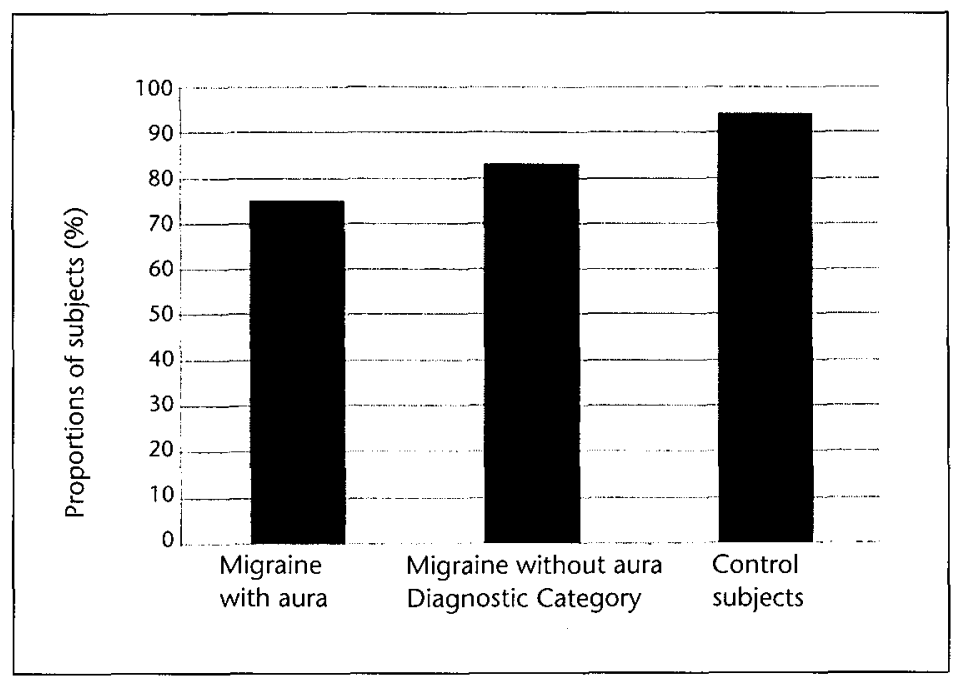

In order to examine the relationship between migraine frequency and phosphene thresholds, a posthoc correlation analysis was conducted on individual phosphene thresholds and the time interval between the assessment and the closest migraine attack (either before or after the assessment). The correlation was not significant $[\mathrm{N}=18(\mathrm{MA}=10 ; \mathrm{MO}=8)$; $\left.\left(R=.296 ; r^{2}=.09 ; F(1,16)=1.5 ; p=.23\right)\right]$. 


\section{Figure 2}

\section{Group mean phosphene threshold (\% of maximal stimulator output)}

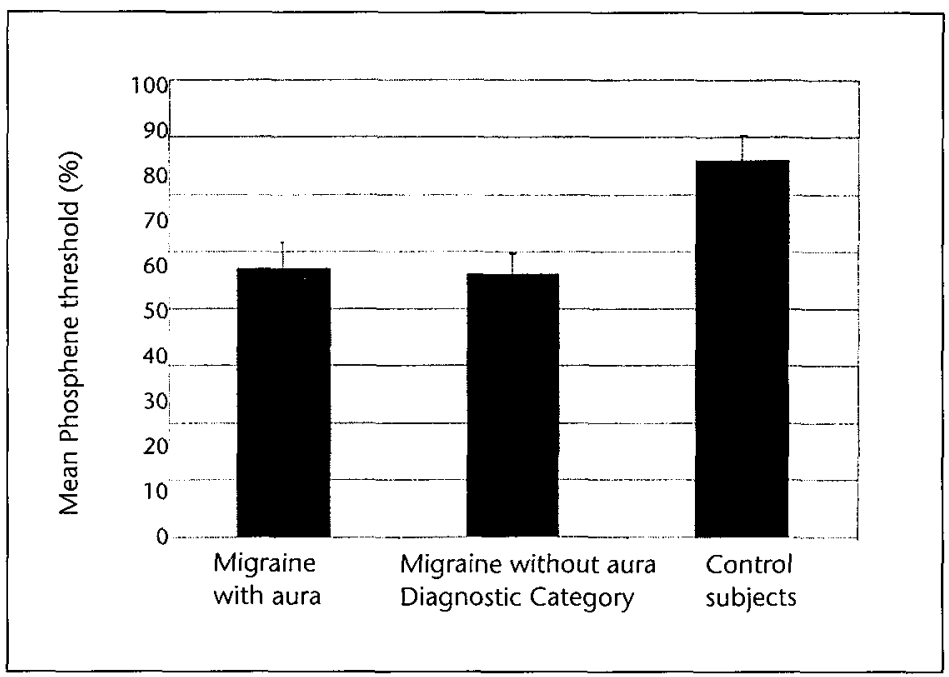

\section{Discussion}

Increased excitability of human cerebral cortex might play a role in migraine pathophysiology in the sense that it predisposes the brain to developing spontaneous neuronal depolarisation which may lead to cortical spreading depression ${ }^{4}$. Although still speculative, there is a vast amount of indirect evidence that the latter phenomenon is at the very basis of migraine attacks, at least in migraine with aura. There are several indicators of hyperexcitability of the migraine brain in the literature of the past decade ${ }^{5-10}$, and transcranial magnetic stimulation is one of the latest tools that has been applied in humans to study this topic. Early reports have focussed on the motor cortex, providing heterogeneous results ${ }^{19-23}$. Theoretically, however, the occipital cortex would be a more obvious region of interest since it has become more and more clear from earlier research that it is probably the occipital lobe in which cortical spreading depression is initiated ${ }^{3}$.

TMS is a safe and non-invasive way to induce an high-frequent electrical field in a volume conductor and thus depolarising axons of nerve cells. The degree to which this activation is successful is not only dependent on equipment-related variables (i.e. coil size, magnetic flux generated by the TMS apparatus), but also on the characteristics of the volume conductor (i.e. 
local conductivity changes, distance from coil to stimulation site, orientation of the excited nerve cells relative to the coil) ${ }^{27}$. We used a standardised TMS design in all subjects in an attempt to reduce the effects of these variables as much as possible and trying to identify an optimal stimulation site in each of the individuals.

Our findings lend support to the notion that excitability of neurons in the visual cortex may be enhanced not only in MA but also in MO. The mean threshold at which phosphenes were obtained were similar in MA and MO, and significantly lower compared to controls, and this is indicative of a reduced capacity of visual neurons to withstand disruption of electrical stability by (externally applied) stimuli, both in MA and MO. The observation that this hyperexcitable state of the migrainous brain is not limited to MA suggests that the theory of 'central neuronal hyperexcitability' may not only be of relevance to the aura in migraine, but may extend to the generation of the head pain and vegetative disturbances of an attack of MO. Despite earlier research not supporting this notion ${ }^{1}$, it is conceivable that the increased susceptibility to spontaneous depolarisations and hence initiation of SD-like events ${ }^{4}$ may be relevant to $\mathrm{MO}$ as well.

Although we did not find a difference of phosphene prevalence between groups, our threshold results are in line with earlier reports by Aurora and coworkers $^{16,17}$ and Aguggia et $\mathrm{al}^{18}$, but do not support the findings of Áfra's group $^{19}$ (see Table). The reasons for these discrepancies between observations may be manifold. For instance, it is well known that, although the electric field threshold at depth is generally lower in the visual than in the motor area, the threshold variability among subjects is greater in the primary visual cortex. It has been speculated that this variability may be primarily explained by the high interindividual variation of the shape and depth of the posterior horn and topography of nearby fibers, causing differences in local conductivity change between individuals ${ }^{27}$. However, we think it is more likely that the variation in results obtained is a reflection of technical and methodological differences. As to the relatively low proportion of control subjects reporting phosphenes in the studies by Aurora, we believe that may be, at least partly, explained by the smaller coil size used. It is well known that the magnetic flux falls off to about one-third at a distance of one coil radius ${ }^{28}$, and since the probable site of stimulation is approximately $4 \mathrm{~cm}$ away from the skull surface ${ }^{27}$ it is conceivable that a smaller coil may be less effective in generating phosphenes. The fact that Aurora et al preferentially included migraineurs who were susceptible to visual stimulation ${ }^{16}$, may explain why the mean phosphene threshold was nevertheless comparatively low in their migraine population. Compared to our results, Aguggia et al report a lower phosphene prevalence in their healthy controls and higher mean thresholds in MA and $\mathrm{MO}$, which again may reflect the difference in peak magnetic flux. Áfra et al, however, used equipment similar to ours, and although in general the results compare very well, their findings of a low phosphene 
prevalence in MA and low thresholds in controls disagree with our data. Although there is no straightforward explanation for this, we think that, as has been argued before 29,30 , this may be due to several methodological differences. First, contrary to their fixed stimulation site (unless phosphenes could not be obtained), we moved the coil in 2-cm steps in an attempt to find an optimal stimulation point relative to the inion. Thus we found a high degree of interindividual variability and, although the majority of subjects had their optimum at the reference point (midline, $8 \mathrm{~cm}$ above inion), many did not keep to this rule but rather had their phosphenes best elicited at a site somewhere in an area covering $16 \mathrm{~cm}^{2}$, distant from the point of reference. Second, Áfra's group kept a wider time window around the migraine attack in which stimulation was not performed. However, as we did not find a correlation between threshold levels and the temporal distance of TMS to the closest migraine attack, it is unlikely to explain the diffences in results. Third, we found that varying the perpendicular axis of the coil relative to the scalp (flipping of the coil) could profoundly affect the phosphene threshold.

Table 1

Studies of occipital magnetic stimulation in migraine

\begin{tabular}{lcccc} 
& $\begin{array}{c}\text { Equipment } \\
(\text { MF/EFS/OCD) }\end{array}$ & $\begin{array}{c}\text { Diagnosis } \\
\text { (no. of subjects) }\end{array}$ & $\begin{array}{c}\text { Prevalence } \\
(\%)\end{array}$ & $\begin{array}{c}\text { Threshold } \\
(\%)\end{array}$ \\
\hline Aurora 1998 & $2.0 / 530 / 95$ & MA (11) & 100 & 44 \\
Aurora 1999 & \multirow{2}{*}{$2.0 / 530 / 95$} & $\mathrm{C}(11)$ & 27 & 69 \\
& & $\mathrm{MA}$ & 100 & 43 \\
& & $\mathrm{MO}$ & 55 & 56 \\
Áfra 1998 & \multirow{2}{*}{$2.0 / 530 / 130$} & $\mathrm{MA}(18)$ & 30 & 57 \\
& & $\mathrm{MO}(22)$ & 82 & \pm 50 \\
Aguggia 1999 & \multirow{2}{*}{$1.9 /$ ? / 140 } & $\mathrm{C}(19)$ & 89 & \pm 50 \\
& & $\mathrm{MA}(10)$ & 70 & 750 \\
& & $\mathrm{MO}(19)$ & 68 & 74 \\
Mulleners 2000 & \multirow{3}{*}{$2.0 / 530 / 130$} & $\mathrm{C}(22)$ & 31 & 86 \\
& & $\mathrm{MA}(16)$ & 75 & 47 \\
& & $\mathrm{MO}(12)$ & 83 & 46 \\
& & $\mathrm{C}(16)$ & 94 & 66 \\
\hline
\end{tabular}

MF : peak magnetic flux (T)

EFS : peak electric field strength $(\mathrm{V} / \mathrm{m})$

OCD : outer coil diameter (mm) 
Finally, it is our experience that the concept of phosphenes is not always easy to grasp for subjects and false positive reports (i.e. visual phenomena not temporarily related to the magnetic pulse) are potential pitfalls. It is our contention that, in many subjects, it takes repeated enquiry and explanation of the perception of phosphenes to obtain the best results. Even after such explanation, there still remains a considerable learning effect in some subjects, as we have observed in a longitudinal study that is currently ongoing.

The pathophysiological basis for increased cortical excitability in migraine remains speculative and may be multifactorial. Abnormal presynaptic P/Q-type calcium channels ${ }^{31}$, low brain magnesium levels ${ }^{32}$ and a disorder of mitochondrial energy metabolism ${ }^{33-35}$ may be implicated. Lauritzen has put forward that the occipital cortex may be particularly prone to CSD because of its low glial/neuron ratio and thus reduced $\mathrm{K}^{+}$clearance capacity $^{3}$. Alternatively, cortical excitability may be increased through a lack of cortical inhibitory modulation ${ }^{36}$, possibly as a consequence of repeated $\mathrm{CSD}^{37}$, which has been shown in the motor cortex by Aurora ${ }^{23}$. In a separate study, we intend to explore this possibility further by assessing phosphene thresholds in patients before and after treatment with sodium valproate, a prophylactic agent for migraine which is thought to modulate inhibitory potential in cortical areas through a GABA-agonist mode of action.

In conclusion, our findings suggest increased excitability of the occipital cortex in migraine, and add to the growing body of evidence in support of central neuronal hyperexcitability. 


\section{References}

1. Cutrer FM, Sorensen AG, Weisskoff RM, Ostergaard L, Sanchez del Rio M, Lee J, Rosen BR, Moskowitz MA. Perfusion-weighted imaging defects during spontaneous migrainous aura. Ann Neurol 1998;43:25-31

2. Cao Y, Welch KMA, Aurora SK, Vikingstad EM. Functional MRI-BOLD of visually triggered headache in patients with migraine. Arch Neurol 1999;56:548-554

3. Lauritzen $M$. Pathophysiology of the migraine aura: the spreading depression theory. Brain 1994;117:199-210

4. Welch KMA, Barkley GL, Tepley N, Ramadan NM. Central neurogenic mechanisms of migraine. Neurology 1993;43(suppl 3):S21-S25

5. Marcus DA, Soso MJ. Migraine and stripe-induced visual discomfort. Arch Neurol 1989;46:1129-1132

6. Khalil NM. Investigations of visual function in migraine using visual evoked potentials and visual psychophysical tests. PhD Thesis: University of London, 1991

7. Legg $N$, Khalil N. Visual dysfunction in migraine with aura. Cephalalgia 1995;15:536

8. Coleston DM, Kennard C. Visual changes in migraine: indications of cortical dysfunction. Cephalalgia 1993;13 Suppl 13:11

9. Chronicle EP, Wilkins A], Coleston DM. Thresholds for detection of a target against a background grating suggest visual dysfunction in migraine with aura but not migraine without aura. Cephalalgia 1995;15:117-122

10. Wray SH, Mijovic-Prelec D, Kosslyn SM. Visual processing in migraineurs. Brain $1995 ; 118: 25-35$

11. Palmer JE, Chronicle EP. Cognitive processing in migraine: a failure to find facilitation in patients with aura. Cephalalgia 1998;18:125-132

12. Schoenen J. Clinical neurophysiology studies in headache: a review of data and pathophysiological hints. Funct Neurol 1992;7:191-204

13. Wang W, Timsit-Berthier M, Schoenen J. Intensity dependance of auditory evoked potentials is pronounced in migraine: an indication of cortical potentiation and low serotonergic neurotransmission? Neurology 1996;46:1404-1409

14. Kropp $P$, Gerber W-D. Contingent negative variation-findings and perspectives in migraine. Cephalalgia 1993;13:33-36

15. Áfra J, Cecchini AP, De Pasqua V, Albert A, Schoenen J. Visual evoked potentials during long periods of pattern-reversal stimulation in migraine. Brain 1998;121:233-241

16. Aurora SK, Ahmad BK, Welch KMA, Bhardhwaj P, Ramadan NM. Transcranial magnetic stimulation confirms hyperexcitability of occipital cortex in migraine. Neurology 1998;50:1111-1114

17. Aurora SK, Al-Sayed F, Welch KMA. The threshold for magnetophosphenes is lower in migraine. Neurology 1999;52 (Suppl 2):A472

18. Aguggia $M$, Zibetti $M$, Febbraro A, Mutani R. Transcranial magnetic stimulation in migraine with aura: further evidence of occipital cortex hyperexcitability. Cephalalgia 1999;19:465

19. Áfra J, Mascia A, Gérard P, Maertens de Noordhout A, Schoenen J. Interictal cortical excitability in migraine: a study using transcranial magnetic stimulation of motor and visual cortices. Ann Neurol 1998;44:209-215

20. Maertens de Noordhout A, Pepin IL, Schoenen J, Delwaide PJ. Percutaneous magnetic stimulation of the motor cortex in migraine. Electroencepalogr Clin Neurophysiol 1992;85:110-115 
21. Kamp Van der W, MaassenVanDenBrink A, Ferrari MD, Dijk van JG. Interictal cortical hyperexitability in migraine patients demonstrated with transcranial magnetic stimulation. I Neurol SCi 1996;139:106-110

22. Kamp Van der W, MaassenVanDenBrink A, Ferrari MD, Dijk van JG. Interictal cortical excitability to magnetic stimulation in familial hemiplegic migraine. Neurology 1997; 48:1462-1464

23. Aurora SK, Ahmad BK, Al-Sayed F, Welch KMA. Cortical stimulation silent period is shortened in migraine with aura. Neurology 1998;50 (Suppl 4):A351-A352

24. Barkley GL, Tepley N, Nagel-Leiby S, Moran JE, Simkins RT, Welch KMA. Magnetoencephalographic studies of migraine. Headache 1990;30:428-434

25. Burdette D, Aurora SK, Moran J, Tepley N, Welch KMA. Neuromagnetic measurements of evoked and spontaneous migraine with aura. Cephalalgia 1999;19:352

26. Headache Classification Committee of the International Headache Society. Classification and diagnostic criteria for headache disorders, cranial neualgias and facial pain. IHS Members' Handbook 1998/1999

27. Marg E, Rudiak D. Phosphenes induced by magnetic stimulation over the occipital brain: description and probable site of stimulation. Optom Vis Sci 1994;71:301-311

28. Marg E. Magnetostimulation of vision: direct noninvasive stimulation of the retina and the visual brain. Optom Vis Sci 1991;68:427-440

29. Mulleners WM, Chronicle EP, Vredeveld JW, Koehler PJ. Cortical excitability in migraine. Ann Neurol 1999;45:415-416

30. Aurora SK, Welch KMA. Phosphene generation in migraine. Ann Neurol 1999;45:416

31. Ophoff RA, Terwindt GM, Vergouwe MN, Eijk R van, Oefner PJ, Hoffman SM et al. Familial hemiplegic migraine and episodic ataxia type- 2 are caused by mutations in the Ca2+ channel gene CACNL1A4. Cell 1996;87:543-552

32. Ramadan NM, Halvorson $H$, Vande-Linde A, Levine SR, Helpern JA, Welch KMA. Low brain magnesium in migraine. Headache 1989;29:590-593

33. Welch KMA, Levine SR, D'Andrea G, Schultz LR, Helpern JA. Preliminary observations on the brain energy metabolism in migraine studied by in vivo phosphorus 31 NMR spectroscopy. Neurology 1989;39:538-541

34. Barbiroli B, Montagna P, Cortelli P, Martinelli P, Sacquegna T, Zaniol P, Lugaresi E. Complicated migraine studied by phosphorus magnetic resonance spectroscopy. Cephalalgia 1990;10:263-272

35. Barbiroli $B$, Montagna $P$, Cortelli $P$, et al. Abnormal brain and muscle energy metabolism shown by 31P magnetic resonance spectroscopy in patients affected by migraine with aura. Neurology 1992; 42:1209-1214

36. Chronicle EP, Mulleners WM. Might migraine damage the brain? Cephalalgia $1994 ; 14: 415-418$

37. Krüger $H$, Luhmann $H$ J, Heinemann $U$. Repetitive spreading depression causes selective suppression of GABA-ergic function. Neuroreport 1996;7:2733-2736 


\section{Chapter 5}

Visual cortex excitability in migraine before and after valproate prophylaxis.

A transcranial magnetic simulation study

Mulleners WM, Chronicle EP, Vredeveld JW, Koehler PJ 


\section{Abstract}

\section{Objectives}

Evidence for hyperexcitability of the visual cortex in migraine is accumulating and it has been suggested that there may be a correlation between attack frequency and level of excitability. We therefore examined the effect of standard migraine prophylaxis with sodium valproate on repeated measures of occipital excitability using transcranial magnetic stimulation. We predicted that, comparing pre- and post-treatment assessments, a reduction in clinical migraine parameters would be paralleled by a decrease in excitability measurements.

\section{Methods}

31 migraine patients enrolled in the study, for assessment prior to and 1 month after commencement of sodium valproate prophylaxis. At each assessment, we used a standardized protocol to stimulate the occipital cortex with a $90 \mathrm{~mm}$ circular (coil A) and $70 \mathrm{~mm}$ figure-of-eight (coil B) coil. We recorded the threshold stimulation intensity at which subjects just perceived phosphenes. Subjects kept detailed records of headache parameters 1 month before and also during the study period.

\section{Results}

Valproate therapy significantly improved both headache frequency and headache index, as expected. In MA subjects assessed with coil B, phosphene thresholds were significantly higher post-treatment than pre-treatment, whereas those for MO did not change. When assessed with coil A, neither MA nor $\mathrm{MO}$ subjects showed significantly raised thresholds post-treatment.

\section{Conclusions}

Although preliminary, the findings with coil B lend some support to the notion that effective migraine prophylaxis may be achieved through lowering cortical excitability by GABA-ergic intervention. Further investigation of the effect of sodium valproate or other similarly-acting substances on cortical excitability in migraine is however warranted. 


\section{Introduction}

Transcranial magnetic stimulation (TMS) offers a safe and convenient tool for the investigation of cortical functioning in vivo'. During the past years, headache researchers have begun to utilise TMS as a method of examining the question of cortical excitability in migraine. An increase in excitability, particularly in visual areas, may predispose the brain to episodes of cortical spreading depression, which is thought by many to be the pathophysiological mechanism responsible for the aura symptoms of migraine ${ }^{2}$. Given that the aura may trigger the cascade of physiological events that lead to headache and the various autonomic disturbances of migraine ${ }^{3}$, it is important to understand the basis of the brain dysfunction responsible for the aura.

Several groups, including our own ${ }^{4}$ have established that the threshold for the induction of phosphenes in patients with migraine by single-pulse TMS is reduced, as compared to age and sex-matched normal control subjects. This finding is not universal, but only one laboratory has reported a substantially different pattern of results ${ }^{5}$. A thoroughgoing analysis ${ }^{6}$ of the relationship between electric field strengths and phosphene thresholds in the 5 published reports on this topic has suggested (i) that the phosphene thresholds of migraine patients are moderately reliable across studies; (ii) that the measure of 'phosphene prevalence' established by previous investigations ${ }^{\mathrm{eg} .} 7$ is possibly an artefact of differences in power of the magnetic stimulators used in the different studies. Although the assessment of patients using the phosphene threshold method is thus not straightforward, it is a feasible method for use in longitudinal designs.

Previous work on excitability of motor cortex in migraine has established a correlation between headache frequency and levels of excitability: high migraine frequency was paralleled by a significantly higher MEP/CMAP amplitude ratio ${ }^{8}$. Furthermore, it is known that cortical excitability (as assessed by magnetic stimulation of the motor cortex) in patients with epilepsy is significantly reduced by standard anticonvulsant therapy ${ }^{9}$. From these two observations, it is reasonable to predict that effective migraine prophylaxis may not only be apparent through a reduction in attack frequency, but also by a decrease in neurophysiological or other parameters that index cortical hyperexcitability.

Sodium valproate is a widely used anticonvulsant that is gaining increasing ground in the prophylactic treatment of migraine. Several doubleblind placebo controlled studies attest to its effectiveness in reducing migraine frequency ${ }^{10-13}$. Its mode of action is unknown and potentially multifactorial ${ }^{14}$ but it is undoubtedly the case that sodium valproate crosses the blood brain barrier and acts centrally as a GABA-A agonist via a mechanism involving increased presynaptic availability.

From the foregoing, it is reasonable to hypothesise that patients established on valproate and experiencing fewer attacks of migraine as a 
result, may also exhibit increased thresholds for phosphene induction as a consequence of reduced cortical hyperexcitability, mediated by increased GABA-ergic tone. In this paper, we therefore report the results of a longitudinal study assessing the outcome of sodium valproate therapy in migraine patients both with and without aura, in terms both of clinical improvement and change in TMS parameters.

\section{Methods}

\subsection{Subjects}

Thirty-nine migraine patients, diagnosed according to IHS criteria ${ }^{15}$, were selected from the Headache Outpatient Clinic of the Neurology Department at Atrium Medical Center Heerlen, The Netherlands, and agreed to participate. Patients were eligible for entry if suffering from two or more attacks per month in the three months prior to entry. Diary data were collected through the study period, starting the month before the first TMS assessment, and finishing the month after the second.

Subjects with a contra-indication for magnetic stimulation, any neurological or ophthalmological condition other than refractive error, or use of prohibited concomitant medication (antidepressants, minor and major tranquillisers, lithium, anti-convulsants, anti-parkinsonians, muscle relaxants, systemic anticholinergics, migraine prophylactics, Ca-entry blockers, antiemetics, betahistine, cinnarizine, piracetam, hormone replacement therapy) in the month prior to study entry were excluded. The study protocol was approved by the local Ethics Committee and all subjects gave informed consent to participation in the study.

Of the 39 subjects enrolled, 31 completed the first stage of TMS assessment, prior to valproate administration. This paper reports assessments of only those patients who completed the course of sodium valproate and were successfully assessed at the second stage. Drop-outs were caused by failure to attend the second assessment stage ( 3 patients).

28 patients therefore completed this study, although not all provided complete data from headache diaries. All had attended the headache clinic for routine management, and were deemed to require prophylactic migraine therapy because of high frequency of attacks ( $>2$ attacks per month). Dosage was individualised according to clinical judgement, but was typically either $300 \mathrm{mg}$ t.d.s. (enteric coated) or $500 \mathrm{mg}$ b.d. (sustained release). The daily valproate dose was gradually build up over the first ten days of treatment, to minimise the risk of gastro-intestinal side effects. 


\subsection{Procedure}

\subsubsection{Study design}

Upon entry into the study, subjects were required to keep a diary of headaches for the remainder of the study. The diary was a standardised instrument in common use in The Netherlands: it required subjects to record any headache symptoms on a daily basis, noting severity on a 0-3 scale. Medication usage was also recorded. After a 1 month baseline migraine frequency assessment, subjects had a first assessment of TMS-induced phosphenes. Valproate treatment was not started until one day after this first TMS procedure. A second TMS assessment very similar to the first was performed 1 month after the first visit for magnetic stimulation. Subjects continued the valproate treatment and were seen again approximately 2 months after the first TMSassessment for a clinical follow up on treatment efficacy.

\subsubsection{TMS procedure}

Occipital TMS was not performed within 24 hours of a migraine attack or use of migraine abortive medication. During magnetic stimulation, subjects were seated in a dark room with their eyes shut during the assessment, any source of ambient light being placed behind them. They were instructed to pay attention to any bright forms or objects that might appear in their visual field, and when observed report to the staff immediately. A tightly fitting EEG cap, marked with an orientation grid at the back and stripped of its metal containing electrodes and wiring, was fitted onto the head, such that the grid was symmetrically projected over the occipital area of the scalp. Inion, nasion and preauricular points were used as reference points for the appropriate fitting of the cap. The orientation grid covered a rectangular area ranging from 4 to $10 \mathrm{~cm}$ superior to the inion and $4 \mathrm{~cm}$ from the midline on either side; stimulation coordinates were at $2 \mathrm{~cm}$ intervals along $\mathrm{X}$ - and $\mathrm{Y}$-axis.

Transcranial magnetic stimulation was performed with a MagStim 200, The MagStim Company, with a maximal output of $\sim 2.0 \mathrm{~T}$. Both a circular coil (core diameter $90 \mathrm{~mm}$ ) and a figure-of-eight coil (core diameters $70 \mathrm{~mm}$ ) were used with each subject. The centre of the coil was held tangentially against the occipital scalp in the midline $6 \mathrm{~cm}$ above the inion. The interval between consecutive stimuli was kept at a minimum of 5 seconds. If the subject hesitated at reporting phosphenes, additional pulses at the same intensity level were allowed, observing the 5 seconds interstimulus interval.

Stimulation started at $30 \%$ stimulus intensity and was increased by $10 \%$ increments until either phosphenes were reported or the $100 \%$ maximum was reached. As soon as phosphenes were reported by the subjects, the stimulus intensity was fine tuned to determine the threshold for phosphenes to be just visualised. The area surrounding the stimulation point thus obtained was 'scanned' in 2-cm steps by moving the coil in each direction along the axes of 
the grid in search for a coordinate with an even lower phosphene threshold. To improve results further, the coil was then slightly tilted and turned, such that the magnetic field axis would follow the interior of an imaginary cone with its base pointing towards the brain. A similar procedure was followed in case no phosphenes could be induced at the $100 \%$ level at the initial stimulation point. The stimulation intensity threshold and the grid coordinate for optimal phosphene generation were recorded.

The post-treatment procedure was identical to the first, except that only the optimal stimulation point established at baseline assessment was used. The grid was thus no longer scanned in search for the optimum point.

\section{Results}

Data on the clinical intervention with sodium valproate were available as frequency of attacks in $16 \mathrm{MA}$ patients and $9 \mathrm{MO}$ patients. Headache index data (defined below) were available in $14 \mathrm{MA}$ patients and $8 \mathrm{MO}$ patients. Overall, there was a significant effect of valproate on headache parameters. Headache frequency (defined as number of attacks per month) was significantly lower post-treatment than pre-treatment $(F[1,23]=7.12$; $p=0.014$ ). Furthermore, headache index (calculated by summing severity of headache scores for each day of a one month period) was significantly lower after intervention $(F[1,20]=24.25 ; p<0.001)$. Both effects are illustrated in Figure 1 . The effects of valproate treatment were not significantly different across MA and MO groups.

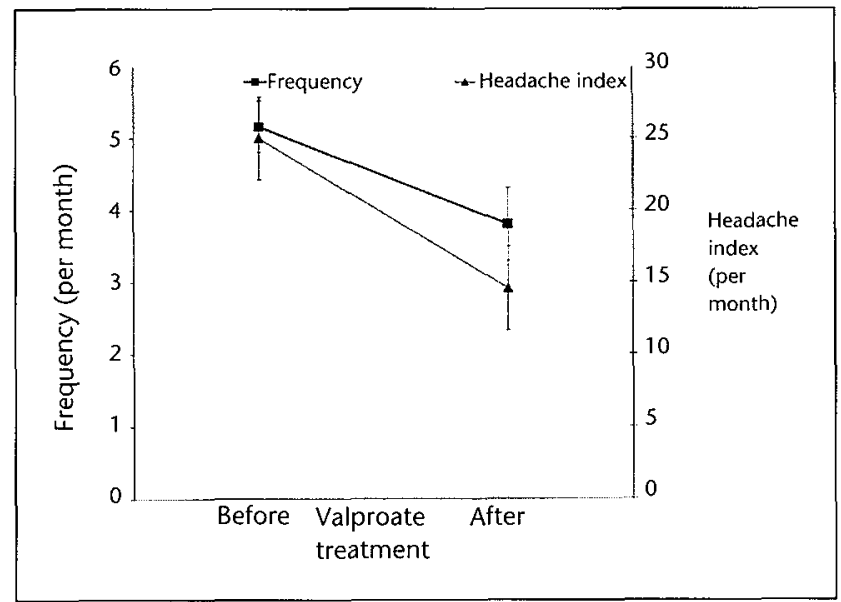

Figure 1

Effect of valproate on frequency of attacks and headache index. Bars show standard errors of the mean. 


\section{Figure 2}

Change in phosphene threshold before and after treatment with valproate for patients tested with the figure of eight coil (B) (Analysis 1).

Bars show standard errors of the mean.

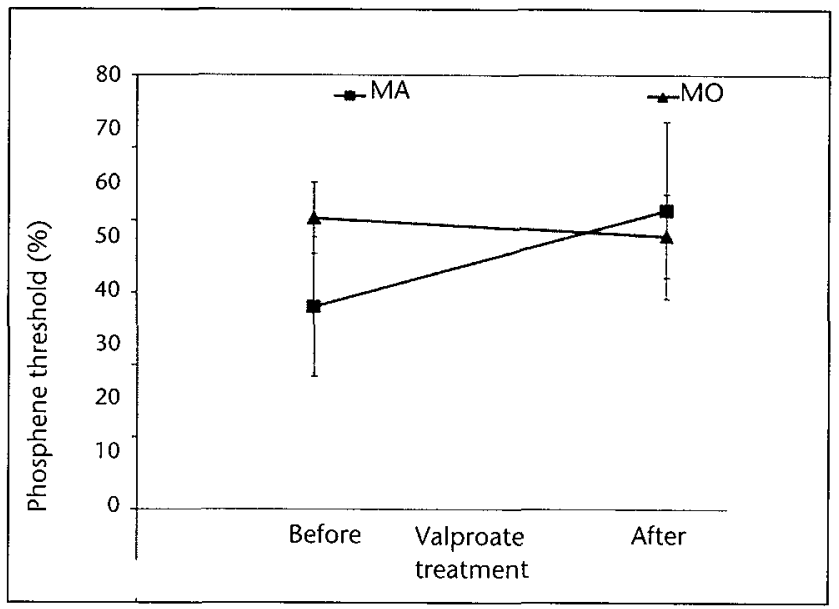

Data from the TMS assessments were analysed separately by coil type (type A: circular $90 \mathrm{~mm}$ coil; type B: figure-of-eight $70 \mathrm{~mm}$ coil). The subject numbers in each group were unbalanced, due to the fact that some subjects perceived phosphenes with one coil type but not the other. Subjects failing to report phosphenes with one of the coils, at either assessment, were not included in the analysis for that coil, as this would not allow a judgement of threshold change after treatment. For each coil, thresholds (percentage of maximum stimulator output at which phosphenes were reported) were submitted to mixed ANOVA, with diagnosis (MA vs. MO) as a betweensubjects factor and time (pre-treatment vs. post-treatment) as a withinsubjects factor. Two separate ANOVAs were calculated: first, including those subjects for whom data on both headache parameters and thresholds for the coil under consideration were complete at both assessments (subsequently referred to as Analysis 1); second, adding also those subjects for whom thresholds were available at both assessments but who had provided only incomplete headache parameter data (Analysis 2).

For coil A, Analysis 1, eight MA patients and seven MO patients were entered into the analysis. There was no significant interaction of diagnosis and time $(F[1,13]=0.59 ; p=0.46)$, and no significant main effects of either factor. For coil A, Analysis 2, data from $12 \mathrm{MA}$ patients and $8 \mathrm{MO}$ patients were available: again, there were no significant interaction or main effects $(F[1,18]=0.10 ; p=0.76$ for the interaction).

For coil B, Analysis 1, seven MA patients and eight MO patients were entered into the analysis. There was a significant interaction of diagnosis and 
time $(F[1,13]=5.00 ; p=0.04)$, as shown in Figure 2. MA patients had low thresholds pre-treatment and considerably raised thresholds post-treatment, whereas the comparatively high threshold of $\mathrm{MO}$ patients pre-treatment did not change significantly post-treatment. Neither statistical main effect reached significance. For coil B, Analysis 2, which included data from $10 \mathrm{MA}$ patients and $9 \mathrm{MO}$ patients, although the interaction of diagnosis and time took the same form, it failed to reach statistical significance $(F[1,17]=1.34$; $p=0.263$ ).

\section{Discussion}

In this study we followed migraine patients over a course of prophylactic treatment, rigorously assessing both clinical and neurophysiological parameters at various intervals. Sodium valproate significantly reduced (a) migraine frequency and (b) headache index in both MA and MO patients. The efficacy of this drug was therefore consistent with what was expected on the basis of previously published trials. TMS assessments were made using two coil types. For coil A, the $90 \mathrm{~mm}$ round coil, there was no interaction between diagnosis (MA vs. $\mathrm{MO}$ ) and assessment time (pre- and post-treatment): thresholds remained similar throughout for both groups. On the other hand, for coil B, the double-70 mm figure-of-eight coil, the same interaction was significant: MA patients had low thresholds pre-treatment and these were significantly increased at posttreatment, whereas MO patients had relatively high thresholds throughout.

These data, while undoubtedly raising a number of issues of interpretation, as we discuss below, are nonetheless suggestive of a mode of action for sodium valproate in migraine prophylaxis, at least for MA patients. These patients have significantly reduced thresholds for phosphene induction in their medicationfree state, and their cortical excitability is therefore likely to be increased relative to control subjects. With the administration of sodium valproate over the trial period of 30 days, brain GABA is increased, the inhibitory tone of cortical areas relevant to the initiation of an attack of migraine with aura is likewise increased, cortical spreading depression is presumably less probable and attack frequency correspondingly decreases. Data from coil B speak strongly in favour of this account. However, it is clear that the data from coil $A$ are not consistent with it. There are a number of possible reasons for this inconsistency.

First, as is common for all longitudinal data collection, our study was somewhat hampered by issues relating to compliance over time. Of the 31 patients starting the study, we were left with evaluable data for 7-12 MA patients (depending on analysis type) and 7-9 with $\mathrm{MO}$; thus, just over $1 / 3$ dropped out at some stage. This implies a considerable reduction in statistical power compared to that initially envisaged. There is also an issue of how data is selected for analysis. We have addressed this issue in this paper by reporting 
two separate analysis for the TMS data: first (Analysis 1), a conservative approach of only entering patients who had completed the study and returned their headache diaries; second (Analysis 2), a less stringent selection of patients for whom at least full TMS data were available.

Second, it is possible that different methodological artefacts are introduced with the different coil types. As we have previously observed ${ }^{6}$, effective stimulation of visual cortex may depend on many factors, such as coil size, coil design, coil placement and orientation, and potentially even individual differences in occipital lobe anatomy ${ }^{16}$. Given the highly focussed nature of the magnetic field produced by the figure-of-eight coil, the risk of slightly different coil alignment relative to the tangent of the skull surface may. yield dramatically different positioning of the electrical field relative to the underlying brain. It is thus possible that test-retest reliability of coil B might have influenced our findings. Against this interpretation is the fact that prepost treatment differences in thresholds themselves depended on patient group: this pattern of data would be exceptionally unlikely to arise from random fluctuation in threshold introduced by coil placement variability. Moreover, randomly occurring increases in threshold would presumably be cancelled out by equivalent decreases. A perhaps more compelling explanation of the findings with coil $B$ is that its focal field may have allowed more specific stimulation of the primary visual cortex, which we have hypothesised to be hyperexcitable in migraine. A beneficial effect of sodium valproate is most likely in this brain area, as it is where spreading depressionlike phenomena seem to be initiated in migraine ${ }^{17}$.

Third, it is difficult with the phosphene threshold technique to derive any gold standard description or report from subjects that unequivocally describes the moment at which a phosphene is first seen. While reports from neurologically sophisticated observers may be reliable, the assessment procedure for naive subjects is unusual and perhaps unnerving. It would not be surprising, therefore, if subjects unconsciously responded to the demand characteristics of the experimental situation.

In conclusion, although preliminary, the findings with coil B are sufficiently suggestive to warrant further investigation of the effect of sodium valproate or other similarly-acting substances on cortical excitability in migraine. What is clear is that a more sophisticated and objective dependent measure is required in order to gauge the consequence of occipital TMS without the difficulties mentioned above. We are currently piloting a technique based on the suppression of letter perception by single-pulse TMS, after Amassian et $\mathrm{al}^{18}$. This technique has the advantage that data are not contaminated by subjective biases or expectations, and a range of parameters may be investigated (rather than a single measure of threshold). Such improvements in TMS techniques will in future permit confirmation of the promising findings based on phosphene threshold that are reported here. 


\section{References}

1. Walsh V. Brain mapping: Faradization of the mind. Curr Biol 1998;8:R8-R11

2. Parsons AA. Recent advances in mechanisms of spreading depression. Curr Op Neurol 1998;11:227-231

3. Welch KMA, Cao Y, Aurora S, Wiggins G, Vikingstad EM. MRI of the occipital cortex, red nucleus, and substantia nigra during visual aura of migraine. Neurology 1998; 5:1465-1469

4. Chronicle EP, Mulleners WM, Palmer JE, Koehler PJ, Vredeveld JW. Exciting excitable brains: recent progress with transcranial magnetic stimulation in migraine research. Cephalalgia 2000;20:397

5. Áfra J, Mascia A, Gérard P, Maertens de Noordout A, Schoenen J. Interitcal cortical excitability in migraine: A study using transcranial magnetic stimulation of motor and visual cortices. Ann Neurol 1998;44:209-215

6. Mulleners WM, Chronicle EP, Vredeveld JW, Koehler PJ. Cortical excitability in migraine. Ann Neurol 1999;45:415-416

7. Aurora SK, Ahmad BK, Welch KMA, Bhardhwaj P, Ramadan NM. Transcranial magnetic stimulation confirms hyperexcitability of occipital cortex in migraine. Neurology 1998;50:1111-1114

8. Kamp Van der W, MaassenVanDenBrink A, Ferrari MD, Dijk van JG. Interictal cortical hyperexitability in migraine patients demonstrated with transcranial magnetic stimulation. J Neurol Sci 1996;139:106-110

9. Reutens DC, Berkovic SF, Macdonell RAL, Bladin PF. Magnetic stimulation of the brain in generalized epilepsy: reversal of cortical hyperexcitability by anticonvulsants. Ann Neurol 1993;34:351-355

10. Hering R, Kuritzky A. Sodium valproate in the prophylactic treatment of migraine: a double blind study versus placebo. Cephalalgia 1992;12:81-84

11. Jensen $R$, Brink $T$, Olesen J. Sodium valproate has a prophylactic effect in migraine without aura: a triple-blind placebo-controlled crossover study. Neurology 1994;44:647-651

12. Klapper J, on behalf of the Divalproex Sodium in Migraine Prophylaxis Study Group. Divalproex sodium in migraine prophylaxis: a dose-controlled study. Cephalalgia 1997;17:103-108

13. Mathew N, Saper J, Silberstein S, Rankin L, Markley H, Solomon S, et al. Migraine prophylaxis with divalproex. Arch Neurol 1995;52:281-286

14. Cutrer FM, Limmroth V, Moskowitz MA. Possible mechanisms of valproate in migraine prophylaxis. Cephalalgia 1997;17:93-100

15. Headache Classification Committee of the International Headache Society. Classification and diagnostic criteria for headache disorders, cranial neualgias and facial pain. IHS Members' Handbook 1998/1999

16. Marg E, Rudiak D. Phosphenes induced by magnetic stimulation over the occipital brain: description and probable site of stimulation. Optom Vis Sci 1994;71:301-311 
17. Sanchez del Rio M, Bakker D, Hadjikhani N, Wu O, Cutrer FM, Sorensen G, Tootell R, Kwong K, Rosen B, Moskowitz MA. Neurovascular cortical spreading phenomenon during spontaneous visual aura. Cephalalgia 1999;19:310

18. Amassian VE, Cracco RQ, Maccabee PJ, Cracco JB, Rudell AP, Eberle L. Transcranial magnetic stimulation in study of the visual pathway. J Clin Neurophysiol 1998; $15: 288-304$. 
Chapter 5 


\section{Chapter 6}

Suppression of perception in migraine: evidence for reduced inhibition in the visual cortex

Mulleners WM, Chronicle EP, Palmer JE, Koehler PJ, Vredeveld JW

Neurology 2001;56:178-183 


\section{Abstract}

\section{Background}

Results from transcranial magnetic stimulation (TMS) studies of visual cortex have confirmed visual cortical hyperexcitability in migraine patients. It has been speculated that this may be due to deficient intracortical inhibitory tone. However, the TMS induction of phosphenes relies on the reporting of a subjective experience, and may thus be subject to bias.

\section{Methods}

Seven migraineurs with visual aura and seven sex and age matched controls were studied. Fifty-four different three-letter-combinations were briefly displayed and followed by a magnetic pulse at 40, 70, 100, 130, 160 and $190 \mathrm{msec}$. Subjects were required to report as many letters they thought they had recognized.

\section{Results}

In the migraine group, the mean proportion of correctly identified letters was significantly higher at $100 \mathrm{msec}$, as was the proportion of trials with two or three letters correctly reported. The time window in which perceptual suppression could be introduced was narrower in migraineurs compared to controls.

\section{Conclusion}

Our findings suggest that inhibitory systems are activated to a lesser extent by TMS pulses in patients. This observation is in agreement with the hypothesized deficiency of intracortical inhibition of the visual cortex, at least in migraineurs with aura. 


\section{Introduction}

Migraine is a paroxysmal headache disorder, the cause of which is unknown. It has been proposed that trigeminovascular as well as central serotonergic, nor-adrenergic ${ }^{1}$ and possibly even dopaminergic ${ }^{2}$ modulatory systems may be involved in the pathogenesis of the head pain. Moreover, researchers are turning to the idea that the cerebral cortex may play a pivotal role early on in the sequence of events leading to a migraine attack, even in migraine without aura ${ }^{3}$. Several studies have shown that the cerebral cortex in migraine patients displays an enhanced responsiveness to various external stimuli4-11. This cortical neuronal hyperexcitability has been postulated as an important contributing factor in the pathogenesis of migraine ${ }^{12}$.

One possible mechanism for this supposed cortical hyperexcitability may be a lack of inhibitory control in the primary visual cortex (V1). Previous research into functional changes has demonstrated differences between migraine patients and control subjects on certain visual tasks, which are believed to depend on GABA-mediated inhibition in visual cortex ${ }^{13}$. For instance, it has been reported that migraine with aura patients admit more illusions and greater visual discomfort than headache free controls, when viewing high contrast square wave gratings (striped patterns) ${ }^{14}$. Very recent work in our laboratory using the method of metacontrast masking ${ }^{15}$ has shown that perceptual suppression of a simple target (presented on a computer screen) by a subsequently presented and spatially non-overlapping mask is less effective in migraine with aura ${ }^{16}$. As, in primates, this type of perceptual suppression is known to be dependent upon inhibitory interactions at the level of the primary visual cortex ${ }^{17}$, our observation that metacontrast masking is lessened in migraine with aura is highly consistent with a decrease in the functioning of inhibitory neuronal systems in the primary visual cortex of these patients.

Transcranial magnetic stimulation of the visual cortex has been one of the tools used to demonstrate increased cortical excitability in migraineurs, showing that thresholds for the induction of magnetophosphenes are consistently reduced in migraineurs ${ }^{8-11}$. Although the magnetophosphene induction method is an important first step towards understanding cortical dysfunction in migraine, it is somewhat prone to artifact, as we have mentioned elsewhere ${ }^{18}$. In this paper, we sought to explore other paradigms that permit a more detailed examination of neuronal processes, utilizing objective dependent measures. It has been demonstrated that veridical perception of a visual stimulus can be suppressed by a single TMS pulse administered 60-120 milliseconds after the stimulus presentation ${ }^{19}$, in a fashion rather similar to the metacontrast masking technique mentioned above. It has been proposed that this effect is the net result of an enhancement of inhibitory mechanisms, either by direct action of the magnetic pulse on cortical neurons ${ }^{20}$ or by the induction of inhibitory post- 
synaptic potentials by the pulse $\mathrm{e}^{21,22,23}$. In an attempt to evaluate further the state of the occipital inhibitory neuronal systems in migraineurs, we therefore applied the TMS-suppression-of-perception design in a sample of migraineurs with aura and an age and sex matched control group. By direct analogy with the results from our metacontrast masking study, we predicted that suppression of visual perception by a TMS pulse would be lessened in migraineurs as compared to controls.

\section{Methods}

\subsection{Subjects}

Seven migraine with visual aura patients (MA) (six female; one male) and seven headache-free age and sex matched controls (C) participated in the study. Subjects were recruited from the Headache Outpatient Clinic of the Neurology Department at the Atrium Medical Center, Heerlen, The Netherlands and from Lancaster University, Lancaster, UK. All patients were seen by a neurologist experienced in headache diagnosis (WM) and were classified according to the criteria of the International Headache Society ${ }^{24}$. All migraine patients reported that they experienced visual aura on at least $50 \%$ of their migraine attacks. None of the control subjects had any family history of migraine. The mean age of the MA patients was 34.43 years (SD: 12.04; range: $18-55$ ) and the $C$ subjects 35.71 years (SD: 12.62; range: 23-60).

Subjects were not eligible for study participation if magnetic stimulation was considered unsafe, i.e. in case of epilepsy or attachment of electronic or metal objects to or in the body. Moreover, neurological or ophthalmologic conditions other than refractive error were not allowed, nor was the use of prohibited concomitant medication (antidepressants, minor and major tranquilizers, lithium, anti-convulsants, anti-parkinsonians, muscle relaxants, systemic anticholinergics, migraine prophylactics, Ca-entry blockers, antiemetics, betahistine, cinnarizine, piracetam, hormone replacement therapy) in the month prior to the study. Acute migraine medication, not containing opioids, was permitted but not in the 24 hours prior to the assessment. Ethical approval for the study was obtained from the ethical committees of Atrium Medical Center, Heerlen, The Netherlands and from the Department of Psychology, Lancaster University, Lancaster, UK. Written informed consent was obtained from all participants prior to testing.

\subsection{Stimuli and Apparatus}

All subjects had normal (corrected) visual acuity as assessed by Snellen chart. Visual target stimuli consisted of low contrast letter trigrams presented centrally within a frame (Figure 1). The letters were presented in upper case 
Helvetica, font size 48. The presence of a frame helped to equalize any crowding effect on the letters and therefore also improve their legibility ${ }^{25}$. The letters used were chosen from a subset of letters of approximately equal legibility ${ }^{26}$. The letter trigrams, within the frame, subtended $1.73^{\circ} \times 0.79^{\circ}$ of visual angle when viewed from a distance of $175 \mathrm{~cm}$. The mean luminance of the stimuli was $24 \mathrm{~cd} / \mathrm{m}^{2}$ whilst the mean luminance of the background was 30 $\mathrm{cd} / \mathrm{m}^{2}$. There was no additional color contrast between the trigrams and the background: they differed only on a calibrated grey scale. Visual stimuli were presented on an Apple Macintosh monitor driven by a Macintosh Power Mac computer, running SuperLab (Cedrus Corp., Phoenix, Arizona, USA) software.

\section{Table I}

Mean percentages of correct responses by group and time interval. Standard errors are shown in parentheses

\begin{tabular}{lcccccc} 
& \multicolumn{5}{c}{$\begin{array}{c}\text { Time interval } \\
\text { (msec) }\end{array}$} \\
Group & 40 & 70 & 100 & 130 & 160 & 190 \\
MA & $93.6 \%$ & $69.2 \%$ & $62.4 \%$ & $80.6 \%$ & $84.0 \%$ & $92.6 \%$ \\
& $(1.9)$ & $(6.0)$ & $(6.4)$ & $(7.0)$ & $(5.9)$ & $(4.4)$ \\
C & $88.9 \%$ & $54.0 \%$ & $49.2 \%$ & $68.8 \%$ & $76.7 \%$ & $83.6 \%$ \\
& $(2.3)$ & $(9.7)$ & $(3.1)$ & $(6.7)$ & $(6.6)$ & $(5.4)$
\end{tabular}

Transcranial magnetic stimulation (TMS) was conducted using a MagStim 200 (The MagStim Company, Cardiff, UK). This has a maximal output of $\sim 2 \mathrm{~T}$ when used with a $90 \mathrm{~mm}$ circular coil. Subjects wore a tightly fitting EEG cap, marked with an orientation grid at the back and stripped of its metal containing electrodes and wiring. The grid was placed symmetrically over the occipital area of the scalp. Inion, nasion and preauricular points were used as reference points for the appropriate fitting of the cap. The orientation grid covered a rectangular area ranging from 4 to $10 \mathrm{~cm}$ superior to the inion and $4 \mathrm{~cm}$ from the midline on either side; stimulation co-ordinates were marked on the EEG cap at 2-cm intervals along $\mathrm{X}$ - and $\mathrm{Y}$-axis.

\subsection{Procedure}

All patients were tested interictally at least 24 hours after the last migraine attack. The letter trigrams were presented for $40 \mathrm{msec}$ and subjects were asked to report verbally the letters in the correct order, which were then recorded by an experimenter (subjects were asked to say 'blank' or 'don't know' if they were unaware of a letter at a specific position). A magnetic pulse 
was given following presentation of the letters at variable intervals. Testing consisted of two phases.

\section{Phase One - Threshold Determination}

Before magnetic stimulation began subjects completed a series of practice trials. The first three trigrams were presented for $250 \mathrm{msec}$ to familiarize subjects with the stimuli. Subjects then completed ten practice trials at $40 \mathrm{msec}$. If subjects were unable to report the letters accurately by the end of this session, the practice trials were rerun to ensure that subjects were familiar with the procedures and were able to accurately perceive the stimuli. Following this, one of the migraine patients was still unable to accurately report the letters. Consequently, the contrast of the letters was increased slightly (background luminance was raised to $37 \mathrm{~cd} / \mathrm{m}^{2}$ ) for this subject only so that her performance at baseline was equal to that of all other subjects.

Next a TMS pulse was triggered at a fixed interval of $100 \mathrm{msec}$ after the onset of the target trigram (stimulus onset asynchrony, SOA), observing an interval of at least five seconds between successive magnetic pulses. Previous studies $^{19,27}$ and our own pilot experiments have demonstrated that the 100 $\mathrm{ms}$ interval provides peak suppression in normals. Magnetic stimulation started at $50 \%$ stimulus intensity and was increased in 10\% steps until the subject was unable to identify at least two of the three target letters correctly in the order presented ( $<33 \%$ accuracy). Once this was achieved, the level of stimulation was fine-tuned. Then, without changing the stimulator output, the coil was moved around the grid to exclude a co-ordinate with a lower intensity at criterion. In our own studies of phosphene thresholds it has been shown that the interindividual variability of the lowest-threshold co-ordinate requires that the occipital area must be 'scanned' to determine the optimal stimulation point ${ }^{11}$. This is consistent with the high interindividual variability of the amount and distribution of striate cortex on the surface of the occipital pole ${ }^{28}$. As phosphenes and suppression of visual perception may be produced in similar parts of the visual cortex ${ }^{29}$, it was felt prudent to apply similar methodological standards.

\section{Phase Two - Time Course of Suppression}

In Phase Two, subjects were presented with 54 trials in which the letter trigrams were followed at a variable interval by the magnetic pulse. Six SOA's were tested: 40,70,100,130, 160 and $190 \mathrm{msec}$, with subjects completing nine trials at each SOA. The order of presentation of trials was randomized for each subject. The intensity of the TMS pulse and point of stimulation was set as determined in Phase One. Throughout, an interval of at least five seconds between successive magnetic pulses was observed. Subjects responded verbally by trying to name the letters in the order as they were presented. An experimenter recorded their responses. 


\section{Results}

The mean output of the stimulator (expressed as percentage of maximum output) required for successful suppression was not significantly different between the groups (MA: mean 78.43, SD 8.79; C: mean 76.43, SD $6.95 ; \mathrm{t}(12)=0.472 ; \mathrm{p}=0.65)$. For each individual, the proportion of letters correctly identified (PC) at each SOA (i.e. number correct as a proportion of the total of 27 letters presented over nine trials at each of the six intervals) was calculated. The group mean PC obtained during the time course phase were then submitted to a diagnosis (MA; C) by SOA $(40,70,100,130,160,190)$ mixed analysis of variance (ANOVA), with diagnosis as the only between group factor (Table $1 \&$ Figure 2). There was a main effect of diagnosis, in that the MA patients identified more letters correctly than the $C$ subjects $(F(1,12)=7.03, p<0.05)$. There was also a main effect of SOA: suppression of perceptual accuracy was least at SOA's 40, 160 and $190 \mathrm{msec}$, whilst suppression peaked at $100 \mathrm{msec} \operatorname{SOA}(F(5,60)=11.08, p<0.01)$. This is consistent with previous studies ${ }^{19,27}$ which have shown that suppression is maximal at approximately $100 \mathrm{msec}$ SOA. The interaction between diagnosis and SOA was not significant.

An alternative method of examining accuracy data was also used, in which suppression was defined as the number of trials out of nine at each SOA in which one or fewer letters were correctly identified. This alternative method of scoring gave rise to similar results: overall, MA patients were significantly more accurate than $C$ subjects $[F(1,12)=5.07 ; p=0.04]$.

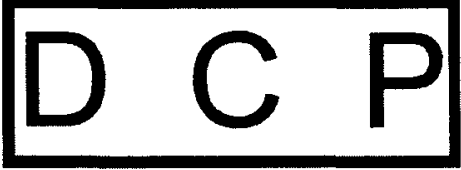

Figure 1

Example of displayed letter trigram

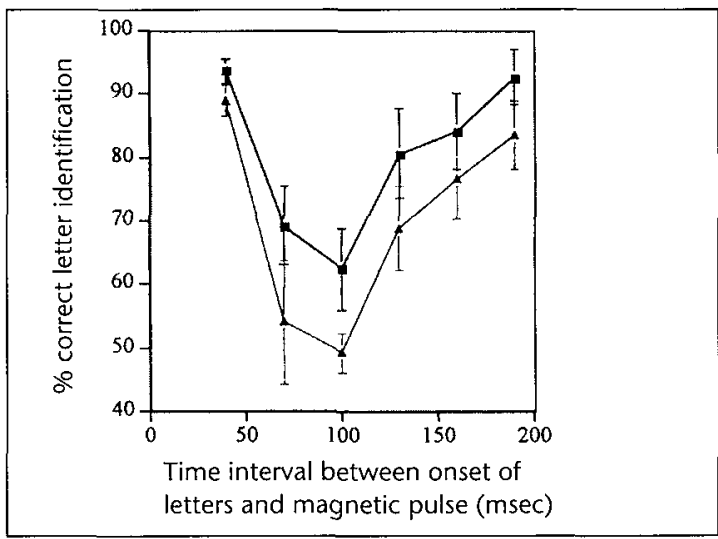

Figure 2

Mean percentage of correct letter identifications for the MA patients and $C$ subjects at each time interval. Error bars denote standard errors of the mean 
Although these analyses showed a clear superiority in performance for the MA patients overall, the method of comparing group means has been criticized for not providing a comprehensive picture of performance in situations such as these $\mathrm{e}^{30}$. In particular, the variance in individual performance is obscured so that the means of the groups as a whole may not reflect accurately the data of any one given individual in that group. Additional analyses were therefore conducted. The mean PC at extreme SOA's (40 and $190 \mathrm{msec}$ ), when it was not expected that suppression would occur, were compared between the groups. There was no difference in performance of the MA patients and the $C$ subjects at either SOA. In order to obtain a measure of the spread of suppression, the area of the curve under a criterion level of performance was compared between the groups ${ }^{30}$. There are several ways in which such a criterion might be defined. As it is complex to define chance levels of performance with letter stimuli, we initially followed the definition used in the threshold determination phase of the experiment. Here, suppression was deemed to have occurred if one or fewer letters $(<33 \%$ accuracy) were correctly reported from the given stimulus, whereas a correct report of two or more letters ( $>67 \%$ accuracy) was judged as no suppression. There is hence an indeterminacy between these two extremes, the mid-point of which is $50 \%$. It initially seemed appropriate to select this as the criterion. However, only one of seven MA patients had a curve that dropped below 50\% at any SOA, and therefore between-group statistical comparisons were impossible. Hence, we re-defined a cut-off performance level of $67 \%$ accuracy (suppression of only one letter when considering a single trial). The mean area of the curve below $67 \%$ in the MA patients was 353.29 arbitrary units (SD 330.5 ) and for the $C$ subjects 1069.08 (SD 648.15). This difference was statistically significant, $t(12)=2.6, p<0.05$. Inspection of individual plots (Figures 3 and 4) suggests that the significant difference between the groups arises because the time window during which suppression was possible in the MA patients was significantly narrower than in the control subjects. 
Figure 3

Individual suppression plots for control subjects (percentage of correct letter identifications versus time interval). Here and in Figure 4, individual plot symbols are omitted for clarity. The horizontal line denotes the criterion level of performance for the area-under-curve analyses.

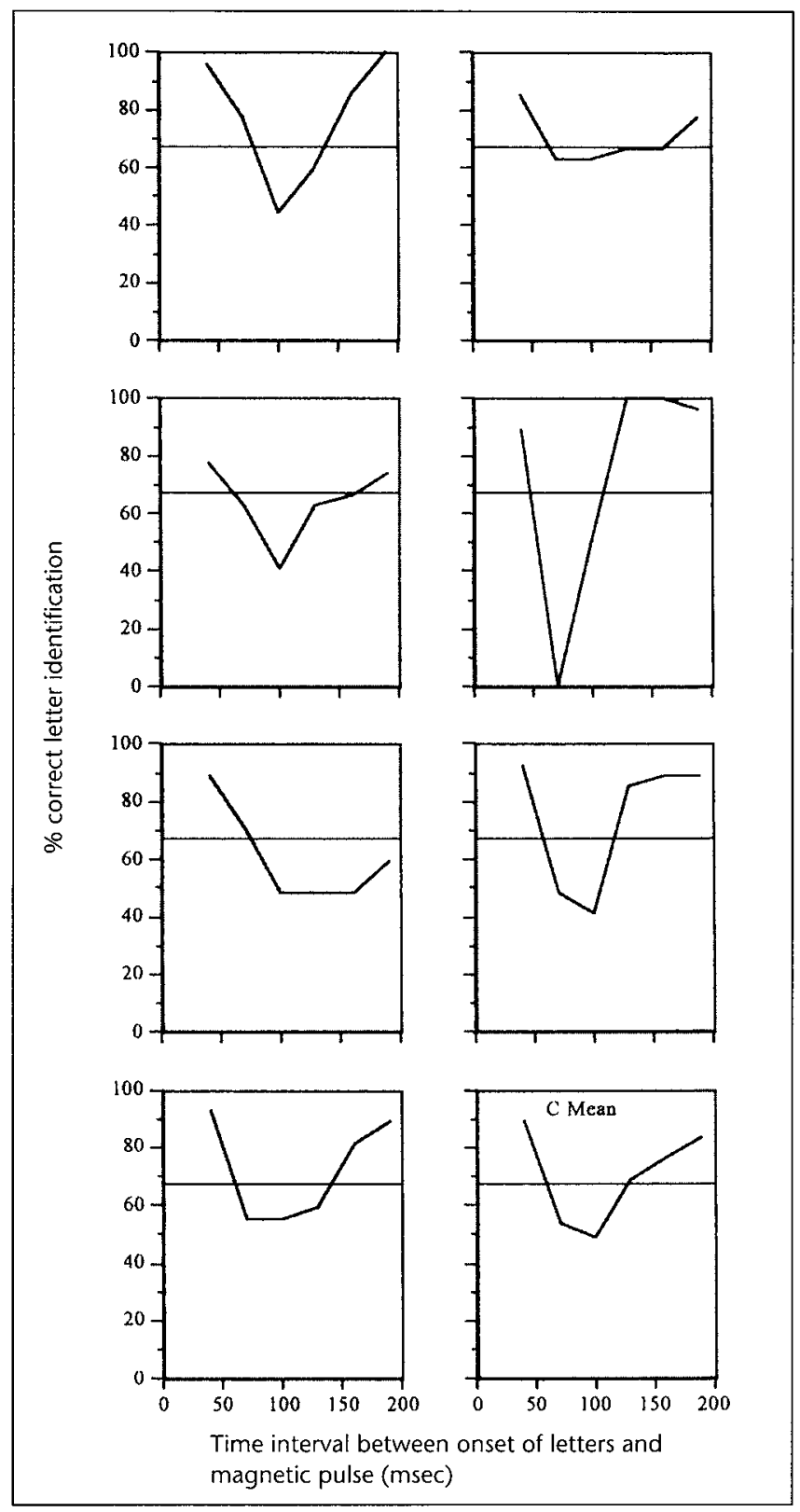


Figure 4

Individual suppression plots for migraine patients

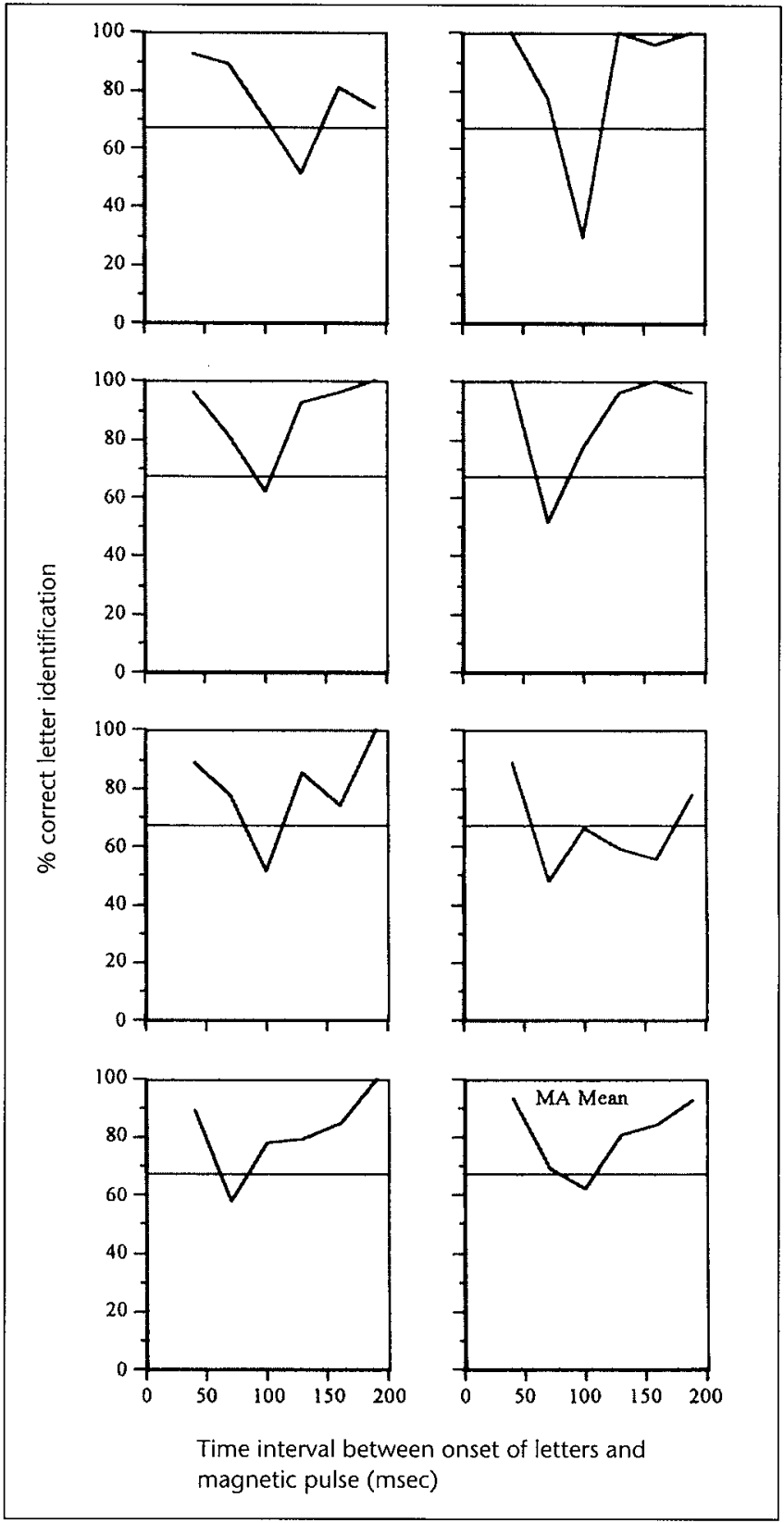




\section{Discussion}

Our findings confirm that visual stimulus processing is disturbed in migraine with aura to the extent that it is more difficult, in these patients as compared to matched controls, to suppress perception of simple targets by a TMS pulse over the primary visual cortex. Several points of interest concerning patient/control differences emerge from the study results. First, there was a significant difference in perceptual accuracy at the $100 \mathrm{msec}$ interval, at which the migraine subjects showed a clear superiority in target visibility compared with controls. This observation matches very well with the results we obtained using metacontrast masking ${ }^{16}$. Moreover, our study results are highly consistent with an earlier finding of superiority of target recognition in migraineurs ${ }^{4}$. Second, an area-under-curve analysis demonstrated that a significant feature of the performance of MA subjects was the narrower time window (smaller bandwidth) in which suppression occurred.

In 1994, we speculated about a possible role of selective damage to intracortical inhibitory neurons in the primary visual cortex of migraineurs as a major factor in hyperexcitability and the origin of spontaneous cortical spreading depression (CSD) ${ }^{31}$. In human motor cortex, it has been shown that the cortical stimulation silent period (CSSP), a measure of local cortical inhibition, is shortened in migraine, possibly pointing at a deficiency of cortical inhibition ${ }^{32}$. Our recent findings demonstrating that metacontrast masking is reduced in migraine with aura are also consistent with reduced cortical inhibition ${ }^{16}$. The present study employed a parallel experimental procedure in which the target consisted of a letter trigram and the suppressing stimulus was a transcranial magnetic stimulus over V1 (rather than the spatially nonoverlapping visual mask used in the metacontrast technique). The response curves (stimulus recognition versus target-pulse-interval) in the two designs are remarkably similar, with maximal suppression of perception occurring when the visual mask/TMS pulse is delivered approximately $100 \mathrm{msec}$ after target onset. Although other investigators ${ }^{27}$ have, more recently, suggested that TMS suppression of letter targets may occur at earlier intervals, these are much less consistent across subjects - completely absent in some - and generally weaker, and we therefore concentrated on the suppression period centered on 100 msec post-stimulus, as being the most reliable index for a comparison of patient and control groups.

Several mechanisms have been forwarded in an attempt to explain the neuronal correlates of TMS induced visual suppression. First, it can be argued that the masking effect of TMS might be caused by a collision of incoming visual impulses and the excitation of thalamo-cortical projections ${ }^{22}$. However, as phosphenes were not perceived by subjects when TMS was applied without a visual stimulus, it has been noted that visual suppression cannot be regarded as masking by such an excitatory effect ${ }^{20}$. Second, evidence suggests that the visual 
cortex may be suppressed either by the local immediate interference of the induced electric field with neuronal membrane potential and resulting inhibition of action potentials ${ }^{20}$ or through the generation of cortical inhibitory postsynaptic potentials (IPSP's) ${ }^{21,22}$, possibly due to TMS-induced synchronisation ${ }^{23}$. It is thus possible, by direct analogy with the explanation of metacontrast masking presented in the introduction to this paper, that the cortical IPSP's generated by the magnetic pulse serve to inhibit activity in cells processing information about the letter targets, thereby attenuating their visibility.

Given the foregoing, it is a plausible and reasonable claim that the enhanced visual accuracy at the $100 \mathrm{msec}$ interval demonstrated in this study represents reduced cortical inhibition in migraineurs. Further support for this argument comes from the finding of a recent pilot study conducted in our laboratories, that visual suppression is augmented in a migraine subject after 15 minutes of $1 \mathrm{~Hz}$ repetitive magnetic stimulation (rTMS) of the visual cortex. rTMS has recently been reported to increase the inhibitory potential of cortical networks ${ }^{33}$

With regard to the narrower time-window in which suppression occurred in the migraine patients, it is interesting to consider possible mechanisms. It would appear that the timing of the magnetic pulse is more critical in the migraineurs in order to interfere with the processing of the visual stimulus. One way of interpreting this finding is that it may be due to synchronization of impulses before or at the level of V1. It remains speculative to predict what this possible hypersynchronization of signal processing in the visual system of migraineurs with aura implies at the level of neurophysiological processes in neuronal circuitry.

One possible criticism of the current results is that they were obtained from a rather small number of subjects: however, it must be emphasized that the testing procedure is objective, and under computerized control. Furthermore, a large number of data points are obtained from each individual. Nonetheless, it remains possible that the relatively large within-group variances might have obscured statistical effects: clearly, a replication of the findings we report here will be desirable.

A second possible criticism is that, although suppression in the second phase of the study was markedly different between groups at the $100 \mathrm{msec}$ SOA, thresholds for suppression (at the same SOA) in the first phase were not significantly different. This could give the impression that the results obtained in the suppression experiment were simply an artifact of inadequate threshold estimation. Although a bias in estimating thresholds cannot be ruled out in an unblinded design, we do not believe that threshold estimation errors can account for the threshold-suppression paradox, considering the stringent method of fine-tuning we applied. We believe that it is more likely that this apparent contradiction was due to the relatively small number of threshold determination trials, which would certainly have resulted in a very considerable 
variance in levels of suppression. One must thus be extremely cautious in inferring that the results in phase one contradict the data of the suppression phase. In this respect, there is no doubt that it would have been more informative to obtain robust stimulus-response curves at the $100 \mathrm{msec}$ suppression interval. However, to obtain meaningful results, this would have implied many more magnetic stimuli, considerably prolonging the duration of each experiment. We therefore chose not to use such a design, but rather apply the randomized time-course experiment.

Enhanced responsiveness of the visual cortex is now a widely appreciated characteristic of the migrainous brain, manifested as an increased sensitivity to various physiological environmental stimuli ${ }^{34-36}$, deficient habituation and increased excitability of the visual cortex $5,6,13$. Magnetic stimulation of the occipital cortex has shown fairly consistently that the thresholds for the induction of phosphenes are lowered in migraine ${ }^{8-11}$, but a reliable interpretation of the data from the various studies may have been hampered by differences in methodology and the subjective nature of the parameter under consideration ${ }^{18}$. The increased objectivity of the suppression of perception technique reported in this paper has considerable potential, we believe, in advancing the state of knowledge about cortical dysfunction in migraine patients, in particular by substantiating or negating these earlier claims of enhanced excitability. Use of the same assessment techniques before and after the introduction of a pharmaceutical agent with a known neuromodulatory effect, would also add to its potential for aiding the understanding of the pattern of normal and dysfunctional neurophysiological processes in the migrainous cortex.

In conclusion, these results obtained in this case-control sample confirm the previously reported hyperexcitability of the occipital cortex in migraine with aura ${ }^{8}$, and provide preliminary though highly consistent and converging evidence that it may be due to attenuated cortical inhibition. 


\section{References}

1. Goadsby PJ. Current concepts in the pathophysiology of migraine. Neurol Clin 1997;15:27-42

2. Peroutka, S.J. Dopamine and migraine. Neurology 1997;49:650-656

3. Woods RP, lacoboni M, Mazziotta JC. Bilateral spreading cerebral hypoperfusion during spontaneous migraine headache. N Eng I Med 1994;331:1689-1692

4. Chronicle EP, Wilkins AJ, Coleston DM. Thresholds for detection of a target against a background grating suggest visual dysfunction in migraine with aura but not migraine without aura. Cephalalgia 1995;15:117-122

5. Wray SH, Mijovic-Prelec D, Kosslyn SM. Visual processing in migraineurs. Brain 1995; 118:25-35

6. Schoenen J. Cortical electrophysiology in migraine and possible pathogenetic implications. Clin Neurosci 1998;5:10-17

7. Dijk Van JG, Maassen Van Den Brink A, Kamp Van Der W, Ferrari MD. Cortical excitability to magnetic stimuli is increased in migraine with and without aura and asymmetrical in familial hemiplegic migraine. Cephalalgia 1997;17:255

8. Aurora SK, Ahmad BK, Welch KMA, Bhardhwaj P, Ramadan NM. Transcranial magnetic stimulation confirms hyperexcitability of occipital cortex in migraine. Neurology 1998;50:1111-1114

9. Aurora SK, Al-Sayed F, Welch KMA. The threshold for magnetophosphenes is lower in migraine. Neurology 1999;52 (Suppl 2):A472

10. Aguggia M, Zibetti M, Febbraro A, Mutani R. Transcranial magnetic stimulation in migraine with aura: further evidence of occipital cortex hyperexcitability. Cephalalgia 1999;19:465

11. Chronicle EP, Mulleners WM, Palmer JE, Vredeveld JW, Koehler PJ. Transcranial magnetic stimulation confirms visual cortical hyperexcitability in migraine, but response to valproate is variable. Neurology 2000;54 (Suppl 3):A128

12. Welch KMA, Barkley GL, Tepley N, Ramadan NM. Central neurogenic mechanisms of migraine. Neurology 1993;43 (Suppl 3):S21-S25

13. Chronicle EP, Mulleners WM. Visual dysfunction in migraine: a review of clinical and psychophysical findings. Cephalalgia 1996; 16:525-535

14. Wilkins A, Nimmo-Smith 1, Tait A, et al. A neurological basis for visual discomfort. Brain 1984;107:989-1017

15. Breitmeyer BG. Visual Masking: An Integrative Approach. Oxford: Clarendon Press, 1994

16. Palmer JE, Chronicle EP, Rolan P, Mulleners WM. Cortical hyperexcitability is cortical under-inhibition: evidence from a novel functional test of migraine patients. Cephalalgia 2000;20:525-532

17. Macknik SL, Livingstone MS. Neuronal correlates of visibility and invisibility in the primate visual system. Nature Neurosci 1998;1:141-149

18. Mulleners WM, Chronicle EP, Vredeveld JW, Koehler PJ. Cortical excitability in migraine. Ann Neurol 1999;45:415-416

19. Amassian VE, Cracco RQ, Maccabee PJ, Cracco JB, Erberle L, Rudell A. Suppression of visual perception by magnetic cortical stimulation of human occipital cortex. Electroencephalogr Clin Neurophysiol 1989;74:458-462

20. Kamitani $Y$, Shimojo S. Manifestation of scotomas created by transcranial magnetic 
stimulation of the visual cortex. Nature Neurosci 1999;2:767-771

21. Amassian VE, Cracco RQ, Maccabee PI, Cracco JB, Rudell AP, Erberle L. Transcranial magnetic stimulation in study of the visual pathway. J Clin Neurophysiol 1998; $15: 288-304$

22. Cracco RQ, Amassian VE, Maccabee, Cracco JB. Flow of symbolic visual information from retina to vocalisation. In: Kimura J, Shibasaki $H$, eds. Recent Advances in Clinical Neurophysiology. Amsterdam: Elseviers Science, 1996:962-969

23. Jahanshahi M, Rothwell J. Transcranial magnetic stimulation studies of cognition: an emerging field. Exp Brain Res 2000;131:1-9

24. Headache Classification Committee of the International Headache Society. Classification and diagnostic criteria for headache disorders, cranial neuralgias and facial pain. Cephalalgia 1988;8 (suppl 7)

25. McGraw PV, Winn B. Glasgow acuity cards - a new test for the measurement of letter acuity in children. Ophth Physiol Optics 1993;13:400-404

26. Grimm W, Rassow B, Wesemann W, Saur K, Hilz R. Correlation of optotypes with the landolt ring - a fresh look at the comparability of optotypes. Optometry Vision Science 1994;71: 6-13

27. Corthout E, Uttl B, Ziemann U, Cowey A, Hallett M. Two periods of processing in the (circum)striate visual cortex as revealed by transcranial magnetic stimulation. Neuropsychologia 1999;37:137-145

28. Stensaas SS, Eddington DK, Dobelle WH. The topography and variability of the primary visual cortex in man. J Neurosurg 1974;40:747-755

29. Meyer BU, Diehl R, Steinmetz H, Britton TC, Benecke R. Magnetic stimuli applied over motor and visual cortex: influence of coil position and field polarity on motor responses, phosphenes, and eye movements. Electroencephalogr Clin Neurophysiol 1991;43 (Suppl):121-134

30. Matthews JNS, Altman DG, Campbell MJ, Royston P. Analysis of serial measurements in medical research. Br Med J 1990;300:230-235

31. Chronicle EP, Mulleners WM. Might migraine damage the brain? Cephalalgia 1994; 14:415-418

32. Aurora SK, Ahmad BK, Al-Sayed F, Welch KMA. Cortical stimulation silent period is shortened in migraine with aura. Neurology 1998;50 (Suppl 4):A351-A352

33. Siebner HR, Tormos JM, Ceballos-Baumann AO, et al. Low-frequency repetitive transcranial magnetic stimulation of the motor cortex in writer's cramp. Neurology 1999;52:529-537

34. Aurora SK, Gopal S, Mulleners W, Chronicle E, Cao Y. Visual habits and discomfort are indicative of photophobia in migraine. Neurology 2000;54 (Suppl 3):A144

35. Chabriat H, Danchot J, Michel P, Joire JE, Henry P. Precipitating factors in migraineurs: a reappraisal in a national control-matched population. Cephalalgia 1997; 17:318-319

36. Hay KM, Mortimer M], Barker DC, Debney LM, Good PA. 1044 women with migraine: the effect of environmental stimuli. Headache 1994;34: 166-168 
Chapter 6 


\section{Chapter 7}

\section{Cortical hyperexcitability is cortical under-} inhibition. Evidence from a novel functional test of migraine patients

Palmer JE, Chronicle EP, Rolan P, Mulleners WM

Cephalagia 2000;20:525-532 


\section{Abstract}

Recent studies of the visual cortex in patients with migraine have generally concluded that migraine (particularly migraine with aura) is associated with a state of functional cortical hyperexcitability. The mechanisms giving rise to this hyperexcitability have hitherto been unclear. This paper reports two studies that used a novel investigative technique, dervied from basic research in vision science, to examine specific deficits of inhibitory processing in primary visual cortex. The technique is termed the metacontrast test, and it examines visual masking under highly-specified conditions. In Study 1, 12 migraine with aura patients (MA), 12 age-matched migraine without aura patients $(\mathrm{MO})$ and 12 age and sex-matched headache-free control subjects (C) were compared using the metacontrast test. MA patients were significantly less susceptible to visual masking in the metacontrast test than both $\mathrm{MO}$ and $\mathrm{C}$ groups: this result is highly consistent with a deficit in cortical inhibitory processing in MA patients. Study 2 examined MA patients taking a variety of migraine prophylactics, again using the metacontrast test. Test results normalised in those MA patients taking sodium valproate, but not in those taking other prophylactics. Sodium valproate is a GABA-A agonist that is known to cross the blood-brain barrier: GABA-ergic networks act as the primary inhibitory mechanism in visual cortex. Taken together, the results of these studies argue that cortical hyperexcitability, at least in MA patients, is likely to be a result of deficient intra-cortical inhibitory processes. 


\section{Introduction}

Recent interest in brain mechanisms of the early stages of a migraine attack has focussed on the complex relationship between the inter-ictal status of cortical neural networks, the physiological events of cortical spreading depression (CSD), and the phenomenology of the visual aura. Since the time of Lashley ${ }^{1}$, a compelling hypothesis has been that CSD is responsible for the visual hallucinations of classical visual aura ${ }^{2}$. Although there is no direct evidence for the existence of CSD in human cortex, very recent investigations using neuroimaging techniques have tended to confirm a spreading neurovascular disturbance originating in the visual cortex during aura ${ }^{3}$. It has been postulated that the headache phase of migraine may follow the aura via activation of a trigeminovascular response which has been demonstrated to occur after induced CSD in an animal model ${ }^{4}$ (although this model has been criticised on technical grounds ${ }^{5}$ ).

What is currently a major topic of interest is why the cortex, especially the visual cortex, in migraine patients may be particularly susceptible to the initiation of CSD-like episodes. A number of research groups have successfully used the method of transcranial magnetic stimulation (TMS) to demonstrate that the visual cortex of migraine patients is functionally hyperexcitable. Aurora et al $^{6}$ demonstrated clearly that the threshold level of magnetic stimulus required to evoke reports of phosphenes in subjects stimulated over the occiput was significantly lower in patients than in controls. This finding has been replicated by other investigators ${ }^{7}$, although it must be pointed out that one group found evidence for decreased excitability in patients ${ }^{8}$. Overall, however, TMS evidence of increased excitability to stimulation is highly consistent with the notion that the cortex of migraine patients may be susceptible to episodes of CSD.

TMS does not at present allow detailed mapping of particular neural systems, and it is therefore not clear how the excitability to magnetic stimulation occurs in patients. Given the morphology of the primary visual cortex (V1), it is plausible to argue that there are (at least) two routes to functional hyperexcitabilty: (i) overexcitation in excitatory systems, (ii) underinhibition in inhibitory systems. We have argued on a number of occasions that there are good reasons to implicate inhibitory systems in cortical dysfunction in migraine ${ }^{9,10}$. Furthermore, it is notable that CSD is more likely in under-inhibited cortex ${ }^{11}$ and may indeed be triggered by trivial environmental changes in appropriate models ${ }^{12}$. Circumstantial evidence also comes from the success of centrally-acting GABA-agonists as migraine prophylactics: sodium valproate crosses the blood-brain barrier ${ }^{13}$, reduces cortical excitability at least in patients with epilepsy ${ }^{14}$ and has been demonstrated to reduce significantly the frequency of migraine attacks in double-blind trials ${ }^{15}, 16$. However, to date there is no direct evidence to 
support the notion that inhibitory systems in V1 of migraine patients are impaired, although findings relating to the functional status of V1 in migraine are consistent with it ${ }^{10,17}$. We therefore investigated patients with migraine using a functional psychophysical test that has recently been shown to depend crucially upon inhibitory interactions at a cortical level. We next describe this task.

Metacontrast masking is a type of visual masking that occurs when judgements about a target are impaired because of a subsequently-presented, spatially non-overlapping mask. For example, a briefly ( -20 milliseconds) presented capital letter of normal size (the target), followed at an interval of $75 \mathrm{msec}$ by a ring shape (the mask) surrounding the letter but not overlapping it in either space or time, will be invisible to observers. However, the same letter presented in the absence of the mask is plainly visible. The masking effect is strongest when the time interval between the presentation of the target and the mask is between $50-100 \mathrm{msec}^{18}$. This results in a characteristic $\mathrm{U}$-shaped masking function, where there is little or no masking when the target and the mask are presented simultaneously, maximal masking at a 50$100 \mathrm{msec}$ time interval, and a return to little or no masking with time intervals above about 150 msec. Macknik and Livingstone ${ }^{19}$ investigated the responses of $V 1$ cells in monkey during the presentation of visual stimuli that give rise to metacontrast masking in humans. Macknik and Livingstone demonstrated, using single and multi-unit recording from V1 neurons, that the metacontrast phenomenon was specifically associated with inhibition of the transient afterdischarge to the target stimulus. In essence, it appears to be the case that the cells responsible for processing features of the mask send inhibitory messages to the cells responsible for the target, before sufficient time has elapsed for processing of the target to be complete, and for it thus to be discriminable. As inhibition between adjacent columns is a crucial feature of the stimulus processing capability of $\mathrm{V} 1$, and a primary reason for the preponderance of GABA-ergic cells in this cortical area ${ }^{20}$, it is reasonable to assume that the metacontrast function provides an index of its overall inhibitory potential.

We therefore predicted (Study 1) that migraine patients with aura should be less susceptible to metacontrast masking if the overall inhibitory function of V1 was compromised because of their condition, and therefore less inhibition of transient after-discharge would occur. Furthermore, we predicted (Study 2) that in migraine patients being treated with prophylactic agents likely to increase inhibitory potential in cortical areas, metacontrast curves would show equivalence with those of migraine free controls. 


\section{Study 1}

\subsection{Method}

\subsubsection{Patients and controls}

Twelve migraine with visual aura patients ( 9 female, 3 male), 12 age matched migraine without aura patients (10 female, 2 male) and 12 age and sex headache-free controls participated in the study (Table 1). Participants were not matched for handedness. The migraine patients were recruited from the local area and were diagnosed according to the diagnostic criteria of the International Headache Society ${ }^{21}$. All but one of the migraine with aura patients reported that their attacks were always preceded by visual aura. The other migraine with aura patient had recently started waking up with a migraine headache, although she still experienced aura before the majority of attacks ( $90 \%)$. The migraine without aura patients all reported exclusively attacks without aura. All participants had normal colour vision, normal or corrected to normal visual acuity and normal spatial contrast sensitivity. None of the participants who were included in this study was taking prophylactic medication for migraine, either at the time of testing or for at least one month before. They took only acute medication to control attacks as necessary. All patients were tested inter-ictally, at least 24 hours since the last attack had cleared and 48 hours before the start of the next one. Ethical approval for Study 1 was obtained from the Department of Psychology, Lancaster University. Written informed consent was obtained from all patients prior to testing.

\section{Table I}

Age, age of onset and migraine chronicity for the three experimental groups

\begin{tabular}{lccc} 
& Mean (yrs) & SD (yrs) & Range (yrs) \\
\hline Age & & & \\
MA & 35.58 & 8.51 & $25-51$ \\
MO & 36.25 & 7.51 & $22-50$ \\
C & 35.58 & 9.57 & $22-50$
\end{tabular}

Age of Onset

$\mathrm{MA}$

MO

16.17

$6-48$

4.26

$8-21$

Chronicity

MA

15.75

11.04

$2-37$

MO

20.00

6.44

$6-30$ 


\subsubsection{Stimuli and Apparatus}

The stimuli consisted of an inner target disk and an outer ring shaped mask. The stimuli were black (mean luminance $1.066 \mathrm{~cd} / \mathrm{m}^{2}$ ) presented against a grey background (mean luminance $107.7 \mathrm{~cd} / \mathrm{m}^{2}$, contrast $98 \%$ ) on a $75 \mathrm{~Hz}$ monitor. There were two types of target stimuli, a complete disk (whole target) or one with the right side cut off (cut target). Examples of the stimuli are shown in Figure 1 along with sizes and visual angles. A viewing distance of $50 \mathrm{~cm}$ was maintained with a chin rest. Throughout the experiment participants were asked to focus on a small fixation point, a black square $1 \mathrm{~mm} \times 1 \mathrm{~mm}$ subtending $0.11^{\circ}$ of visual angle, which appeared in the centre of the screen. The target and the mask stimuli then appeared either above or below the fixation point with the outside edge of the mask appearing $10 \mathrm{~mm}\left(1.15^{\circ}\right)$ from the centre of the fixation point.

\section{Figure I}

(a) Stimuli flow-chart for the experiment: each trial consisted of the sequence of events either in the top row or bottom row (selection was quasi-random). Panel 1 shows the 'whole' target (top) and 'cut' target (bottom). Panel 2 shows the four stimulus onset asynchronies (SOAs) employed (SOA was measured from the onset of the target to the onset of the mask). Panel 3 shows the masking stimulus, which was identical for both target types and whose inner edges did not overlap any contours of the target. Panel 4 gives the response required of the subject. At all values of SOA, target and mask were each displayed for 13 milliseconds.

(b) Sizes and visual angles of target and mask.

a.
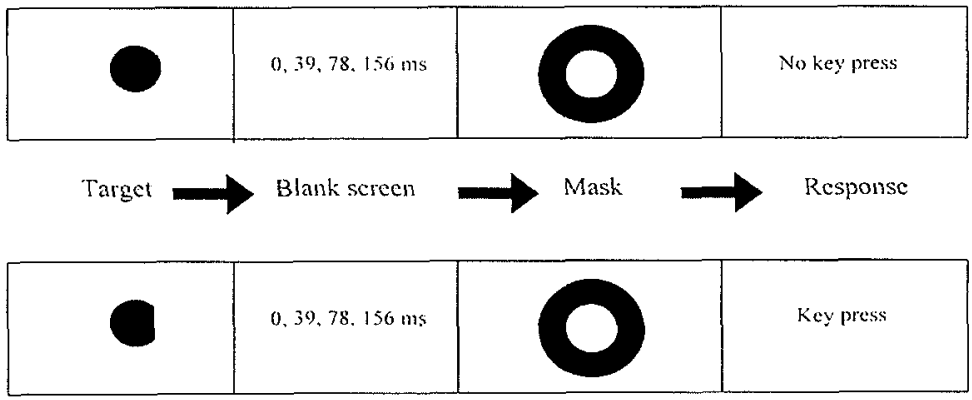

$\begin{array}{llll}\text { Panel } 1 & \text { Panel } 2 & \text { Panel } 3 & \text { Panel } 4\end{array}$

b.

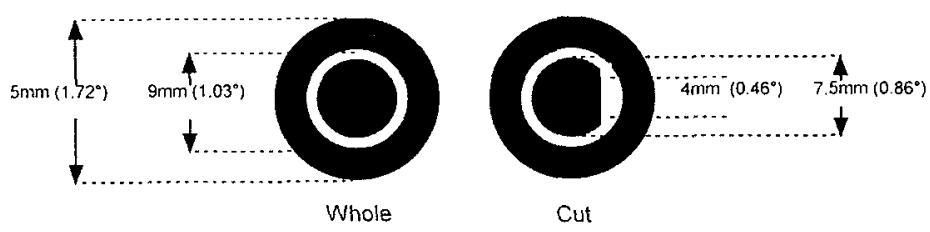




\subsubsection{Procedure}

Subjects were required to decide whether or not the target circle was cut, pressing a key on the keyboard if they thought it was cut and remaining passive if the circle was whole. The instructions emphasised that the task was like a visual illusion, in that the presence of outer mask would make it difficult and sometimes impossible for them to perceive the target circle clearly but that they were to try and complete the task as accurately as possible. Each trial started with the fixation point in the centre of the screen for $1000 \mathrm{msec}$, and then the target and the mask appeared for $13 \mathrm{msec}$ each. After the offset of the mask, the fixation point remained in the centre of the screen for a further $1500 \mathrm{msec}$. During this time the participants responded by pressing a key if they thought the circle had been cut. The target and the mask appeared either simultaneously or with a time interval between the onset of the target and the onset of the mask (stimulus onset asynchrony, SOA) of 39,78 or $156 \mathrm{msec}$. Overall, subjects completed 720 trials, 180 trials for each SOA (60 practice, 120 experimental). The total number of trials was divided equally between three blocks to help reduce any possible effects due to fatigue. The order of trials was randomised over blocks and subjects.

\subsection{Results}

Following an appropriate statistical transformation, mean proportions correct were submitted to a group (migraine with aura, migraine without aura, control) $\times \operatorname{SOA}(0,39,78,156)$ analysis of variance with group as the only between factor. This analysis included the data from the two experimental blocks only (data from practice trials were discarded). Mean proportions correct are shown in Figure 2.

There was a main effect of Group, $F(2,3)=3.48, p<0.05$; the migraine with aura patients made more correct responses than either the migraine without aura patients or the headache-free control subjects. This effect is also shown in Figure 2. 
Figure 2

(a) Overall proportion of correct target judgements in the metacontrast test, separated by diagnostic group. In this and all subsequent figures, error bars show standard errors.

(b) Proportion of correct target judgements plotted on a stimulus onset asynchrony scale and separated by diagnostic group. The dotted horizontal line shows the chance level of target judgement.

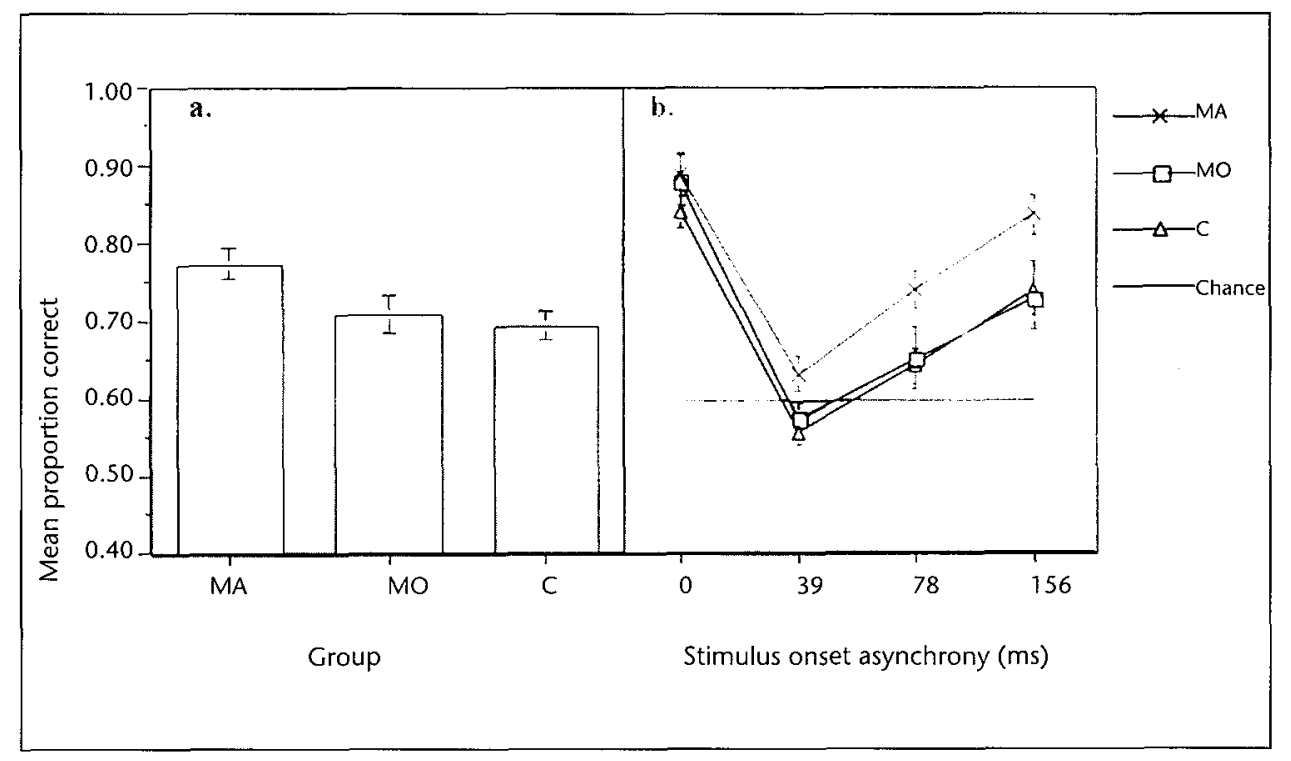

Planned comparisons were conducted to investigate this group difference further. The mean performance of the migraine with aura patients was significantly better than the mean performance of the migraine without aura patients and the controls $(F(1,33)=6.379, p<0.05)$. The accuracy of the migraine without aura patients and the accuracy of the control subjects was not significantly different $(F(1,33)=0.577, p=0.45)$. There was also a main effect of $\operatorname{SOA}(F(3,99)=$ $105.33, p<0.01$ ) resulting in a $U$-shaped masking function overall, as expected. The interaction between Group and SOA was not significant.

A secondary analysis of the data examined the relationship between task performance and frequency of migraine attacks. A standard regression of frequency of migraine on overall target judgement accuracy was performed for each patient group separately. Figure 3 shows the scatterplots and regression lines. For the migraine without aura group, there was no significant effect of attack frequency on accuracy. For the migraine with aura group, overall accuracy increased with frequency of migraine $(R 2=3.73, F(1,10)=5.937, p<0.05)$. 


\section{Figure 3}

Overall proportion of correct target judgements (pooled over SOA) as a function of frequency of migraine (self-reported number of attacks per annum). The solid regression line is fitted through the points from migraine with aura patients; the dotted regression line through the points from migraine without aura patients.

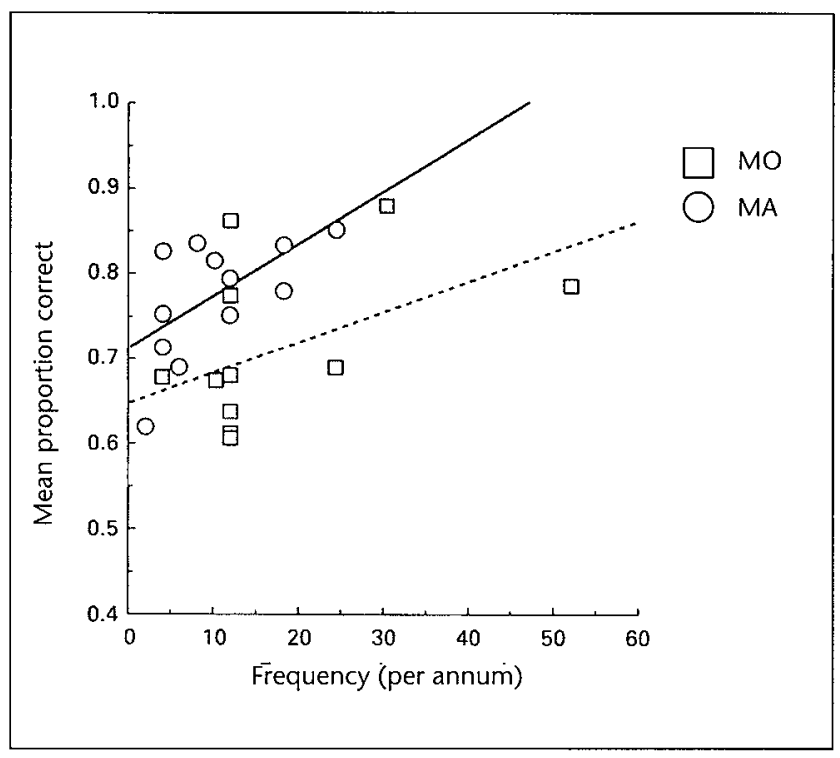

\subsection{Discussion}

The main effect of diagnostic group (Figure 2) demonstrates that migraine with aura patients are better able to make target judgements than normal control subjects. This is a powerful dissociation, as a performance enhancement is unlikely to be explainable in terms of non-specific factors such as the experiment's demand characteristics. It is supportive of impaired inhibitory function in V1 of these patients: reduced inhibition of transient channel after-discharge ${ }^{19}$ is likely to reduce the metacontrast masking phenomenon. The effect of attack frequency on target judgement accuracy in migraine with aura patients possibly reflects a differential loss of inhibitory function in patients with varying headache frequency: greater levels of inhibitory impairment render the cortex more likely to support an episode of a CSD-like event and hence headache frequency is increased. We comment further on this issue later in the paper.

As the major inhibitory neurotransmitter in visual cortex is GABA, and neurotoxins for cortical GABA-ergic inhibitory systems render visual cortex highly susceptible to spreading depression 22 , Study 2 examined responses to 
the metacontrast test in a small number of patients who were established on sodium valproate for the prophylaxis of migraine. These patients were compared with others taking prophylactics with no known action on cortical GABA-ergic systems, and the drug-free patients tested in Study 1. It was predicted (a) that the metacontrast results of patients taking valproate would be similar to normal subjects, and (b) that the results of patients taking other prophylactics would be similar to drug-free patients.

\section{Study 2}

\subsection{Subjects}

Six migraine with visual aura patients and one migraine aura without headache patient, who were taking prophylactic medication for migraine at the time of testing were recruited from the Head Pain Clinics at Manchester Royal Infirmary and the Royal Preston Hospital. All patients were diagnosed according to the diagnostic criteria of the International Headache Society ${ }^{21}$. Clinical details are shown in Table 2.

\section{Table 2}

Clinical characteristics of patients in Study 2

\begin{tabular}{|c|c|c|c|c|c|c|c|c|c|c|c|c|}
\hline Partic & $\begin{array}{c}\text { cipant } \\
\text { Sex }\end{array}$ & Age & dica & $\begin{array}{l}\text { tion } \\
\text { Chronicity } \\
\text { (years) }\end{array}$ & $\begin{array}{c}\text { Previous } \\
y \text { attack } \\
\text { freq. }\end{array}$ & $\begin{array}{l}\text { Current } \\
\text { attack } \\
\text { freq. }\end{array}$ & $\begin{array}{l}\text { Pre } \\
\text { aura } \\
\text { freq. }\end{array}$ & $\begin{array}{l}\text { Post } \\
\text { aura } \\
\text { freq. }\end{array}$ & $\begin{array}{l}H / A \\
\text { side }\end{array}$ & $\begin{array}{l}\text { Aura } \\
\text { loc. }\end{array}$ & $\begin{array}{l}\text { Last } \\
\text { attack } \\
\text { ended }\end{array}$ & $\begin{array}{l}\text { Next } \\
\text { attack } \\
\text { began }\end{array}$ \\
\hline CS & $\mathrm{F}$ & 30 & V & 78 & $>3 / \mathrm{mnth}$ & 1 in 5 mnths & $100 \%$ & $100 \%$ & $\mathrm{R}$ or $\mathrm{L}$ & $\mathrm{R}$ or $\mathrm{L}$ & 4 mnths & $6 \mathrm{wks}$ \\
\hline $\mathrm{JB}$ & $F$ & 31 & V & 20 & $3 / w k$ & $<3 / w k$ & $100 \%$ & $100 \%$ & $\mathrm{R}$ or $\mathrm{L}$ & $\mathrm{R}$ or $\mathrm{L}$ & 3 days & 2 days \\
\hline $\mathrm{IT}$ & $M$ & 65 & v & 60 & $>5 / w k$ & $<1 / w k$ & $100 \%$ & $100 \%$ & $n / a$ & $R \& L$ & 4 days & $>5$ days \\
\hline $\mathrm{ND}^{*}$ & $M$ & 28 & $\mathrm{Pi}$ & 23 & $2 / \mathrm{mnth}$ & $2 / \mathrm{mnth}$ & $100 \%$ & $100 \%$ & $\mathrm{R}$ or $\mathrm{L}$ & $\mathrm{R}$ & 2 wks & $>2$ wks \\
\hline RK & $\mathrm{M}$ & 33 & $\mathrm{Pr}$ & 22 & $>6 / w k$ & $1 / \mathrm{yr}$ & $100 \%$ & $100 \%$ & $?$ & $\mathrm{R}$ & $>3$ mnths & $>2 \mathrm{wks}$ \\
\hline$A M$ & $\mathrm{~F}$ & 50 & $M$ & 24 & $>4 /$ mnth & $>4 / \mathrm{mnth}$ & $<50 \%$ & $<50 \%$ & $\mathrm{R}$ or $\mathrm{L}$ & $?$ & $1 w k$ & 1 day \\
\hline MF & $\mathrm{F}$ & 57 & $\mathrm{Pr}$ & 4 & $>1 /$ mnth & $1 / \mathrm{mnth}$ & $100 \%$ & $100 \%$ & $\mathbf{R}$ & $\mathrm{R}$ & 3 days & $>1 \mathrm{mnth}$ \\
\hline
\end{tabular}

N.B.: '?' denotes patient unsure of answer; * denotes patient who is colour blind; Headache and aura frequency are given both currently, since the patient started taking prophylactic medication, and previously, prior to the commencement of current prophylactic treatment; Aura proportion is a $\%$ of attacks on which visual aura is present, both before (Pre) as after (Post) treatment. H/A side: side of the headache. 
The one patient with migraine aura without headache had previously had a headache phase following his aura. Three of the patients were taking sodium valproate, two were taking propanolol, one was taking pizotifen and the final patient was taking methysergide. As it was the effect of taking sodium valproate on metacontrast masking that was of particular interest, and as there were a range of different prophylactic medications being taken by the patients, two experimental groups were formed. The first group included only those patients taking sodium valproate (Valproate), whilst the second included the patients on any other prophylactic medication which are not known to affect GABA levels (Other). The results of these two groups were then compared to the 12 drug-free migraine with visual aura patients who were tested in Study 1.

All of the patients had normal or corrected to normal visual acuity. Colour vision was normal in all of the patients, except the patient who was taking pizotifen, whose scores were consistent with deuteranopia. Participants were not matched for handedness. Ethical approval for Study 2 was obtained from the Department of Psychology, Lancaster University, the Royal Preston Hospital Ethical Committee and the Central Manchester Health Care Trust Ethical Committee. Written informed consent was obtained from all patients prior to testing

\subsection{Method} Study 1 .

The study used the same metacontrast masking test as described in

\subsection{Results}

Following an appropriate statistical transformation mean proportions of correct responses were submitted to a medication (valproate, other prophylactic, none) $\times \operatorname{SOA}(0,39,78,156)$ analysis of variance with medication as the only between factor. There was a main effect of Medication, $F(2,16)=5.36, p<0.05$, the patients taking sodium valproate made more errors than either of the other two groups (Figure 4).

Planned comparisons were conducted to investigate this group difference further. The mean performance of the migraine with aura patients taking sodium valproate was significantly less accurate than the mean performance of the migraine with aura patients who were taking either no prophylactic or ones which are not known to effect GABA (propanolol, pizotifen, methysergide) $(F(1,16)=8.43, p<0.05)$. The accuracy of the two migraine with aura patient groups not taking sodium valproate was not significantly different $(F(1,16)=0.681, p=0.43)$. There was also a main effect of SOA $(F(3,48)=22.06, p<0.01)$ with the results once again showing the characteristic effect of SOA in producing a U-shaped function. 


\section{Figure 4}

(a) Overall proportion of correct target judgements, separated by medication type. 'Acute' refers to those patients taking only acute treatment for attacks, and are the same data as reported in Study 1. 'Valproate' refers to patients taking sodium valproate for prophylaxis of migraine; 'Other' refers to patients taking other prophylactics.

(b) Proportion of correct target judgements plotted on a stimulus onset asynchrony scale and separated by medication type. The control group data from Study 1 are included in the plot for ease of comparison.

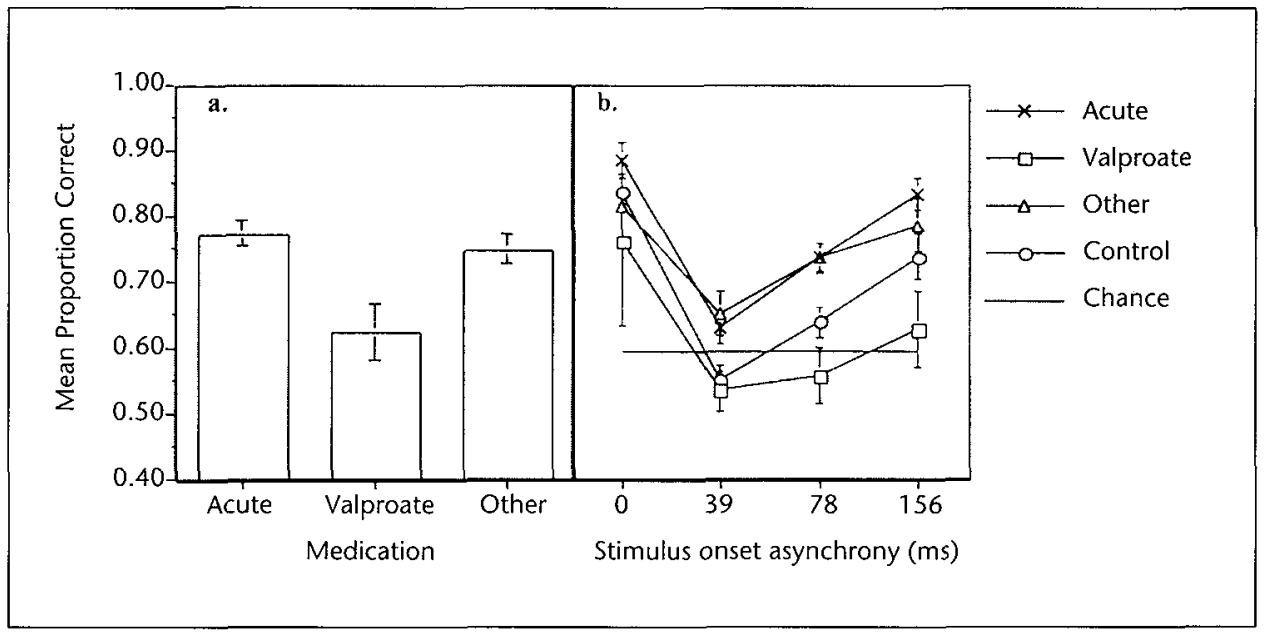

\subsection{Discussion}

Inspection of Figure 4 reveals clearly that the patients taking propanolol, pizotifen and methysergide performed similarly to drug-free patients on the metacontrast test: their overall performance was statistically indistinguishable. However, patients taking valproate were significantly less accurate overall: curves were if anything shallower than those of normal subjects. This pattern of data is entirely consistent with the predictions that stem from the known activity of sodium valproate on cortical GABA-ergic inhibitory systems. All three patients taking sodium valproate reported good therapeutic success with valproate: it is plausible to argue that this is perhaps because of restoration of normal cortical inhibitory potential in these patients. It is evident, however, that sodium valproate has a rather diverse pharmacological profile of activity, and its efficacy as a prophylactic for migraine may result from 'a combination of actions at different loci'13,23. It remains possible, though in our opinion unlikely, that a valproate-mediated increase in brain GABA is uncorrelated with therapeutic outcome in migraine. 


\section{General Discussion}

In this paper, a novel functional test - the metacontrast test - of the functioning of $\mathrm{V} 1$ has demonstrated a likely reduction of cortical inhibitory potential in migraine patients with aura. The relationship between attack frequency and results of the metacontrast test also suggests that the greater the impairment of inhibitory function, the more likely are attacks. Furthermore, the normalisation of metacontrast test results in a small number of patients taking a known cortical GABA-agonist for the prophylaxis of migraine, but not in patients taking prophylactics with no known GABAagonist activity, serves as a preliminary confirmation of the importance of this neurotransmitter system in the genesis of pathological cortical excitability in these patients. The data reported here are highly consistent with findings that cortical tissue that is deficient in inhibitory potential is susceptible to CSD ${ }^{12}$

A number of issues stem from these data. First, what might be the cause of inhibitory loss in V1 of migraine patients with aura? The authors (EC \& WM) have previously argued that the cumulative physiological effects of many episodes of aura may cause ultrastructural changes to the selectively vulnerable GABA-ergic systems of $\mathrm{V} 1^{9}$. Although there is no direct evidence as yet to support this view, it is interesting to note that, in animal models, repeated episodes of CSD have been shown to cause selective suppression of GABA-ergic inhibitory function ${ }^{24}$. At present, however, the notion of an intrinsic cortical hyperexcitability in migraine is equally attractive and plausible. The data we report here suggest that, if this second notion is correct, the functional hyperexcitablity of V1 may still stem from an intrinsic disorder of inhibitory systems.

Second, it is apparent that the metacontrast test results are only significantly different from control subjects in patients with aura. In Study 1 patients with aura were selected on the basis of having aura before all, or the vast majority of attacks, whereas patients without aura had never experienced a classical visual aura. It is possible therefore that cortical hyperexitability is a matter of degree even within the migraine population, and is maximised in those patients who frequently have aura. This suggestion is bolstered by the finding of Study 1 of a significant correlation between attack frequency and overall probability of correct judgments in the metacontrast test. It will be of great interest in future to examine the inter-relationships between the overall frequency of attacks, the ratio of attacks with to attacks without aura and metacontrast test results.

Study 2 used very small numbers of patients, and it may be argued that the results are not representative. Against this argument are the two points (a) that the metacontrast testing procedure is effectively blinded: the testing is under computer control and neither patient nor experimenter knows what type of target will next appear; and (b) a very large number (480) of data 
points are gained from each patient, and so the potential for error is considerably reduced as compared to, say, the provision on a rating scale of a single headache intensity score. Nonetheless, it is clear that intervention studies will be required in order to examine the changes in metacontrast test results prior to and during therapy with valproate: such studies are currently under way in our laboratory.

Previous studies have proposed that migraine with aura is associated with cortical hyperexcitability, and have found evidence for disordered visual cortical processing. The threshold for the generation of phosphenes by transcranial magnetic stimulation of the occipital cortex is probably lower in migraine with aura patients than headache-free control subjects ${ }^{6,7}$. Migraine patients - in particular those with aura - also exhibit a variety of deficits on other visual tasks that is consistent with functional cortical hyperexcitability ${ }^{10}$. The results of the present study extend and give further support to these findings, by providing evidence that specifically inhibitory mechanisms are disrupted in the visual cortex of migraine with aura patients. Furthermore, they suggest that the disruption of inhibition may be reversed pharmacologically: this may have implications for the future development of prophylactic agents. 


\section{References}

1. Lashley KS. Patterns of cerebral integration indicated by the scotomas of migraine. Arch Neurol Psychiatry 1941;46:331-339

2. Lauritzen M. Pathophysiology of migraine aura: The spreading depression theory. Brain 1994;117:199-210

3. Sanchez del Rio M, Bakker D, Hadjkhani N, Wu O, Cutrer FM, Sorensen G, Tootell R, Kwong $\mathrm{K}$, Rosen B, Moskowitz MA. Neurovascular cortical spreading phenomenon during spontaneous visual aura. Cephalalgia 1999;19:310

4. Moskowitz MA, Nozaki K, Kraig RP. Neocortical spreading depression provokes the expression of $c$-fos protein-like immunoreactivity within trigeminal nucleus caudalis via trigeminovascular mechanisms. I Neurosci 1993;13:1167-1177

5. Parsons AA. Recent advances in mechanisms of spreading depression. Curr Op Neurol 1998;11:227-231

6. Aurora SK, Ahmad BK, Welch KMA, Bhardhwaj P, Ramadan NM. Transcranial magnetic stimulation confirms hyperexcitability of occipital cortex in migraine. Neurology 1998;50:1111-1114

7. Aguggia M, Zibetti M, Febbraro A, Mutani R. Transcranial magnetic stimulation in migraine with aura: Further evidence of occipital cortex hyperexcitability. Cephalalgia 1999;19:465

8. Áfra J, Macia A, Gérard P, Maertens de Noordhout A, Schoienen J. Interictal cortical excitability in migraine: A study using transcranial magnetic stimulation of motor and visual cortices. Ann Neurol, 1998;44: 209-215

9. Chronicle EP, Mulleners WM. Might migraine damage the brain? Cephalalgia $1994 ; 14: 415-418$

10. Chronicle EP, Mulleners WM. Visual system dysfunction in migraine: a review of clinical and psychophysical findings. Cephalalgia 1996;16:525-535

11. Kryzhanovskii GN, Rebrov IG, Glebov RN. Action of metrazol on regulation of the GABA-A receptor-channel complex. Bull Exp Biol Med 1992;114:1249-1253

12. Harreveld van A, Stamm JS. Cortical responses to metrazol and sensory stimulation in the rabbit. Electroencephalogr Clin Neurophysiol 1955;7:363-370

13. Balfour JA, Bryson HM. Vaproic acid: A review of its pharmacology and therapeutic potential in indications other than epilepsy. CNS Drugs 1994;2:144-173

14. Reutens DC, Berkovic SF, Macdonell RAL, Bladin PF. Magnetic stimulation of the brain in generalized epilepsy: reversal of cortical hyperexcitability by anticonvulsants. Ann Neurol 1993;34:351-355

15. Hering R, Kuritzky A. Sodium valproate in the prophylactic treatment of migriane: $A$ double-blind study versus placebo. Cephalalgia 1992;12:81-84.

16. Klapper J. Divalproex sodium in migraine prophylaxis: a dose-controlled study. Cephalalgia 1997;17:103-108

17. Chronicle EP, Wilkins AJ, Coleston DM. Thresholds for detection of a target against a background grating suggest visual dysfunction in migraine with aura but not migraine without aura. Cephalalgia 1995;15:117-122

18. Kahneman D. Methods, findings, and theory in studies of visual masking. Psycho Bull 1968;70:404-425

19. Macknik SL, Livingstone MS. Neuronal correlates of visibility and invisibility in the primate visual system. Nature Neurosci, 1998;1:144-149 
20. Hendry S, Carder RK. Organization and plasticity of GABA neurons and receptors in monkey visual cortex. Prog Brain Res 1992;90:477-502

21. International Headache Society. Members' Handbook 1998/99. Oxford: Scandinavian University Press, 1999

22. Chagnac-Amitai $Y$, Connors BW. Horizontal spread of synchronized activity in neocortex and its control by GABA-mediated inhibition. J Neurophysiol 1989;61:747-758

23. Cutrer FM, Limmroth V, Moskowitz MA. Possible mechanisms of valproate in migraine prophylaxis. Cephalalgia 1997;17:93-100

24. Krüger $H$, Luhmann $H$, Heinemann $U$. Repetitive spreading depression causes selective suppression of GABA-ergic function. Neuroreport 1996;7:2733-2736 
Chapter 8

General discussion 
Chapter 8 
On this theory [of nerve-storms], then, the fundamental cause of all neuroses is to be found, not in any irritation of the visceral or cutaneous periphery, nor in any disorder or irregularity of the circulation, but in a primary and often hereditary vice or morbid disposition of the nervous system itself;....

The immediate antecedent of an attack is a condition of unstable equilibrium and gradually accumulating tension in the parts of the nervous system more immediately concerned, while the paroxysm itself may be likened to a storm, by which this condition is dispersed and equilibrium for the time restored.

Edward Liveing, 1873

\section{Introduction}

As witnessed by this statement quoted from Liveing in his monograph 'On the origin of megrim, sick headache and some allied disorders: a contribution to the pathology of nerve storms ${ }^{\prime}$, hyperexcitability of the cerebral cortex has been appreciated as a possible mechanism in the early pathophysiologic disruptions of a migraine attack for over a century. Although there remains little doubt that the regulation of cranial vascular tone does play a role, it is currently believed that this is restricted to the intracranial circulation and that any disturbance of vessel tone is primarily due to neuronal factors. What these neuronal factors comprise and what their functional consequences are, remains as yet elusive. Hereditary defects in Ca-channels, reduced mitochondrial energy reserve, altered potassium homoeostasis and brain magnesium deficiency are just some of the factors that, alone or in combination, may be implicated.

In the late 1980s Welch and colleagues started a reappraisal of what since then has been known as the concept of central neuronal hyperexcitability ${ }^{2}$. Initiated by their observations of certain neuromagnetic events in migraineurs, a broad array of modern neurophysiological and psychophysical techniques have yielded new insights in support of this theory. However, this is not to say that there are no grounds for further exploration and debate. Some findings have been difficult to replicate by independent research groups, others have provided data contradictory to what would have been expected on the basis of a supposed hyperexcitability. Therefore, this study aimed at resolving some of these issues, in part by repeating earlier techniques with special attention to methodological controversies, and additionally by applying new tools previously unexplored in migraine research. 


\section{Interpretation of study results}

We chose to employ transcranial magnetic stimulation, because this emerging neurophysiological technique provides a powerful tool for direct brain stimulation that is safe to use in clinical populations. Although TMS is applied for several clinical indications in many hospitals, it is still mainly used for research purposes, predominantly involving brain and behaviour studies. It allows comparing the results of regional brain excitation between populations, either by studying the remote effects of activation of afferent and efferent pathways or the disruption of ongoing sensory and cognitive processing.

Our study of self-reported photophobia symptoms shows that the excitability of the visual system as assessed by meaningful clinical parameters is enhanced in migraineurs, which is reflected by both the increased reporting of cumbersome symptoms of stress conveyed by ordinary visual stimuli, and the increased levels of discomfort perceived with the standardised visual stress cards. Although one might argue that these findings merely reflect methodological bias or a hypochondriacal tendency on behalf of the migraine subjects, we belief that these results point at a functional derangement in the visual system somewhere between the globe and the primary visual cortex, though in our opinion most likely at the level of V1.

The phosphene study adds weight to the earlier claim of occipital hyperexcitability in migraine when using TMS, with now four positive studies compared to just one negative report. We applied a stringent study design to try and avoid methodological caveats, but nonetheless some bias could not be ruled out. In our experience, some subjects found the phosphene concept difficult to grasp and needed repeated instruction. Moreover, in an ongoing longitudinal study it is striking that in many subjects phosphene thresholds are higher in the first than in all other assessments. Despite these potential sources of bias, the current occipital TMS studies in general support hyperexcitability.

The results from the valproate intervention study were somewhat disappointing. Although the clinical efficacy of sodium valproate was clear, this was not paralleled by a general increase of phosphene threshold in the migraine patients. A threshold increase after valproate intervention was only apparent in the migraineurs with aura, analysed for the figure-of-eight coil data. It is conceivable that the test results were hampered by a low test-retest reliability, which, although not assessed, may well have been superior for the figure-ofeight coil type. Moreover, the intervention study was seriously troubled by a comparatively high dropout rate, resulting in small group sizes and therefore making it impossible to draw firm conclusions. We nevertheless belief that some of the findings are interesting enough to warrant further investigation with the drug intervention technique.

The finding in the metacontrast masking experiment that target recognition is less amenable to disruption by the visual mask provides good 
evidence that visual cortical inhibition is impaired in migraine with aura. Furthermore, the normalising effect of valproate prophylaxis on target recognition performance emphasises the point of cortical GABA-deficiency in migraine with aura; rather than reflecting an epiphenomenon, it lends some support to the notion that this neurotransmitter system is involved in the pathogenesis of migraine. The positive correlation between attack frequency and target recognition suggests that the frequency of migraine attacks is determined by the extent of inhibitory impairment. Conversely, as it seems reasonable to assume that a higher attack frequency is correlated with a higher cumulative migraine load, it might on the other hand indicate that GABA-ergic dysfunction increases with higher migraine exposure over time. However, as the years of exposure were not assessed, it needs to be stressed that such a claim cannot be made with sufficient confidence from the current data set. In order to resolve this issue, specifically designed -and preferably prospective longitudinalstudies are warranted.

In order to avoid many of the methodological problems inherent to previously used TMS techniques mentioned above, we applied a more objective technique that is less amenable to bias. In the visual suppression study the assessment was under computerised control, when both the letter trigram and the pulse delay were randomly varied across 54 trials per individual. Moreover, a more straightforward study parameter (letter rather than phosphene recognition) lowered the risk of bias from subjective interpretation, which was further reduced by allowing individuals more time to become acquainted to the target under consideration. Our findings were rather similar to the results of the metacontrast masking experiment and although the subject numbers were relatively small in this study, we believe that the findings in the visual suppression study give solid evidence of occipital hyperexcitability in migraine with aura. Furthermore, these findings again indicate that the enhanced excitability may be caused by attenuation of cortical inhibition.

In summary, by employing three independent research tools (two neurophysiological and one psychophysical), we obtained convergent proof of enhanced excitability of the visual cortex in the migraine interictum (at least in migraine with aura and possibly also migraine without aura), as compared to matched headache-free individuals, and that this cortical hyperexcitability is probably mediated by reduced cortical inhibitory neurotransmission. Moreover, by studying symptoms which may be a reflection of a lowered threshold to everyday visual stress, we focussed attention on a possible clinical counterpart of experimental hyperexcitability. Indeed, the enhanced responsiveness of the visual cortex may be reflected clinically by the aversion to bright light, sensations of discomfort by exposure to patterned objects and visually triggered migraine attacks, as is so often reported by migraine subjects and reproduced in our patient surveys. 


\section{What's new?}

Hyperexcitability of the visual cortex is now a well established feature with relevance to the pathogenesis of in migraine. It is apparent from our findings that the enhanced excitability of the visual cortex in migraine, rather than reflecting an enhanced excitatory drive (either thalamocortical or through recurrent excitation), is conferred through an attenuation of inhibitory neurotransmission. GABA plays a major role in the field of neocortical neurotransmitters and because of its abundant presence in the occipital cortex it is tempting to speculate that migraine may be viewed as a GABA deficiency syndrome of the occipital cortex. In this respect, the efficacy of current migraine prophylactic remedies like valproate, and possibly topiramate and baclofen, might be interpreted as correcting a regional GABA deficiency, although none of these agents can be regarded as pure GABA agonists. The mechanisms that could lead to GABA deficiency in migraine remain as yet enigmatic: whether inherited or acquired through environmental factors needs to be established. In parallel with the observation in certain non-human, primate occipital neurones, selective vulnerability to hypoxic/ischemic conditions during migraine aurae has been forwarded as a possible explanation ${ }^{3}$ and it was argued that repeated migraine attacks are deleterious to specific neuronal populations in the primary visual cortex, thereby self-perpetuating its basic defect. In this view, an (inherited?) defiency of GABA neurotransmission in the primary visual cortex may lead to a lowered excitability threshold, thus rendering the brain vulnerable to episodes of spontaneous spreading depression and attacks of migraine with aura. Repeated episodes of spreading depression may then inflict repetitive insults to these GABA-ergic cell populations, thus self-perpetuating the intrinsic hyperexcitability of $\mathrm{V} 1$ and further increasing the risk of spontaneous spreading depression. Although the current literature regards it as unlikely that frank ischemia does occur during attacks of migraine, other intermediate factors (i.e. NMDA-receptor activation and excitotoxicity) may form the connection between the repeated excessive neuronal activation of cortical spreading depression and this hypothesised frank selective damage to GABA-ergic neurones. Indeed, in animal experiments it has been shown that repeated episodes of spreading depression lead to attenuation of cortical inhibition ${ }^{4}$.

Until now, there has only been a limited amount of research addressing inhibitory neurotransmission in the visual cortex in migraine. Case-control studies of visual orientation discrimination thresholds ${ }^{5}$ and visual contrast gain control ${ }^{6}$, which are thought to depend on cortical inhibitory neurotransmission in V1, did not, on the whole show significant differences between migraine with aura, migraine without aura and control subjects, although a weak trend between a long lifetime history of frequent migraine aura and higher orientation discrimination threshold was observed ${ }^{5}$. Thus, these findings did not support a persistent large reduction in cortical inhibition in either migraine with or without 
aura, but did show that there might be an indication of weakened inhibitory processes due to longstanding migraine with aura. Khalil and colleagues found lower P100 amplitudes in cases with a long history of migraine with aura ${ }^{7}$, suggesting reduced excitability in subjects with longstanding migraine with aura. Several points of debate can be made, however, some of which have already been addressed by Wilkinson ${ }^{5}$. First, while single cell recordings under metacontrast masking conditions have convincingly demonstrated the inhibitory nature of the masking phenomenon, to our knowledge the ultimate proof of the inhibitory dependency of the measures used by Wilkinson's group remains as yet to be established. Second, although we are not under the impression that there are great intra-individual variations in excitability during the migraine interictum, we can not discard the possibility that the heterogeneity between Wilkinson's and our findings may be partially explained by the smaller time interval between the experiments and the last migraine attack in our subjects. Third, as inhibition plays multiple roles in neocortical functioning, it may be possible that the circuitry mediating orientation selectivity and visual contrast gain are distinct from the ones subserving target visibility as assessed in the metacontrast and TMS suppression experiments. Fourth, research data are rather heterogeneous with respect to cortical inhibition and its possible correlation with cumulative aura load, and thus this view cannot be negated on the basis of the research currently available. Fifth and final, retrospectively acquired data on cumulative aura load are extremely difficult to collect reliably because of extreme variations in individual attack frequency over the years, and may thus be seriously hampered by recall bias. As was argued in the previous paragraph, this may only be resolved by acquiring longitudinal data over many years. Alternatively, though obviously less reliable, experiments designed to study the extremes of the frequencyduration spectrum may provide a more feasible means of addressing this issue.

Although the acquired cumulative GABA-deficiency position provides an attractive framework for several clinical and experimental observations, several important questions remain. For one, it is now well established that hereditary factors play an important role in the development of migraine, notably in migraine with aura. It remains to be established if, and how, an inherited GABAergic deficiency can cause a phenotype that usually ameliorates or indeed disappears with advancing age. Second, cumulative 'self-sustained' damage to GABA-ergic systems would be expected to cause an ever increasing cortical excitability and thus an increment in attack frequency with longer migraine duration. Although an increment in attack frequency is frequently observed in second and third line centres, it is common knowledge that migraine is a disease of young and middle age groups, which usually ends in later life. Obviously then, the GABA-deficiency hypothesis cannot be the only pathophysiological explanation for migraine and other independent factors need to be involved. Currently, none of the prevailing theories on migraine pathogenesis provide a sufficient explanation for this phenomenon. 


\section{Future directions}

Although the phosphene threshold method has yielded significant and in general reproducable differences between migraine subjects and controls, it is less than optimal to obtain meaningful quantitative data on cortical excitability. Because of the subjective process of phosphene perception, this design may be prone to interpretation bias, which may be particularly troublesome when obtaining measures of cortical excitability longitudinally. The visual suppression method has proven to be more reliable in this respect and, in our view, is the better choice when studying occipital excitability with transcranial magnetic stimulation.

Transcranial magnetic stimulation may provide a means of further studying the GABA-deficiency hypothesis postulated here. In particular, $1 \mathrm{~Hz}$ repetitive TMS (rTMS) has been used to enhance cortical inhibition for up to 15-30 minutes, arguebly due to longlasting potentiation of GABAneurotransmission. If, then, GABA-ergic synaptic utilisation were to be attenuated in migraine, it would be predicted that the reduced visual suppression in migraine with aura may be temporarily augmented shortly after rTMS. Piloting this method in one migraine volunteer, we were able to show that suppression at the $100 \mathrm{msec}$ interval was indeed augmented after 15 min $1 \mathrm{~Hz}$ rTMS, when compared to the pre-rTMS condition. Following up on this observation, a case-control study is currently in preparation.

There is nowadays little doubt that genetic factors play a significant role in the pathophysiology of migraine. Any new theory on the mechanisms of migraine should therefore consider potential genetic factors in an attempt to provide an integrated explanation of, on the one hand the phenomena observed and otherwise firmly established knowledge. Thus, future genetic studies may focus on loci involved in the make-up of GABA neurotansmission. As a first steps, efforts may be targeted at association studies between polymorphisms in the genes encoding the GABA-A and GABA-B receptor in migraine with aura patients and controls.

To study the possible detrimental effects of repeated aurae on V1 GABAergic function ${ }^{3}$, a between-group comparison of TMS visual suppression data obtained in migraineurs with a low and high estimated cumulative aura load may be an informative initial approach. Obviously, establishing the total number of aurae based on history taking may be hampered by recollection bias and can at best only provide a rough estimate of cumulative aura load, which may render group seperation difficult. However, if an interaction between aura load and measures of suppression can be established, longitudinal collection of suppression data over a prolonged time interval may be warranted. 


\section{References}

1. Liveing $\mathrm{E}$. On the origin of megrim, sick headache and some allied disorders: a contribution to the pathology of nerve storms (1873). IHC Congress Edition Nijmegen, 1997, Arts \& Boeve

2. Welch KMA, D'Andrea G, Tepley N, Barkley GL, Ramadan NM. The concept of migraine as a state of central neuronal hyperexcitability. Neurol Clinics 1990;8:817-828

3. Chronicle EP, Mulleners WM. Might migraine damage the brain? Cephalagia 1994; 14:415-418

4. Krüger $\mathrm{H}$, Luhmann $\mathrm{HJ}$, Heinemann U. Repetitive spreading depression causes selective suppression of GABA-ergic function. Neuroreport 1996;7:2733-2736

5. Wilkinson $\mathrm{F}$, Crotogino J. Orientation discrimination thresholds in migraine: a measure of visual cortical inhibition. Cephalalgia 2000;20:57-66

6. McColl SL, Wilkinson F. Visual contrast gain in migraine: measures of visual cortical excitability and inhibition. Cephalalgia 2000;20:74-84

7. Khalil NM, Legg NJ, Anderson DJ. Long term decline of P100 amplitude in migraine with aura. J Neurol Neurosurg Psychiatry 2000;69:507-511 
Chapter 8

130 
Chapter 9

Summary 


\section{Summary}

The studies collected in this thesis aimed at obtaining more evidence for and new insights into the supposed cortical hyperexcitability in migraine patients -in particular the occipital areas of the brain involved in visual perception and processing-, which is generally considered to be of relevance in the pathogenesis of the migraine constellation. The studies reported herein were, for the most part, embedded in a collaborative project of the Departments of Psychology (Lancaster, United Kingdom) and Neurology/Clinical Neurophysiology (Heerlen, The Netherlands), and were supported by a generous Project Grant of The Migraine Trust.

The data in the chapter on self-reported photophobia were in part obtained at a patient's information meeting in Heerlen (The Netherlands), though also in the United Kingdom and at a specialist headache clinic in Detroit. Most of the transcranial magnetic stimulation studies were performed at the Department of Clinical Neurophysiology of Atrium Medical Center (Heerlen, The Netherlands), although some of the subjects reported in chapter 6 were recruited at Lancaster University (UK). The subjects for the metacontrast study (chapter 7), were recruited from the headache clinic at Manchaster Royal Infirmary (Dr. P. Rolan) as well as at the Lancaster Campus.

Chapter 2 reviews the available research data concerning the various neurological and ophthalmologic systems involved in the adaptation to and processing of visual stimuli, with respect to migraine. All structures of the visual system were systematically discussed, starting at the globe and continuing through the optic tract, lateral geniculate body and optic radiation back to the occipital pole. The clinical and psychophysical findings reviewed reveal a broad agreement that migraine is associated with (i) a pupillary sympathetic hypofunction, and (ii) a cortical hypersensitivity to visual stimuli (perhaps only in migraine with aura). It is put forward that evidence for other dysfunctionality in the eye, retina or visual pathways is still equivocal. Research aimed at understanding the neurological basis of the visual triggering of migraine, and of photophobia would assist a more complete understanding of the disorder, and perhaps shed light on processes occurring at the very initiation of an attack. Moreover, further investigations into the nature and cause of the dysfunction of the visual cortex in migraine with aura may assist the development of general pathophysiological theories.

In chapter 3 the findings of three studies examining self-reported interictal photophobic symptoms of patients with migraine and responses to a laboratory visual stress test (in a subset of the same patient groups) are described. Interest was focussed on these migraine symptoms as they may represent possible clinical counterparts of cortical neuronal hyperexcitability. 
Thus, it would be predicted that migraineurs will report increased levels of discomfort to environmentally shared visual stimuli. Data on self-reported photophobic symptoms were obtained in a cohort of self-selected patients in The Netherlands and a series of consecutive referrals to a specialised Headache Clinic in the United States, and compared to a headache-free control population. In the United States study a specially designed laboratory test to examine the threshold for visual stress was also used. Patients reported significantly more everyday symptoms of photophobia than did controls and thresholds for visual stress were significantly lower in patients than in controls. These findings are important because they (i) highlight the high prevalence of photophobia in patients in the interictum, (ii) add weight to the notion that photophobic symptoms in everyday life may provide another diagnostic pointer for migraine in cases of clinical uncertainty, and (iii) are supportive of the growing consensus that migraine patients may be characterised by visual cortical hyperexcitability.

Chapter 4 reports the prevalence of magnetophosphenes and the median thresholds at which they were obtained, using transcranial magnetic stimulation (TMS) of the occipital cortex. The study design was similar to those used in previous occipital TMS studies. Data were obtained in migraine with and without aura, and were compared to an age and sex matched control group. The finding of lowered phosphene thresholds could be replicated in the migraine with aura group, and very similar thresholds were obtained in migraineurs without aura. It was argued that these observations confirm the existence of occipital hyperexcitability in migraine.

On the assumption that enhanced GABA-ergic neurotransmission may interact with cortical excitability parameters, the findings on magnetophosphene thresholds before and after valproate treatment in the migraine population described in the previous chapter are presented in chapter 5. Additionally, changes in phosphene threshold were analysed in relation to alterations in migraine frequency, postulating that the neuronal hyperexcitability concept would dictate that an increase in phosphene threshold should be paralleled by a decrease in migraine load. It was found that phosphene thresholds were raised after treatment, paralleling a decrease in headache parameters. However, these results were dependent on coil type in that they were obtained with the figure-ofeight coil only, possibly because of a higher test-retest reliability with this coil.

In chapter 6 the TMS-induced suppression of visual perception was compared in migraineurs with aura and headache-free subjects. It has been argued that this phenomenon most likely represents activation of cortical inhibitory networks. Moreover, the technique is very similar to the metacontrast masking design in that, rather than an abutting visual stimulus, a cortically applied electromagnetic masking stimulus is used as the mask, providing further 
clues as to the inhibitory dependency of the perceptual suppression. As this parameter may be a more objective measure than phosphene threshold, and since deficient intracortical inhibition may be responsible for enhanced excitability, we applied this technique in migraine for the first time, in search for a more robust indication of cortical hyperexcitability and its putative mechanism. Overall, suppression of letter recognition was less effective in migraine with aura, peaking at the $100 \mathrm{msec}$ target-pulse interval. Moreover, the significant difference between the groups probably arose because the time window during which suppression was possible in the MA patients was significantly narrower than in the control subjects.

Finally in chapter 7, the findings of a study employing a psychophysical paradigm known as metacontrast masking were reported. As there is very good evidence that the performance on this task is dependent on cortical inhibitory function, migraineurs with visual aura were tested and compared to headache free controls to test the hypothesis that visual cortical inhibition is deficient in migraine with aura. Moreover, the effect of prophylactic drug intervention on the masking experiment was studied. Migraineurs were more accurate in their target recognition and showed less interference of the target by the mask. Subjects on valproate had recognition curves similar to controls (and indeed overcompensated somewhat), as opposed to the patients on non-GABA prophylactics. Finally, for the migraine with aura patients a correlation between attack frequency and performance on the metacontrast masking test was observed. 


\section{Samenvatting}

De onderzoeken welke in dit proefschrift vervat zijn, beogen aanvullend bewijs en nieuwe inzichten in de bij migraine veronderstelde corticale hyperexcitabiliteit te verschaffen, waarvan algemeen wordt aangenomen dat deze een belangrijke rol vervult in de pathogenese van migraine. Bij deze studies was de aandacht met name gericht op de occipitale hersengebieden, welke betrokken zijn bij de perceptie en verwerking van visuele informatie. Het merendeel van de onderzoeken werd verricht in het kader van een samenwerkingsproject tussen de afdelingen Psychologie (Lancaster, GrootBrittannië) en Neurologie/Klinische Neurofysiologie (Heerlen, Nederland), hetgeen financieel mogelijk gemaakt werd door een Project Grant van The Migraine Trust.

De gegevens in hoofdstuk 3 werden deels verzameld tijdens een patiënten informatieavond welke gehouden werd in het Atrium Medisch Centrum te Heerlen, en verder bij personen in Groot-Brittannië alsmede in een gespecialiseerde hoofdpijnpolikliniek in Detroit. Het leeuwendeel van de magneetstimulatie onderzoeken werd op de afdeling Klinische Neurofysiologie van het Atrium Medisch Centrum verricht, echter een deel van de onderzochte personen beschreven in hoofdstuk 6 werd gerekruteerd onder studenten en personeel van de Universiteit van Lancaster (Groot-Brittannië). De personen in de 'metacontrast' studie werden verzameld op de hoofdpijnpolikliniek van de Manchaster Royal Infirmary (Dr. P. Rolan) en op de campus van de Universiteit van Lancaster.

In hoofdstuk 2 wordt een overzicht gegeven van de wetenschappelijke stand van zaken met betrekking tot de neurologische en ofthalmologische tracti welke van belang zijn voor de adaptatie en verwerking van visuele stimuli in de context van migraine. Alle onderdelen van het visuele systeem werden systematisch belicht, vanaf de oogbol via de tractus opticus, corpus geniculatum laterale, radiatio optica tot aan de occipitale schors. Op basis van klinische en psychofysische bevindingen kan worden gesteld dat migraine is geassocieerd met (1) een hypofunctie van de sympathische innervatie van de pupil en (2) een corticale hypersensitiviteit voor visuele stimuli (wellicht alleen in migraine met aura). Er wordt gesteld dat er nog geen overtuigend bewijs bestaat voor andere stoornissen in de functie van het oog, retina of visuele tracti. Voor een beter begrip van de aandoening is het van belang verder onderzoek te verrichten naar de neurologische basis van het luxeren van aanvallen door visuele stimuli, alsook naar de mechanismen van fotofobie, waardoor mogelijk meer inzicht wordt verkregen in de processen welke een rol spelen bij de initiatie van de migraineaanval. Bovendien kan nieuw onderzoek naar de aard en oorzaak van de dysfunctie van de visuele cortex bij migraine met aura bijdragen in de ontwikkeling van allesomvattende pathofysiologische theorieën. 
In hoofdstuk 3 worden de resultaten van drie onderzoeken naar de door migrainepatiënten gerapporteerde symptomen van interictale fotofobie alsmede de reacties op een visuele-stress-test bij een subgroep van deze patiënten beschreven. Deze parameters waren onderwerp van speciale studie, omdat ze mogelijk een klinische weerspiegeling van corticale neuronale hyperexcitabiliteit vormen. De veronderstelling was dat migrainepatiënten meer hinder zouden ondervinden van algemene, in de omgeving aanwezige visuele stimuli. De gegevens met betrekking tot fotofobische symptomen werden verzameld in een deels uit de polikliniek-populatie geselecteerd, deels via een advertentie verkregen patiëntencohort in Nederland, en verder in een serie opeenvolgende verwijzingen naar een gespecialiseerde hoofdpijnpolikliniek in de Verenigde Staten; deze groepen werden vergeleken met een hoofdpijnvrije controlepopulatie. Bij de patiënten in de Verenigde Staten werd bovendien de drempel voor visuele stress onderzocht met behulp van een speciaal ontworpen laboratoriumtest. De patiënten rapporteerden significant meer dagelijkse fotofobiesymptomen en significant lagere drempelwaarden voor visuele stress dan controles. Deze bevindingen zijn temeer belangrijk omdat ze (1) de hoge prevalentie van fotofobie in het migraine interictum onderstrepen, (2) een verdere indicatie vormen dat alledaagse fotofobie (in geval van klinische onzekerheid) de diagnose migraine kunnen ondersteunen en (3) steun geven aan toenemende consensus dat migrainepatiënten gekenmerkt worden door visuele corticale hyperexcitabiliteit.

In hoofdstuk 4 wordt verslag gedaan van de prevalentie van magnetofosfenen, alsmede de mediane intensiteitdrempel waarbij ze werden gegenereerd met behulp van transcraniële magneetstimulatie (TMS) van de occipitale cortex. De onderzoeksopzet was vergelijkbaar met die welke in eerdere occipitale TMS-studies gebruikt werd. De gegevens van patiënten met en zonder aura werden vergeleken met een voor geslacht en leeftijd gematchte controlegroep. In analogie aan sommige eerdere studies werd in de migrainemet-aura populatie een verlaagde fosfeendrempel gevonden, en werden ook bij de patiënten zonder aura vergelijkbare drempelwaarden gezien. Er wordt gesteld dat deze observaties het bestaan van occipitale hyperexcitabiliteit bij migraine bevestigen.

Gebaseerd op de vooronderstelling dat een toegenomen GABA-erge neurotransmissie van invloed zal zijn op parameters van corticale prikkelbaarheid, worden in hoofdstuk 5 de fosfeendrempelwaarden van de migrainepatiënten uit hoofdstuk 4 vóór en ná behandeling met valproinezuur beschreven. Bovendien werden de veranderingen van deze drempelwaarden gerelateerd aan de veranderingen van de aanvalsfrequentie, er van uitgaande dat volgens de theorie van de neuronale hyperexcitabiliteit een toename van de fosfeendrempel gepaard zou moeten gaan met een verlaging van de aanvalsfrequentie. 
Inderdaad was de gemiddelde fosfeendrempel toegenomen na behandeling met valproinezuur met parallel daaraan een afname van de hoofdpijnindices. Echter, de resultaten bleken afhankelijk te zijn van het gebruikte coil type en werden alleen gevonden met de 'figure-of-eight' coil, mogelijk als gevolg van een hogere test-retest betrouwbaarheid met dit type coil.

In hoofdstuk 6 wordt de door TMS geïnduceerde suppressie van visuele perceptie vergeleken tussen patiënten met migraine met aura en hoofdpijnvrije controlepersonen. Er is verondersteld dat dit fenomeen zeer waarschijnlijk veroorzaakt wordt door een activatie van corticale inhiberende netwerken. Bovendien is deze techniek enigszins vergelijkbaar met het 'metacontrast masking' experiment, in die zin dat in plaats van een aanpalende, maskerende visuele stimulus een maskerende electromagnetische stimulus op de visuele cortex aangewend wordt. Deze overeenkomst zou derhalve als een verdere aanwijzing voor de relatie van perceptuele suppressie met corticale inhibitie geïnterpreteerd kunnen worden. Deze techniek werd aangewend om meer overtuigende aanwijzingen voor het bestaan van corticale hyperexcitabiliteit te vinden, met name omdat ze een objectievere maat voor corticale prikkelbaarheid is dan bepaling van fosfeendrempelwaarden, en tevens om de veronderstelling te toetsen dat een afgenomen corticale inhibitie ten grondslag ligt aan de toegenomen excitabiliteit. In het algemeen was de onderdrukking van de letterherkenning minder effectief in de migrainegroep, waarbij het grootste verschil met de controlepersonen werd gevonden bij een tijdsinterval van 100 msec tussen letterpresentatie en magneetstimulus. Dit significante verschil werd waarschijnlijk veroorzaakt doordat het tijdsvenster, waarin onderdrukking van de letterherkenning optrad, bij migrainepatiënten significant smaller was dan bij controlepersonen.

In hoofdstuk 7 tenslotte zijn de bevindingen van een onderzoek, waarbij een psychofysisch paradigma bekend als 'metacontrast masking' gebruikt werd, weergegeven. Aangezien er overtuigende bewijzen zijn dat de prestatie bij deze taak afhankelijk is van corticale inhibitie, werden patiënten met visuele aura vergeleken met hoofdpijnvrije controlepersonen in de veronderstelling dat de inhibitie van de visuele cortex bij migraine met aura tekortschiet. Bovendien werd de invloed van profylactische medicatie op de resultaten bestudeerd. Migrainepatiënten waren accurater in het herkennen van de doelstimulus en waren minder gevoelig voor interferentie door de maskerende stimulus. De patiënten die behandeld werden met valproinezuur presteerden vergelijkbaar met controlepersonen (en overcompenseerden enigszins), in tegenstelling tot de patiëntengroep die non-GABA-erge profylactische medicatie gebruikte. Tenslotte werd bij de migrainepatiënten een correlatie tussen de aanvalsfrequentie en de resultaten bij de 'metacontrast masking' test gevonden. 
Chapter 9 
Appendix 


\section{Dankwoord}

Het schrijven van een dankwoord is tevens het uitgesproken moment om stil te staan bij en terug te blikken op de vele momenten, overpeinzingen en personen welke een onuitwisbare rol hebben gespeeld bij de totstandkoming van dit proefschrift. Hoewel de systematische benadering van een vraagstelling en de wetenschappelijke uitwerking hiervan altijd een belangrijke drijfveer van mijn professioneel handelen waren en nog steeds zijn, is het schrijven van een dissertatie voor mij nooit een doel op zich geweest. Het was mijn overtuiging dat een proefschrift een verhandeling zou moeten zijn over de zoektocht naar de antwoorden op een authentieke wetenschappelijke vraag of concept, waarin de medische literatuur niet of onvoldoende voorziet en welke mij dermate fascineert dat het een voortdurende impuls zou vormen om het probleem trachten te doorgronden. Meer nog dan een kleine bijdrage aan het bevorderen van de (medische) wetenschap en het welzijn van de mensheid is het proefschrift daarmee bovenal een getuigenis van een periode in de wetenschappelijke en levensbeschouwelijke ontwikkeling van de auteur. Een procesmatige gang naar de promotie was voor mij daardoor niet weggelegd.

Het is er dan toch van gekomen, ogenschijnlijk in een betrekkelijk kort tijdsbestek, echter schijn bedriegt, ook hier. Hoewel het concept van de visuele corticale hyperexcitabiliteit door tekortschietende corticale inhibitie reeds in 1993 was geboren, waren het de toevallige kennismaking met en de beschikbaarheid van transcraniële magneetstimulatie in 1997 die mij definitief deden besluiten om te promoveren. In deze geleidelijke ontwikkeling hebben velen een belangrijke en enkelen een prominente rol gespeeld, en voor hun bijdrage wil ik dank zeggen.

First, I would like to thank my co-promotor Dr. E.P. Chronicle. Dear Ed, this thesis would not have existed without your invaluable contribution, as much of it extends on the ideas put forward in your PhD thesis. I remember one day in the summer of 1993, when we first discussed the putative injury to sparcely spinous stellate cells in layer IV of the primary visual cortex and the promotion of spreading depression, while enjoying the beautiful scenery of the Heilig Landstichting forest. Based on our established friendship, it was there that our longstanding scientific collaboration in the migraine area started, of which this thesis is just one of the many results. I hope we will be able to continue our cooperation, both as friends as well as researchers.

Dank ben ik ook verschuldigd aan mijn promotores, Prof. E.J. Jonkman en Prof. J. Troost. Prof. Jonkman, beste Joost, nadat je je bereid had getoond om mijn proefschrift te begeleiden had je al snel doorzien dat het noodzakelijk zou zijn om ook een promotor uit de neurologische hoek te benaderen. Je opmerkingen en suggesties waren van onschatbare waarde: niet alleen hebben 
ze mij behoed voor menige uitglijder, doch bovendien vormden ze het vertrekpunt van waaruit mijn onderzoek gecontinueerd zal worden. De zegeningen van het digitale tijdperk maakten het uiteindelijk mogelijk om de fysieke afstand tussen ons te overbruggen, ook al verliep dat vanuit Limburg niet altijd even vlekkeloos. Prof. Troost, beste Jaap, enigszins schoorvoetend betrad ik de eerste keer je werkkamer, omdat ik je pas in tweede instantie benaderde met het verzoek het voorgekookte en deels lopende promotieproject te begeleiden. Ik was dan ook opgelucht toen je je volledig achter mijn plannen schaarde en mij het vertrouwen schonk om in alle vrijheid mijn onderzoek af te ronden. Je pragmatische en faciliterende inbreng heb ik zeer gewaardeerd en hebben belangrijk bijgedragen tot het resultaat dat nu voor ons ligt.

Dr. P.J. Koehler, beste Peter, de laatste hobbel in de beslissing om te promoveren heb ik samen met jou genomen, al wandelend door het Limburgse heuvelland op een zonnige voorjaarsdag. Dankzij je tomeloze inzet wist je in korte tijd het leeuwendeel van de onderzochte patiënten te recruteren en had ik protocollen en manuscripten altijd snel becommentarieerd retour, waardoor ik mijn onderzoek relatief snel kon volbrengen.

Dr. J.W. Vredeveld, beste Jan-Willem, in deze tijden van tanende belangstelling voor de klinische neurofysiologie heb je me ervan weten te overtuigen dat de nieuwere technieken veelbelovende toepassingsmogelijkheden voor wetenschappelijk patiëntgebonden onderzoek kennen. Je hebt meegeholpen om mijn wetenschappelijke aspiraties op de rails te zetten en te vormen tot dit proefschrift, doch uiteindelijk bleek er meer voor nodig dan het bijeenvoegen van een aantal artikelen en die te bundelen met een nietje.

Dr. J.E. Palmer, dear Joan, even when you were in the midst of your own $\mathrm{PhD}$ thesis you found the time to assist me in testing some of the controls in the magnetophosphene experiments and all the subjects in the SPAM project. Your expert statistical knowledge and skills were indispensible in the analysis of the many study data, and relieved me of the need to catch up with all the novelties in population statistics. Above all, you were great company during our many social hours together.

I am indebted to Dr. S.K. Aurora, who kindly provided the data for the American subjects in the photophobia study. Dear Sheena, it was my great pleasure to meet and work with the pioneering lady of occipital TMS in migraine, as much as I've enjoyed your spontaneity at the many times we've met. I hope that we will be able to keep up our contacts.

Dr. Hans ter Berg ben ik dank verschuldigd voor het verwijzen van enkele patiënten voor de visuele suppressie studie. 
Praktische hulp bij het oproepen, begeleiden en vervolgen van de onderzochten kreeg ik van mevr. T. Simons-Sporken. Bovendien was zij, samen met mej. J. Ladenstein van GlaxoWellcome B.V. verantwoordelijk voor de smetteloze organisatie van de patiëntenvoorlichtingsbijeenkomst, welke de bron vormde voor hoofdstuk 3.

Mijn speciale dank gaat uit naar mijn collega's binnen de maatschap neurologie in Heerlen/Brunssum. Rianne, Jan-Frans, Cees, Stan, Peter en JanWillem, door mij op dinsdagmiddag consequent vrij te stellen van werkzaamheden in de drukke neurologische praktijk was ik in staat om gestaag aan mijn promotie te kunnen werken, zonder dat dit al te zeer ten koste ging van mijn privé-leven. Stan, je suppressie-curve was voorbeeldig.

De arts-assistenten neurologie ben ik erkentelijk, omdat jullie op mijn 'vrije' dinsdagmiddagen vaak weer eens harder moesten lopen om de neurologische praktijk draaiende te houden.

De laboranten van de afdeling Klinische Neurofysiologie en de polikliniekassistentes waren een rots in de branding voor zowel de patiënten als voor mij, wanneer ik weer eens een afspraak vergeten was. Dankzij jullie is het uiteindelijk toch nog allemaal goed gekomen.

When considering one's career development which has spanned nearly two decades, it is impossible to remember everyone that has contributed to it, yet some have left such an ineradicable impression that they come to mind immediately. One of them is Dr. T.J. Steiner. Dear Tim, probably without you knowing, you've played a major role in my preparatory years for this thesis. During my year at the Princess Margaret's you've thoroughly taught me the tricks of the scientific trade. I've always admired the rigour and vigour in your scientific and committee work, which revealed to me the necessity of a comprehensive and in-depth preparation for any scientific work to succeed.

Dank ben ik ook verschuldigd aan de vele onderzochten, welke geheel belangeloos hun medewerking toezegden om de, met spierschokken gepaard gaande, magneetstimulaties te ondergaan.

De Migraine Trust wil ik danken voor het ter beschikking stellen van de benodigde financiële middelen.

Lieve Caron, hoewel je me vaak hebt voorgehouden dat je weinig hinder hebt ondervonden van mijn promotiewerk, moet je zo af en toe toch met gekromde tenen gezeten hebben. Wat dat betreft breekt nu een rustiger tijd aan en zal ik me minder ambitieus opstellen. Hoewel, je weet, leven met eeen medisch specialist is niet altijd gemakkelijk. En voor Anne en Sebastiaan, papa zal nu eindelijk meer uit júllie boekjes kunnen voorlezen. 


\section{Curriculum vitae}

Schrijver dezes werd geboren op 30 januari 1962 te Geleen. Na het behalen van het Atheneum-B diploma aan de Albert Schweitzer Scholengemeenschap in Geleen, studeerde hij tot 1981 Chemie aan de Rijksuniversiteit Utrecht. Alras bleek echter dat de geneeskunde een grotere aantrekkingskracht uitoefende en volgde hij de studie Geneeskunde aan dezelfde universiteit van 1981 tot 1989. In 1984 was hij werkzaam als 'snijzaalassistent' ten behoeve van het practicum 'anatomie van de ingewanden'. Na het artsexamen werkte hij als arts-assistent-niet-inopleiding op de afdeling Neurologie van het Maaslandziekenhuis Sittard, met een korte onderbreking voor het opdoen van meer avontuurlijke levenservaring, tot 1992. De belangstelling voor hoofdpijn werd vervolgens gewekt in het Verenigd Koninkrijk en wel te London, alwaar hij was aangesteld als Lecturer in Neurology aan The Princess Margaret Migraine Clinic van The Charing Cross \& Westminister Medical School (thans Imperial College, hoofd Prof. C. Kennard). In 1993 werd de opleiding tot neuroloog aangevangen in het Canisius-Wilhelmina Ziekenhuis Nijmegen, aanvankelijk als detaché van Dr. J.J. Korten, echter na één jaar voortgezet door Dr. C.W.G.M. Frenken nadat collega Korten zijn opleiderschap had neergelegd. De eenjarige stage psychiatrie werd gedaan bij Dr. A. van Nispen op de PAAZ van het St. Maartensgasthuis in Venlo (onderdeel van het Vincent van Gogh Instituut Venray, Dr. W. Verhoeven). Voor het opleidingsonderdeel klinische neurofysiologie bij Dr. J.W. Vredeveld verhuisde hij naar Atrium medisch centrum in Heerlen, en rondde zijn opleiding eind 1998 af. Aldaar was hij vanaf 1999 werkzaam als neuroloog chef de clinique, gedurende welke tijd het onderhavige onderzoek grotendeels werd verricht. In 1999 werd hem de AASH/Merck Research Award van de American Association for the Study of Headache toegekend voor het onderzoek 'Longitudinal assessment of magnetophosphene threshold in menstrual migraine'. In 2001 trad hij toe tot de neurologenmaatschap van Atrium medisch centrum.

Hij is gehuwd met Caron van Everdingen en trotse vader van Anne en Sebastiaan. 


\section{List of abbreviations}

\begin{tabular}{|c|c|}
\hline ANOVA & Analysis of variance \\
\hline b.d. & Twice daily \\
\hline CFF & Critical flicker fusion \\
\hline SPECT & Single photon emission computerized tomography \\
\hline VDU & Video display unit \\
\hline$C T$ & Computed tomography \\
\hline LTG & low tension glaucoma \\
\hline BRIGHT & Dependent measure of photophobia \\
\hline $\mathrm{C}$ & Control subjects \\
\hline $\mathrm{Ca}$ & Calcium \\
\hline CMAP & Compound muscle action potential \\
\hline CSD & Cortical spreading depression \\
\hline CSSP & Cortical stimulation silent period \\
\hline DV & Diagnosed voters \\
\hline EEG & Electroencephalography \\
\hline EMG & Electromyography \\
\hline fMRI - BOLD & $\begin{array}{l}\text { Functional magnetic resonance imaging - blood } \\
\text { oxygenation level detection }\end{array}$ \\
\hline GABA & $\gamma$-amino butyric acid \\
\hline IHS & International Headache Society \\
\hline IPSP & Inhibitory postsynaptic potential \\
\hline IVS & interactive voting system \\
\hline MA & migraine with aura \\
\hline MANOVA & multivariate analysis of variance \\
\hline MEG & Magnetoencephalography \\
\hline MEP & Motor evoked potentials \\
\hline $\mathrm{MO}$ & Migraine without aura \\
\hline MRI & Magnetic resonance imaging \\
\hline MRS & Magnetic resonance spectroscopy \\
\hline NMDA & N-methyl-D-aspartate \\
\hline rTMS & Repetitive transcranial magnetic stimulation \\
\hline SD & Spreading depression \\
\hline SOA & Stimulus onset asynchrony \\
\hline SUNG & Dependent measure of wearing of sunglasses \\
\hline t.d.s. & Three times daily \\
\hline TMS & Transcranial magnetic stimulation \\
\hline TRIG & Dependent measure of visual triggers \\
\hline UV & undiagnosed voters \\
\hline V1 & Primary visual cortex \\
\hline VEP & Visual evoked potentials \\
\hline
\end{tabular}

